\title{
Choose Your Own Lecture: Students' Motivational Resources as a Consequence of Autonomy-Supportive Instruction
}

James P. Baker

West Virginia University, jpb0020@mix.wvu.edu

Follow this and additional works at: https://researchrepository.wvu.edu/etd

\section{Recommended Citation}

Baker, James P., "Choose Your Own Lecture: Students' Motivational Resources as a Consequence of Autonomy-Supportive Instruction" (2019). Graduate Theses, Dissertations, and Problem Reports. 4117. https://researchrepository.wvu.edu/etd/4117

This Dissertation is protected by copyright and/or related rights. It has been brought to you by the The Research Repository @ WVU with permission from the rights-holder(s). You are free to use this Dissertation in any way that is permitted by the copyright and related rights legislation that applies to your use. For other uses you must obtain permission from the rights-holder(s) directly, unless additional rights are indicated by a Creative Commons license in the record and/ or on the work itself. This Dissertation has been accepted for inclusion in WVU Graduate Theses, Dissertations, and Problem Reports collection by an authorized administrator of The Research Repository @ WVU.

For more information, please contact researchrepository@mail.wvu.edu. 


\title{
Choose Your Own Lecture: Students' Motivational Resources as a Consequence of Autonomy-Supportive Instruction
}

\author{
James P. Baker \\ Dissertation submitted \\ To the Eberly College of Arts and Sciences \\ at West Virginia University \\ in partial fulfillment of the requirements for the degree of \\ Doctor of Philosophy in \\ Communication Studies
}

\author{
Alan K. Goodboy, Ph.D., Chair \\ Mathew M. Martin, Ph.D. \\ Scott A. Myers, Ph.D. \\ Liesel L. Sharabi, Ph.D. \\ Karen E. Rambo-Hernandez, Ph.D. \\ Department of Communication Studies \\ Morgantown, West Virginia \\ 2019
}

Keywords: self-determination theory, autonomy-support, choice, autonomy, intrinsic motivation, interest, free-choice persistence, learning, expressive dissent 


\begin{abstract}
Choose Your Own Lecture: Students' Motivational Resources as a Consequence of Autonomy-Supportive Instruction
\end{abstract}

James P. Baker

The purpose of this dissertation was to extend the self-determination theory literature by investigating the utility of the choose your own lecture method of instruction. This method of instruction allows students to control the direction of a lesson. In line with the theoretical propositions of SDT, the researcher hypothesized that this style of teaching would support students' inner motivational resources (i.e., autonomy-need satisfaction and intrinsic motivation) and in turn, foster students' interest in the topic of the lesson, free-choice persistence, cognitive learning, affect for the course, and expressive dissent. A 50-minute live-lecture experiment on environmental communication (climate change, risk communication, communicating sustainability, and advocacy campaigns) was conducted which randomly assigned students to attend either a lesson where students were given the opportunity to choose the direction of the lesson (treatment) or were given no choice over the direction of the lesson (control). Participants were 207 undergraduate students who were provided minimal extra credit points for attending a lesson on environmental communication, reporting on their autonomy-need satisfaction and intrinsic motivation to learn, affect for the course, interest in the topic of climate change, free-choice persistence, intentions to expressively dissent, as well as answering a short test on the material. In contrast to the predictions, the provision of choice during the lesson did not indirectly (through students' intrinsic motivation to learn) or directly influence students'(a) affect for the course, (b) interest in climate change, (c) free-choice persistence, (d) expressive dissent, and (e) cognitive learning. However, as SDT would posit, students' intrinsic motivation to learn did influence their interest in the topic, likelihood of signing up for free opportunities to learn more about environmental communication, affect for the course, and slightly increased their cognitive learning. Thus, the findings seem to suggest that incorporating this style of teaching into the classroom may not be worth instructors' time to intrinsically motivate their students. The theoretical and instructional (especially for online instruction) implications of the findings are discussed. 
Table of Contents

LIST OF FIGURES vi

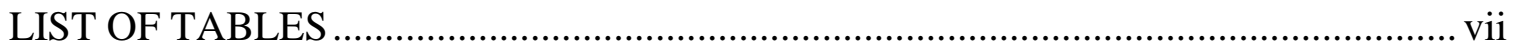

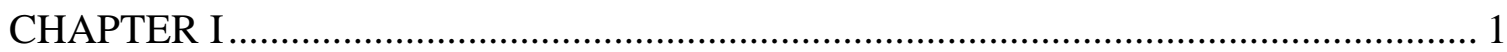

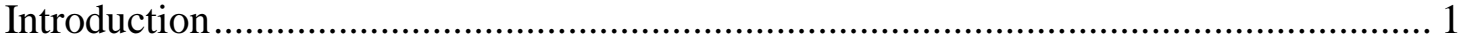

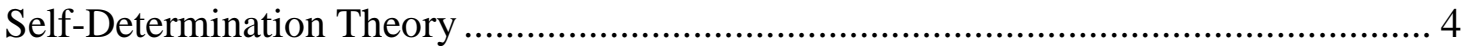

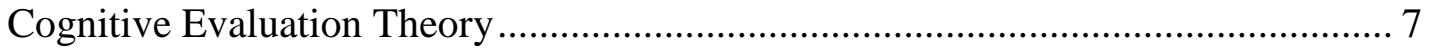

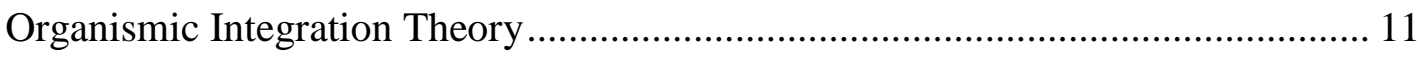

Basic Psychological Needs Theory ................................................................ 17

Self-Determination Theoretical Perspective on Education ..................................... 21

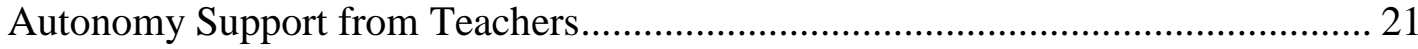

Autonomy-Supportive Teaching Behaviors .................................................. 25

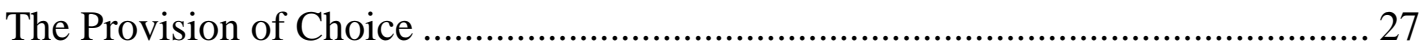

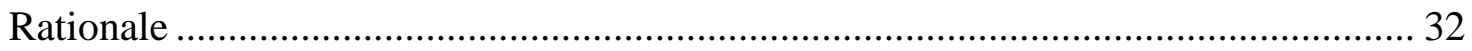

Autonomy-Supportive Teaching and Autonomous Motivation ............................ 33

Consequences of Autonomous Motivation ............................................................ 33

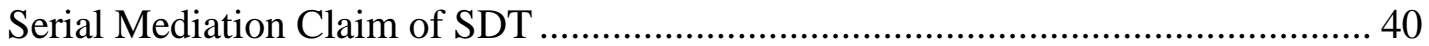

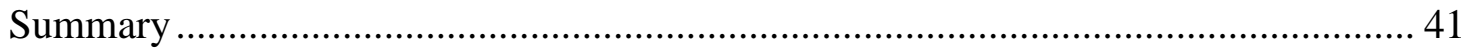

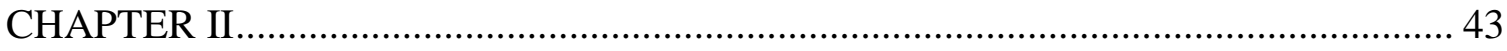

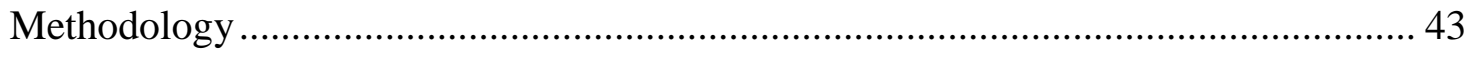

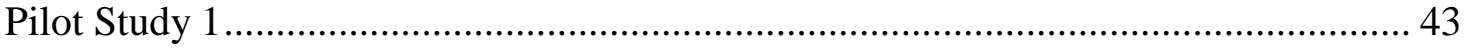

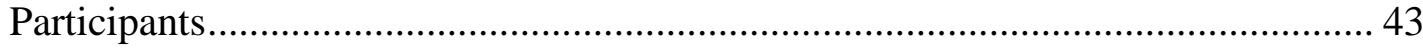

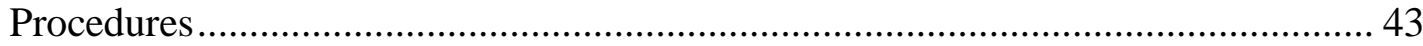

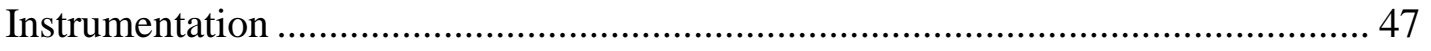

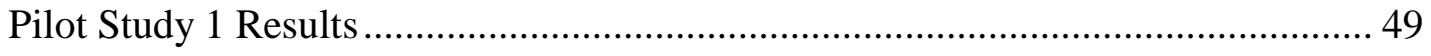

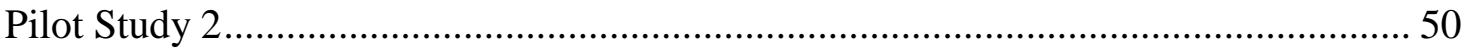

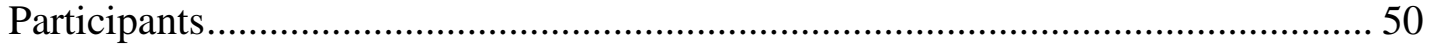

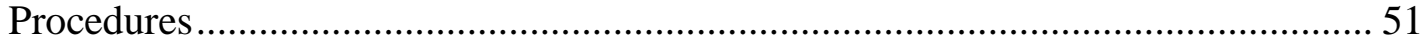

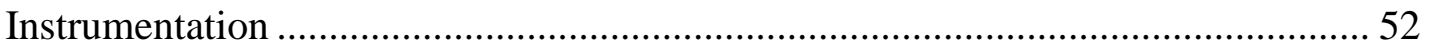

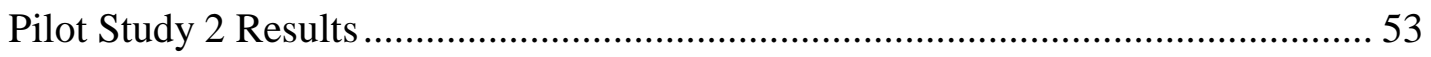

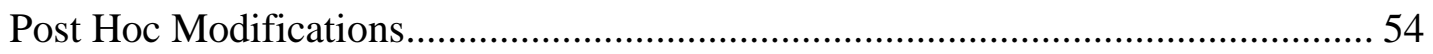

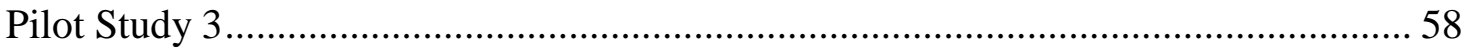

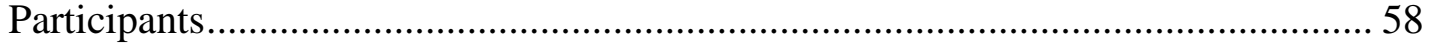




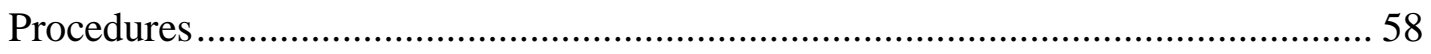

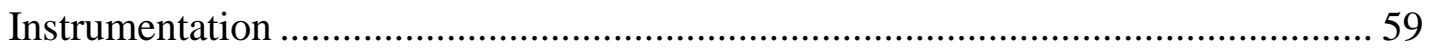

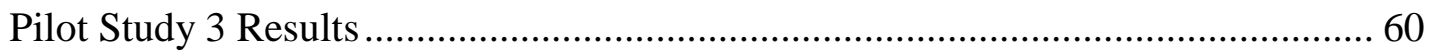

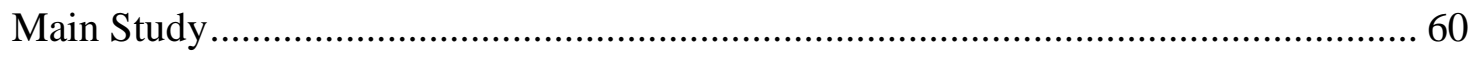

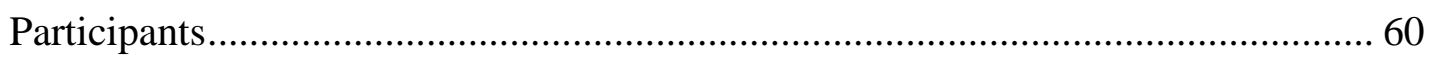

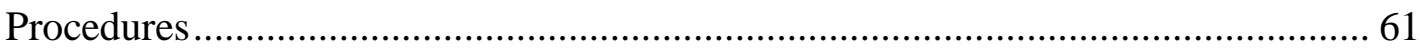

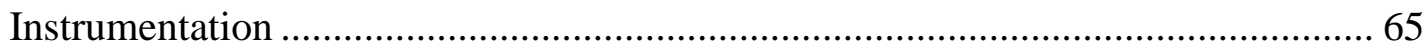

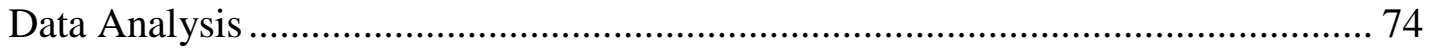

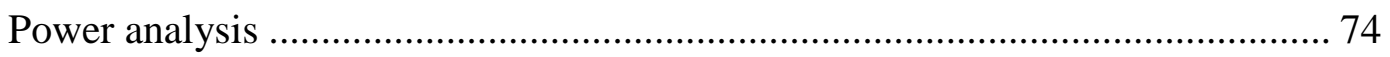

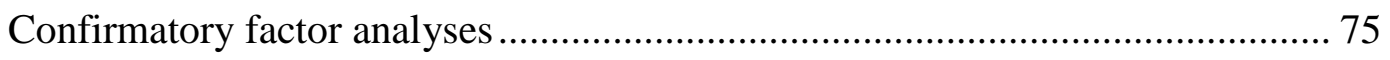

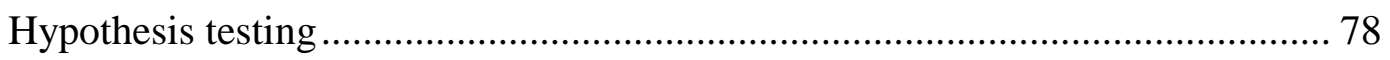

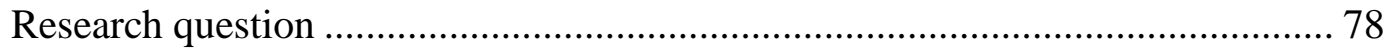

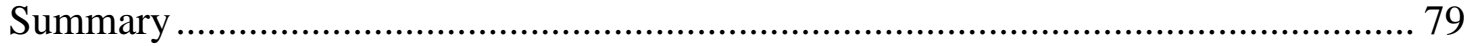

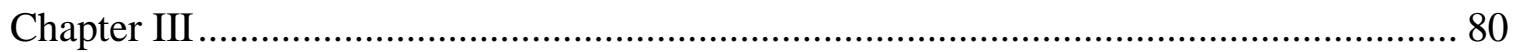

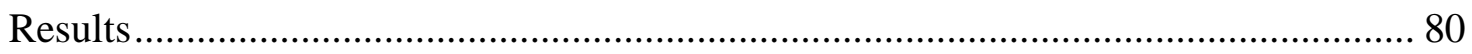

Teaching Effectiveness Check ………………………...................................... 80

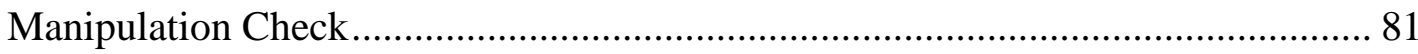

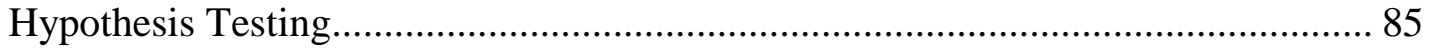

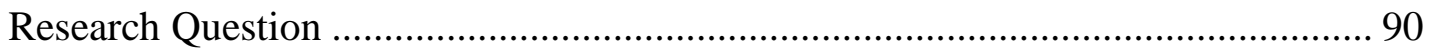

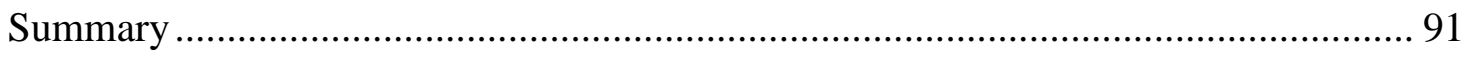

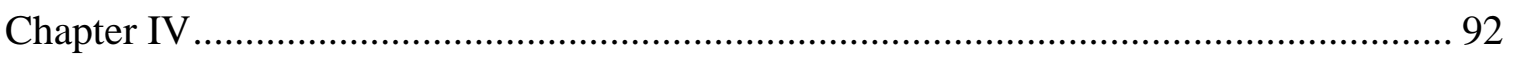

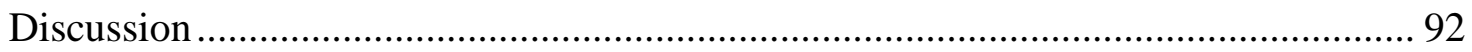

Choose Your Own Lecture Method Did Not Motivate Students............................... 92

Intrinsic Motivation to Learn and Student Learning Outcomes ................................ 98

The Importance of Instructor Clarity and Enthusiasm (Covariates) ......................... 101

Implications for Theory and (Online) Teaching .................................................... 102

Limitations and Future Research ........................................................................ 104

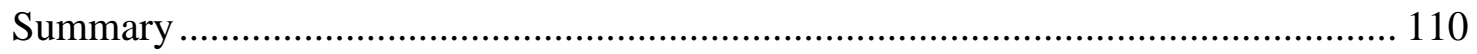

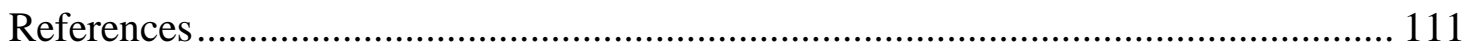

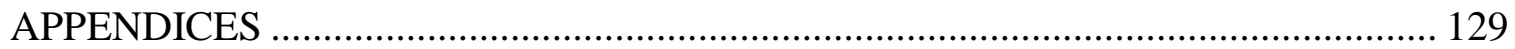

Appendix A. Study Advertisement/Cover Letter....................................................... 129

Appendix B. Email Recruitment Script ................................................................ 130 
Appendix C. Email Reminder for Study ........................................................... 131

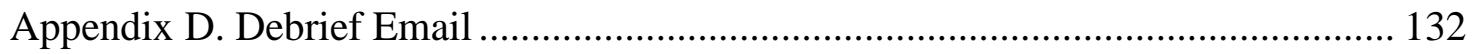

Appendix E. 13-Item Test................................................................................... 133

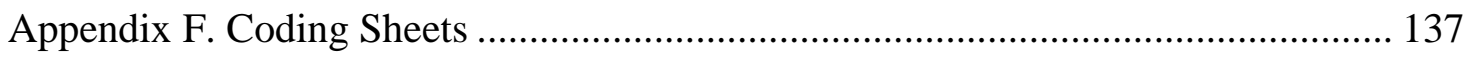

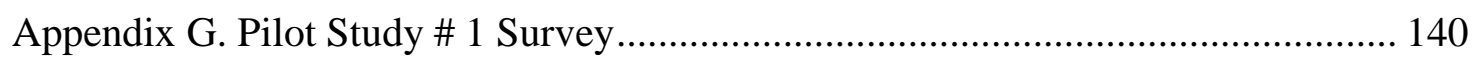

Appendix H. Pilot Study \# 2 Survey ................................................................... 142

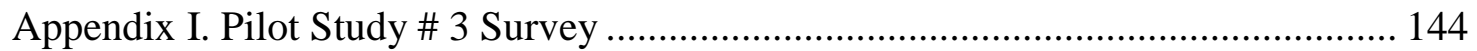

Appendix J. Revised 15-Item Test..................................................................... 145

Appendix K. Lecture Scripts.................................................................... 148

Appendix L. Pre-Survey .......................................................................... 169

Appendix M. Feedback Survey...................................................................... 172

Appendix N. Prezi Presentation of Lecture Material ........................................... 180 


\section{LIST OF FIGURES}

Figure 1. Self-Determination Continuum from Ryan \& Deci (2000a) based on Vallerand

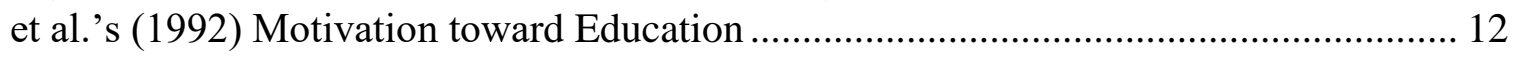

Figure 2. Hypothesized Conceptual Model of Hypothesis 1 ....................................... 35

Figure 3. Hypothesized Conceptual Model of Hypothesis 2 ....................................... 36

Figure 4. Hypothesized Conceptual Model of Hypothesis 3 ........................................ 38

Figure 5. Hypothesized Conceptual Model of Hypothesis 4 ........................................ 39

Figure 6. Hypothesized Conceptual Model of Hypothesis 5 ..................................... 40

Figure 7. Flowchart of Prezi Presentation and Student Choices...................................... 44 


\section{LIST OF TABLES}

Table 1. Theoretical Propositions for CET from Ryan \& Deci (2017) ........................... 10

Table 2. Theoretical Propositions for OIT from Ryan \& Deci (2017) ........................... 16

Table 3. Theoretical Propositions for BPNT from Ryan \& Deci (2017) .......................... 20

Table 4. Autonomy-Supportive and Controlling Behaviors from Ryan \& Deci (2017) .. 24

Table 5. Descriptive Information for the 13-item and 15-item Test.............................. 57

Table 6. Paths the Treatment Group Chose for Each Data Collection ............................. 64

Table 7. CFA Goodness of Fit for Predicted Model Variables...................................... 76

Table 8. Pattern Coefficients and Variance Estimates for Each Scale ........................... 76

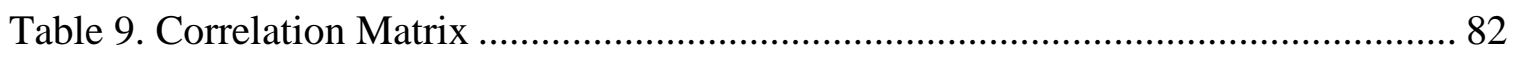

Table 10. Unstandardized Model Estimates for Hypothesis 1 using PROCESS

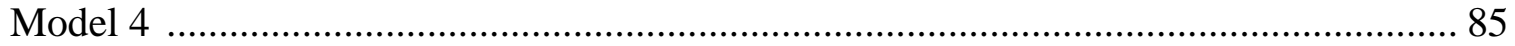

Table 11. Unstandardized Model Estimates for Hypothesis 2 using PROCESS

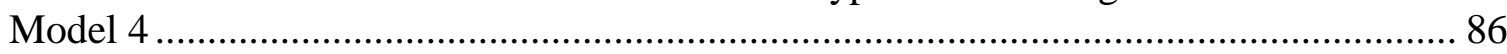

Table 12. Unstandardized Model Estimates for Hypothesis 3 using PROCESS

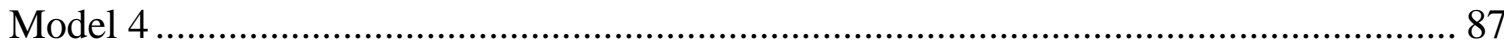

Table 13. Unstandardized Model Estimates for Hypothesis 4 using PROCESS Model 4

Table 14. Unstandardized Model Estimates for Hypothesis 5 using PROCESS Model 4 


\section{ACKNOWLEDGEMENTS}

Sitting in my office in Armstrong Hall writing this part of my dissertation is a bittersweet experience. I am excited to finally be done with the arduous (but necessary) part of my life called doc school and to make my way back to the west coast. But, at the same time, I will miss the people of this great department, learning from some brilliant scholars, and being part of a unique department that is WVU Communication Studies. I would be remiss if I did not acknowledge the people in my life that made this accomplishment possible. Words cannot truly express my gratitude to all the people who have helped me reach this point in my life, but I will do my best.

First, to my adviser, Alan Goodboy, I would not have made it to this point in my career without your guidance and support along the way. Although working with you can be frustrating, I have learned more from you in these last three years than I could have ever possibly imagined. Whether that is spending 12 hours in your office working on counterfactuals, traveling to Baltimore to learn from Muthén, popping into your office to run some quick stats on some new application, or discussing SEM and the different seminars to attend, I appreciate you patiently encouraging me to expand my statistical knowledge. I know these skills will follow me throughout my career. You have not only helped me reach my professional goals, but you have supported me during some of the hardest life experiences I have faced during this program. I will always appreciate the random fishing or hiking trips we went on to escape Armstrong Hall and life, which often led to more conversations about stats and research. From day one, I was upfront with you about what my goals were and what the most important things in my life were. You did not hesitate to challenge me to reach these goals and to encourage me to go home to 
California to be with my family and Megan. I know I was a stubborn advisee who tested your patience quite a bit, but I want you to know that I am grateful for what you have done for me academically and personally these past few years. Working with you has been a rewarding and difficult process, but you are an amazing mentor and great friend.

To my dissertation committee, Matt Martin, Scott Myers, Liesel Sharabi and Karen Rambo-Hernandez, thank you for taking the time and energy to provide me with feedback to improve this dissertation. Dr. Martin, thank you for continuing to be patient with me over the years and for the support you have provided me in and outside of the classroom. Every semester I made it a personal goal of mine to make sure my name never crossed your desk in a bad way, but as you know every semester something would lead to me sitting and chatting in your office. In each of these situations you always encouraged me to learn from my mistakes and to not ruminate on the little things. Thank you for supporting me in the classroom and trusting me to teach courses that doc students do not normally teach. Also, I want you to know that I think you are an incredible dancer. Dr. Myers, I know I have tested your patience quite a bit, but I will cherish all of the academic and personal guidance you have given me. From giving me a heater to pots and pans to life advice I have learned quite a bit from you. Actually, I have learned quite of bit of what I should stop doing. I have thoroughly enjoyed all of the little conversations we have had over random lunches, conference breakfasts, and dinners. Academically, I have never seen a paper bleed so much from feedback in my life, but without failure the feedback you have given me has always been helpful and led to a better final product. Dr. Sharabi, I want to thank you for all of the constructive feedback you have provided me on this dissertation and our turbulence side project. I appreciate the great advice you have 
given me for these projects and allowing me to pop into your office to talk through some of my ideas. Finally, Dr. Rambo-Hernandez, thank you for allowing me to take your SEM course and your advice for this dissertation. Your class taught me a number of invaluable statistical skills (some of what were used in this dissertation) that got me thinking about my research differently.

I would also like to thank the rest of the faculty and staff of WVU, Megan Dillow, Christine Rittenour, Ryan Thompson, Elizabeth Cohen, Jamie Banks and Nick Bowman. I really enjoyed being part of such a unique and lively department. I had the pleasure of being a student in many of your courses and I wanted to thank you for all the resources, information, and assistance you provided me. In some way or another, each of you have helped me with my research, my teaching, or adjusting to doctoral education. I am going to miss this department dearly and I hope to see you all at NCA each year. I would also like to extend a special thank you to Joy and Terri for always dealing with my countless questions about paperwork and travel. Also, Joy thank you for saving me when I had no idea what I was doing with the copier and for working with me to reserve the classroom that was used in this dissertation.

To my beautiful fiancé, Megan Hobbs. You have been the person I rely on to cheer me up when life, school, or even Dr. Goodboy has knocked me down. I am truly grateful to have you in my life and for your unwavering support. I still remember when I told you that I got accepted to WVU to pursue my doctorate, you were incredibly happy for me even though it meant that I was going to be 2,000 miles away from you $(2,676$ miles to be exact). You have always been my biggest fan and encouraged me to pursue my dreams no matter what those dreams entailed. In all the good times and the bad, you 
have been right by my side. There have been times where I doubted my decision to come to WVU and doubted my abilities to finish this program. You were always there motivating me to continue, telling me to get my work done and to hurry back to you. I want you to know that I appreciate all the trips you made to come see me. You may not know this, but every time you told me you were coming to visit I would cling to those moments of hope to get through this program. I know if I got you in my life everything is going to be more than alright. Graduate school is stressful, emotionally demanding, and time consuming, which makes a long-distance relationship even more difficult. I know there were days or weeks that went by where we would barely be able to talk or times where the stress of the program put a strain on our relationship. Even during these difficult times, I never doubted your love and support. I know I can never repay you for this, but I promise that I will always have your back and be there to support you. You deserve this degree just as much as I do for what this distance, program, and dissertation has put you though. Cheers to our future and I can't wait to see what life has in store for us next. I love you with all my heart.

To my wonderful parents, Jack and Cheryl Baker. I know I have been a pain to raise (at times) and challenged you quite a bit, but I want to thank you for all the love and support you have given me throughout my entire life. You both instilled in me a strong work ethic and showed me how to be kind to others. I have been told that I am quite optimistic (sometimes to a fault) and a bit stubborn. I guess that is the Baker approach to life and I am very proud to be a Baker and to be your son. You have both set an example of what it means to be a loving, supportive, and strong-willed parent. If I am half the parent you two have been to us kids, I will consider myself lucky. I know I can never 
repay you for all the things you have done for me, but I will carry forward the countless life lessons you taught me and instill the same values in my family. To my siblings, David Baker, Jessica Baker, Samantha Lozano, Andy Lozano, and Laura Arguijo, I love you all very much. You all kept me focused on getting through this program and always reminded me what was truly important in life. Being the youngest in the family, I always and will continue to look up to you all. Thank you for being such great remodels and being there for me no matter what. These past few years have been really hard for our family and we faced things that no family should have to experience. I am truly grateful to be part of such a wonderful and weird family that continues to make me proud. I would not trade our family for anything in the world. To Randy and Diane Hobbs, my second parents, thank you for welcoming me into your family, treating me like a son, and supporting Megan and I when we needed it the most. I consider myself lucky to have you both in my life and will do my best to be the husband your daughter deserves. I love you all!

To Cathlin Clark-Gordon, Sara Pitts, Evan Watts, and Joe Wasserman, the best cohort to go through doc school with. We started this program as strangers, but through all the wine nights, game nights, conferences, graduate school struggles, and other countless experiences we have grown into good friends. Catie, in addition to establishing a publishing nickname for our research collaboration (Cate \& Bake), we are now up and coming sommeliers as well as roommates. I will miss all the shenanigans and breaking out into songs to make Dr. Goodboy uncomfortable. Thank you to you and Nick for opening up your home for me to stay this last month. Sara, you have always been the "mom" of our cohort and probably saved each of us from making a dumb or rash 
decision. I could always count on you for early rides to the airport and to have the answer to my many mundane questions. Catie and Sara, I would not have made it this far in the program without you two providing the much-needed support and comedic relief necessary to survive graduate school. We have gone through so much together and I am grateful that we became such close friends (\#ConferenceGals). Evan, my office mate, thank you for putting up with me for two years. I know my organized mess and musical choices may have not always been the best, but I enjoyed our random conversations about movies and television. Joe, thank you for always entertaining my many statistical questions and introducing me to many board games. I will miss you all and if you all are ever out west, do not be a stranger. I am proud of all of us and cannot wait to see what we accomplish.

To those who have come before me, Jordan, Molly, Dana, and Mary, thank you for creating a culture among the doc students that made coming into the office fun and that encouraged us to support one another. I appreciate you all answering my countless questions and helping me acclimate to the department and Morgantown. You showed us first years how to be good mentors and saved us from asking the wrong question to the wrong person. To the current first- and second-year doc students, in some way or another you have helped me with my teaching, research, or department responsibilities. I would like to specifically acknowledge Heath Howard who, because of his bet against me and WVU football, was my coder in this dissertation. Thank you for your help and now you know not to bet against the Mountaineers! I wish you all the best and keep working hard.

Finally, to my friends Elijah, David, Shayne, Randy, and Justin, thank you for always having my back. We have been good friends since middle school and made some 
great memories that I will cherish forever. We may be spread out all over the world doing our own things, but I know that I could rely on each of you for anything. You all keep me grounded and motivated to keep working hard for my goals (because that is what we do!). I am proud of each of you and I am grateful to have you in my life. 
For Levi James Lozano, until we meet again. 


\section{CHAPTER I}

\section{Introduction}

With rising budgetary constraints and the pressure to increase class size, it is no surprise that, at the undergraduate level, large classes are prevalent and will continue to grow. Lecturing is the typical teaching style in these large classes, which creates more passive and less engaged students who do not feel connected with their instructors (Cooper \& Robinson, 2000). Cuseo (2007) illuminated several challenges that stem from large-lecture classes, such as these large classes limiting the breadth and depth of course objectives and course-related activities as well as reducing students': (a) active involvement in the learning process, (b) frequency and quality of interaction with, and feedback from, the instructor, (c) depth of thinking in the classroom, (d) academic performance, (e) satisfaction in the course, and (f) overall rating for the course. In fact, reviewing the research on student participation in the classroom, Rocca (2010) argued that one major reason that participation is hampered in the classroom is due to the number of students in the class (i.e., students are more willing to participate in smaller classes). Recently, Baker and Goodboy (2019) demonstrated that an autonomysupportive style, including the provision of choice and rationales, increased student's intrinsic motivation and subsequently their reports of effort and oral participation. Thus, the provision of choice may provide instructors a strategy to counteract the challenges of large-lecture classes and foster more student engagement.

On a daily basis, students make choices regarding their education, such as choosing what classes to take, how to structure their class schedule, which instructors to take/avoid, what extracurricular activities to get involved in, and what major(s) to pursue, 
among others. In addition to these choices over education, students appreciate their instructors who give them choices in the classroom (Williams, Wallace, \& Sung, 2015). According to self-determination theory (SDT; Deci \& Ryan, 1985a), this is because students have three universal psychological needs, including their need for autonomy and control over their behaviors, which is responsible for higher quality motivation and personal fulfillment in education (Ryan \& Deci, 2000a).

Furthermore, SDT suggests that one way in which instructors can foster students' basic psychological needs and give them choices in the classroom is by endorsing an autonomy-supportive style of teaching (Ryan \& Deci, 2017). This style of teaching can be characterized by what instructors do and say in the classroom that make students feel valued and in control of their learning (Reeve, 2009). From the autonomy-supportive literature, we know this style of teaching includes several instructor behaviors, such as providing students rationales and acknowledging students' negative affect (Assor, Kaplan, \& Roth, 2002; Jang, 2008), refraining from using controlling language (Deci, Eghrari, Patrick, \& Leone, 1994), framing lessons as intrinsic goals (Vansteenkiste, Simons, Lens, Sheldon, \& Deci, 2004), teaching in students' preferred ways (Jang, Reeve, \& Halusic, 2016) displaying patience, listening to students, allowing time for students to work on their own, providing students more time to talk, acknowledging students' improvement, encouraging students' efforts, providing hints when students were stuck, and being responsive to students' comments and questions (Reeve \& Jang, 2006). SDT researchers have demonstrated that among these various behaviors, the autonomy-supportive style of giving students choices pays off for students and these students flourish in the classroom (Reeve, 2002). That is, researchers have consistently 
found that when students are given choices in education they feel more competent, motivated, effortful, and autonomous (Patall, 2013; Patall, Cooper, \& Robinson, 2008). This begs the question: What sort of choices are beneficial for students' motivation? Indeed, many researchers have investigated which type of choices promote students' motivation. These scholars have revealed that giving students' choices over their homework (Patall, Cooper, \& Wynn, 2010), refraining from using controlling language (Deci et al., 1994), providing successive choices during an activity (Reeve, Nix, \& Hamm, 2003), and allowing students to pick their preferred method of instruction (Jang et al., 2016) fosters more student motivation and engagement. Furthermore, Williams et al. (2015) argued that giving students choice during instruction, such as giving students the freedom choose their problem-solving method, format of presentation, the topic of information, and whether or not to work alone during instruction, can communicate trust and respect in the classroom.

Students make choices over the information they consume all the time, for example, browsing the internet, what to watch on T.V., what music or station to stream, to name a few. Having the choice over information is enmeshed in their lifestyles, but often times during lectures the information is controlled by instructors. What if students were given the control to choose the direction of the lecture and the information they wanted to discuss or found most interesting, like a "choose your own adventure" method of instruction (e.g., Baker \& Goodboy, 2019). The idea is to put students in control of the lesson and allow them to shape the information as the lecture progresses and determine how the lecture will unfold. This "choose your own lecture" method would allow students to vote and decide from a few options what information to discuss and 
potentially support their fundamental need for autonomy, and in turn foster higher quality motivation in the classroom.

The primary purpose of this dissertation, then, was to extend the SDT research by examining the autonomy-supportive behavior of giving students' choices over what they were learning using a live lecture experiment. This dissertation investigated the utility of the choose your own lecture method of instruction (e.g., Baker \& Goodboy, 2019) to nurture students' inner motivational resources (i.e., autonomy-need satisfaction and motivation) and subsequently facilitate students' learning outcomes. To achieve this objective, the SDT framework and autonomy-supportive literature will be discussed in turn.

\section{Self-Determination Theory}

Self-determination theory (SDT) focuses on people's psychological growth and development (Ryan \& Deci, 2017). According to SDT, people have a natural propensity to grow and develop their sense of self (Deci \& Ryan, 2002), which Deci and Ryan (1985a) termed organismic integration. Taking an organismic approach to motivation, SDT assumes that people are active organisms that desire to grow and integrate new experiences into their sense of self (Ryan \& Deci, 2017). Thus, the social context (e.g., education) is responsible for supporting or thwarting the necessary nutriments to facilitate this natural inclination to grow. These nutriments, which are necessary for psychological development, are people's basic psychological needs for autonomy, competence, and relatedness. More broadly stated, SDT takes an organismic meta-theoretical approach to human motivation by examining the features of the social context that facilitate or undermine people's quality of motivation based on their basic psychological need 
fulfillment (Deci \& Ryan, 1985a, 2002; Ryan \& Deci, 2017).

According to SDT, depending on the degree to which people perceive their behaviors as self-determined, they will have one of three different types of motivation (Ryan \& Deci, 2000a). Amotivation refers to the lack of self-determination or the individual who acts with no intent due to his or her inability to attain desired outcomes (Ryan \& Deci, 2000a). Ryan and Deci (2000a) defined extrinsic (controlled) motivation as motivation that is determined by external regulations, such as rewards, demands, or punishments. In contrast, intrinsic motivation refers to motivation that is self-determined and driven by a natural inclination to learn and develop. Additionally, SDT posits that people have three innate psychological needs, which include the need for autonomy or the desire to have volitional control over their actions; competence or the desire to display their capabilities and be effective within their social environments, and relatedness or the desire to feel a sense of connection with others (Deci \& Ryan, 1985a, 2002; Ryan \& Deci, 2000a). SDT suggests that people's basic psychological need fulfillment is responsible for their quality of motivation; therefore, the satisfaction of people's autonomy, competence, and relatedness promotes autonomous forms of motivation, whereas the thwarting of these needs stifles this motivation (Deci \& Ryan, 1985a, 2002).

Many classic cognitive and motivation theories (e.g., drive/learning theory, Hull, 1943; operant theory, Skinner, 1953; expectancy-value theory, Wigfield \& Eccles, 2000) have described motivation as a unitary concept that focuses solely on the amount of motivation people have for specific tasks or behaviors (Deci \& Ryan, 2008). Deci, Vallerand, Pelletier, and Ryan (1991) argued that these motivation theories only examine 
the outcomes of motivation, but fail to address the question of why those outcomes were desirable to individuals. In line with these limited motivational perspectives, the instructional communication field has historically (e.g., Christophel, 1990; Frymier, 2016; Myers, Goodboy, \& Members of COMM 600, 2014) considered students' motivation as an outcome that varies only in quantity (i.e., state motivation; ranging from low to high "amounts" of motivation). Brophy (1987) defined state motivation as students" "engagement in a particular activity [that] is guided by the intention of acquiring the knowledge or mastering the skill that the activity is designed to teach" (p. 40). In contrast, SDT is more concerned with the type of motivation and not the amount of motivation to predict people's psychological well-being, performance, and creativity (Deci \& Ryan, 2008; Ryan \& Deci, 2017).

SDT is a meta-theoretical perspective including six mini-theories that account for people's basic psychological needs, quality of motivation, and human behavior across domains (e.g., education, work, health care, families, sports, relationships, video games, economics, and psychotherapy; Ryan \& Deci, 2017). These six mini-theories include (a) cognitive evaluation theory, (b) organismic integration theory, (c) causality orientations theory, (d) basic psychological needs theory, (e) goal contents theory, and (f) relationships motivation theory (for recent review, see Ryan \& Deci, 2017). Cognitive evaluation theory (CET; Deci \& Ryan, 1980) focuses on how social contexts influence intrinsic motivation, and in turn, performance and well-being. Organismic integration theory (OIT; Deci \& Ryan, 1985a; Ryan \& Connell, 1989) describes the process through which extrinsically motivated behaviors become more self-determined (i.e., intrinsically motivated). Causality orientations theory (COT; Deci \& Ryan, 1985a, 1985b) focuses on 
three different motivational orientations (i.e., autonomy, controlled, and impersonal) that describe people's propensity to focus on certain aspects of their social contexts that cause their behaviors. Basic psychological needs theory (BPNT; Deci \& Ryan, 1985a; Ryan \& Deci, 2000b, 2017) articulates the requirements for a psychological need to be universal and innate, and specifies the relations between these needs and people's psychological well-being. Goal contents theory (GCT; Kasser \& Ryan, 1993, 1996) posits that the contents of people's goals and aspirations, such as intrinsic goals (e.g., personal growth, affiliation, and health) versus extrinsic goals (e.g., fame, financial success, and appearance), impact their basic psychological need satisfaction, motivation, and wellbeing. Finally, relationships motivation theory (RMT) focuses on the synergism of people's needs for autonomy, competence, and relatedness in their close relationships to form high-quality relationships. Of the six mini-theories mentioned, three are guiding this dissertation: CET, OIT, and BPNT.

\section{Cognitive Evaluation Theory}

CET assumes that the social environment can either support or thwart people's intrinsic motivation, which refers to people's natural inclination to grow and expand their capacities (Ryan \& Deci, 2000a). Ryan and Deci (2017) explained: “CET focuses upon the proximal conditions that facilitate, maintain, and enhance intrinsic motivation or alternatively, diminish and undermine it" (p. 124). CET posits that both competence and autonomy need satisfaction are required for intrinsic motivation. Thus, CET is also focused on the social contexts that support people's basic psychological needs for competence and autonomy (Ryan \& Deci, 2000a).

CET integrates the results from initial laboratory studies examining the influence 
of external demands, including rewards, evaluations, and feedback, on intrinsic motivation. These laboratory studies during the 1970s and 1980s are known as the freechoice paradigm (Ryan \& Deci, 2017). That is, according to this paradigm, intrinsic motivation is operationalized as people's time spent pursuing the target activity when left alone to freely choose what to do (e.g., Deci, 1971). In his first study on intrinsic motivation, Deci (study 1, 1971) created an experiment in which one group of participants received a reward for completing a task whereas the other group of participants completed the task without a reward. More specifically, all of the participants were asked to complete interesting puzzles and then left alone to either complete more puzzles or other interesting tasks; however, one group of participants received a $\$ 1$ reward for each puzzle completed. As predicted by CET, Deci (1971) found that when people were left alone, those who received the reward had less intrinsic motivation (i.e., spent less time completing puzzles when given free choice). Ryan and Deci (2017) noted that results similar to this study were emerging because introducing rewards for tasks that are intrinsically motivated undermine people's need for autonomy. In other words, people who receive the reward view their behavior toward completing an activity as an instrumental way of receiving rewards, which is perceived as controlling (i.e., stifling their need for autonomy).

In addition to tangible rewards, early laboratory studies examined the influence of feedback given to participants while completing the interesting tasks. For example, Deci (study 3, 1971) provided participants with either no feedback or positive feedback while completing puzzles (i.e., interesting tasks). Deci (1971) found that positive feedback focused on enhancing participants' sense of competence was conducive toward their 
intrinsic motivation. However, subsequent researchers (e.g., Deci \& Ryan, 1980; Ryan, 1982) have cautioned that feedback can also be experienced as an external evaluation or pressure, which undermines intrinsic motivation. That is, positive feedback made overly salient to people during task completion or that diminishes people's sense of autonomy (i.e., people being told they did well just as expected or like everyone else) can thwart their intrinsic motivation (Ryan \& Deci, 2017).

Clearly, not all rewards or external demands are created equal. In order to bring coherence to this research, Ryan, Mims, and Koestner (1983) created a taxonomy that included six external reward types: task-noncontingent, engagement-contingent, completion-contingent, task-contingent, performance-contingent, and competitivecontingent. According to Ryan et al. (1983), task-noncontingent rewards refer to receiving a reward that is not contingent upon doing a task, whereas task-contingent rewards refer to rewards that are given for working on or completing a task. Deci, Koestner, and Ryan (1999) defined engagement-contingent and completion-contingent rewards as rewards given based on the amount of time on task or for completing the target task, respectively. Performance-contingent rewards focus on rewarding people for reaching a specific performance standard; however, competitive-contingent rewards are rewards that are given to a winner of a competition (Ryan et al., 1983). Generally, pervious research (e.g., Deci et al., 1999) has demonstrated that verbal rewards (i.e., positive feedback) tend to foster more intrinsic motivation, whereas expected tangible rewards including engagement-contingent, completion-contingent, and performancecontingent undermine intrinsic motivation.

CET highlights an important consideration for this dissertation and instructional 
communication research (see Table 1 for theoretical propositions). As noted, CET posits that students' intrinsic motivation is a function of students' needs for autonomy and competence fulfillment from external environments, such as the classroom (Ryan \& Deci, 2000a). In other words, CET acknowledges that external events in the classroom (i.e., rewards, deadlines, feedback, evaluations, instructional messages, and the general climate) can either be informational to convey self-determined competence or controlling to prompt an external perceived locus of causality (Deci, Koestner, \& Ryan, 2001). According to CET, then, what instructors do and say in the classroom influence students' intrinsic motivation. Therefore, CET is a useful theory for instructional communication scholars to examine how traditional instructor communication behaviors facilitate or stifle students' free-choice persistence (i.e., intrinsic motivation). Although CET focuses on students' intrinsic motivation, SDT acknowledges that intrinsic motivation is not the only type of motivation that students experience.

\section{Table 1}

\section{Theoretical Propositions for CET from Ryan \& Deci (2017)}

Proposition I) External events relevant to the initiation or regulation of behavior will affect a person's intrinsic motivation to the extent that they influence the perceived locus of causality for the behavior. Events that promote a more external perceived locus of causality or have a functional significance of control will thwart autonomy and undermine intrinsic motivation, whereas those that promote a more internal perceived locus of causality will increase feelings of autonomy and enhance intrinsic motivation (p. 129).

Proposition II) External events will also affect a person's intrinsic motivation for an activity to the extent that the events influence a person's perceived competence at that activity. Events that promote greater perceived competence enhance intrinsic motivation by satisfying the person's need for competence. Events that meaningfully diminish perceived competence undermine intrinsic motivation (p. 130).

Proposition III) External events relevant to the initiation and regulation of behavior have three aspects, each with a functional significance. The informational aspect, 
which conveys information about self-determined competence, facilitates an internal perceived locus of causality and perceived competence, thus supporting intrinsic motivation. The controlling aspect, which pressures people to think, feel, or behave in particular ways, facilitates an external perceived locus of causality, thereby diminishing intrinsic motivation. The amotivating aspect, which signifies incompetence to obtain outcomes and/or a lack of value for them, undermines both intrinsic and extrinsic motivation and promotes amotivation. The relative salience of these three aspects for the person, which can be influenced by factors in the interpersonal context and in the person, determines the functional significance of the event, and thus its impact on intrinsic motivation (p. 130).

Proposition IV) Interpersonal contexts can be characterized in terms of the degree to which the motivational climate tends to be controlling, autonomy supportive, or amotivating. This quality of the overarching interpersonal climate both directly impacts motivation and the likely interpretation or functional significance of specific events, with corresponding effects on intrinsic motivation. Environments that are most facilitating of intrinsic motivation are those that support people's basic psychological needs for autonomy, competence and relatedness (p. 160).

Proposition V) Intrapersonal events that bear on the initiation and regulation of behavior can differ in their functional significance. Accordingly, internally informational events are those that facilitate intrinsic motivation by facilitating an internal perceived locus of causality and perceived competence; internally controlling events are those experienced as pressure toward specific outcomes and facilitate an external perceived locus of causality, thereby undermining intrinsic motivation; and internally amotivating events are those that make salient someone's incompetence and inability to attain desired outcomes, thereby diminishing both intrinsic and extrinsic motivation (p. 170).

\section{Organismic Integration Theory}

In addition to intrinsic motivation, SDT recognizes that extrinsic motivation comes in various types. In order to differentiate between several forms of extrinsic motivation, OIT outlines the relevant contextual factors that are responsible for the internalization of external regulations (e.g., punishments, rewards, or demands, etc.). Ryan and Connell (1989) defined internalization as the active process through which people transform extrinsic regulations into their sense of self and align these regulations with their goals for personal growth. More precisely, Ryan and Deci (2017) argued that the internalization process "means assimilating the regulation or value and integrating it 
with the other values, behaviors, attitudes, and emotions that are themselves inherent and/or have been deeply internalized by the individual" (p. 182). Ryan and Deci (2000a) created a visual continuum to reflect the six different forms of motivation that range from amotivation to intrinsic motivation (p. 72). However, in the context of education, Vallerand, Pelletier, Blais, Briere, Senecal, and Vallieres (1992) created a selfdetermination continuum to focus on students' motivation toward education that included seven different forms of motivation: amotivation, three types of extrinsic motivation, and three types of intrinsic motivation (see Figure 1).

Figure 1

Self-Determination Continuum from Ryan \& Deci (2000a) based on Vallerand et al. 's (1992) Motivation toward Education.

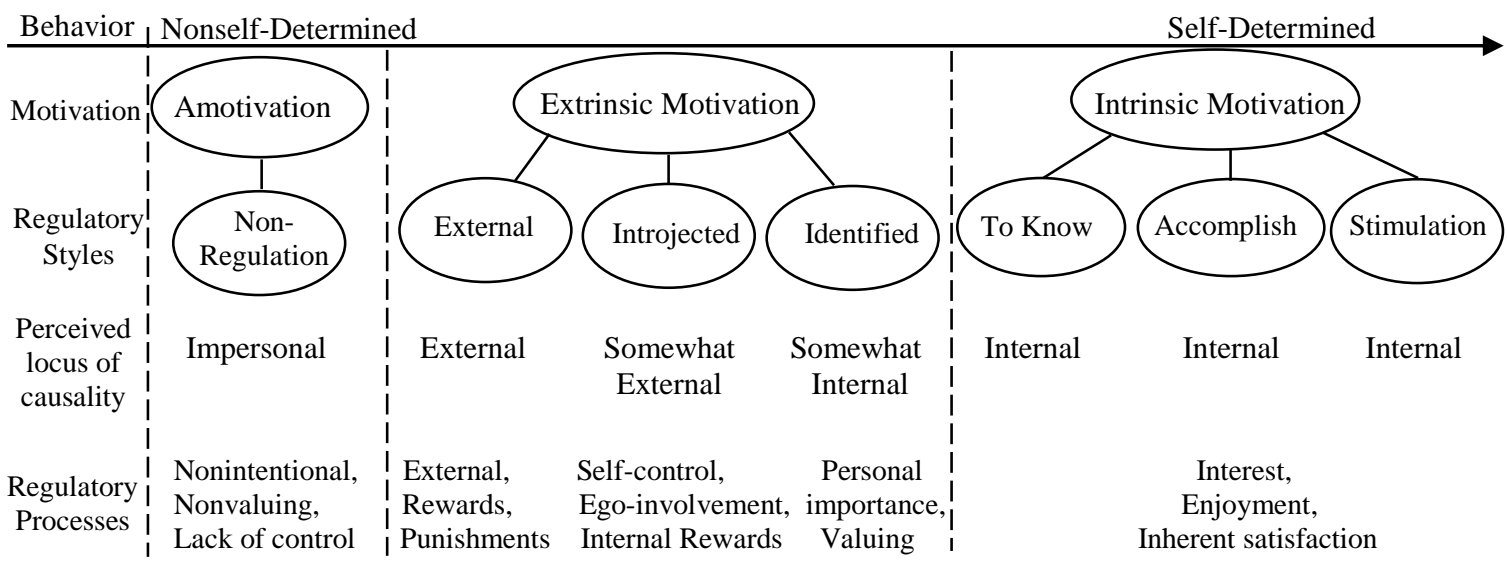

On the far left of the continuum is amotivation, which characterizes the absence

of intent to engage in certain behaviors (Ryan \& Deci, 2000a). Vallerand et al. (1992) argued that people are amotivated when they do not recognize the connection between their own actions and subsequent outcomes. In other words, individuals who are amotivated believe their behaviors are caused by external reasons and/or do not know why they do what they do. Ryan and Deci (2017) suggested that this lack of control stems 
from a feeling of incompetence and believing that engaging in behaviors will not bring about desired outcomes. For example, a student may begin to question his or her reasons for attending school and disengages from academic activities because he or she feels a lack of competence or control.

Deci and Ryan (1985a) also argued that people are motivated to act because of external contingencies, such as demands or rewards. This type of motivation is termed extrinsic motivation and is defined as "the performance of an activity in order to attain some separable outcome" (Ryan \& Deci, 2000a, p. 71). Depending on the amount of internalization, Vallerand et al. (1992) identified three types of extrinsic motivation. According to OIT, when individuals are externally regulated they will only perform a behavior when the external contingency (i.e., reward) is present (Ryan \& Deci, 2017). External regulation corresponds with the conceptualization of extrinsic motivation and is typically considered synonymous with extrinsic motivation in the literature (Ryan \& Deci, 2017). For example, a student may do his or her homework to receive merit points or prizes from their teacher, but as soon as this incentive program stops, the student will also stop doing his or her homework because the motivator is no longer present. Although short-term external regulators can motivate people to act, the issue with this type of motivation is that individuals tend to see their behaviors as instrumental and put forward the least amount of effort (Ryan \& Deci, 2017).

Introjected regulation marks the beginning of the internalization process and the separation of behaviors from external contingencies (Deci et al., 1991). In other words, motivation regulated by introjection involves partial internalization where an external regulation is assimilated, but not fully accepted as one's own. Deci and Ryan (2002) 
argued that introjected regulation is an intrapersonal form of regulation, in which people's behaviors are guided by internal judgments and evaluations. That is, instead of being motivated by purely external contingencies like rewards, people are motivated by self-esteem and ego-involvement judgments (Ryan \& Deci, 2000a). Returning to the student example, the student motivated by introjected regulations may complete his or her homework because he or she believes this is what good students do or because the homework helps him or her maintain a feeling of self-worth.

Regulation through identification describes the acceptance of a regulation as personally important and making a conscious recognition of the value of such regulation (Ryan \& Deci, 2000a; 2017). Vallerand et al. (1992) considered identified regulation as the extent to which behaviors are perceived to be chosen by oneself and personally valuable. That is, people are not "simply complying with an external or introjected demand but are instead acting out of a belief in the personal importance or perceived value of the activity" (Ryan \& Deci, 2017, p. 188). Thus, a student may instead be motivated to complete his or her homework because he or she believes it is important to him or her and/or that the homework is a valuable part of education.

On the far right of the continuum is intrinsic motivation, which refers to doing an activity for itself (Vallerand et al., 1992). Ryan and Deci (2000a) defined intrinsic motivation as the "inherent tendency to seek out novelty and challenges, to extend and exercise one's capacities, to explore, and to learn" (p. 70). In line with Deci's (1975) argument that intrinsic motivation can also be differentiated, Vallerand et al. (1992) created a tripartite taxonomy of intrinsic motivation: to know, to accomplish things, and experience stimulation. Vallerand et al. (1992) defined intrinsic motivation to know as 
"performing an activity for the pleasure and the satisfaction that one experiences while learning, exploring, or trying to understand something new" (p. 1005). Related to a mastery perspective on motivation, intrinsic motivation toward accomplishment refers to the satisfaction experienced when creating something or trying to exceed oneself (Vallerand et al., 1992). Vallerand and Ratelle (2002) defined intrinsic motivation to experience stimulation as engaging "in an activity because of the stimulating sensations associated with it” (p. 42), such as excitement or sensory pleasure.

OIT is pertinent to this dissertation for two reasons (see Table 2 for theoretical propositions). First, OIT specifies that students' motivation ranges in quality and can be described along a continuum of self-determination (see proposition II from Table 2). Vallerand and colleagues (1992) created the academic motivation scale to assess the continuum that differentiated between the seven forms of student motivation. In line with the core assumption of SDT - that students' motivation ranges in quality - scholars have examined how the different types of motivation correlate together (known as the simplex structure; Guay, Ratelle, \& Chanal, 2008). In other words, researchers have tested the assumption that more proximal forms of motivation (i.e., identified regulation and intrinsic motivation) should correlate more highly compared to distal forms of motivation (i.e., external regulation and intrinsic motivation). As predicted by SDT, Grouzet, Otis, and Pelletier (2006) confirmed the simplex structure of the academic motivation scale, meaning students' motivation ranges in quality and not simply in amount. That is, instead of all forms of motivation correlating with one another, Grouzet et al. (2006) demonstrated that students' intrinsic motivation was correlated positively with their identified regulation but correlated negatively to their amotivation. Clearly, instead of 
students' motivation ranging from low to high amounts (i.e., state motivation), students experience a range of motivation in the classroom due to the internalization process of external regulations.

Second, OIT (proposition III) posits that the degree to which the classroom context facilitates students' basic psychological needs fosters the internalization and integration of non-intrinsically motivated behaviors. According to OIT, instructors' communication behaviors and the environments they cultivate in their classrooms enable students to internalize external regulations to align with their goals for development. Thus, OIT offers a suitable theory for instructional communication scholars to not only examine students' quality of motivation, but the classroom conditions that foster students' internalization process and subsequently their autonomous forms of motivation (i.e., identified regulation and intrinsic motivation). Notably, CET and OIT both acknowledge the importance that students' basic psychological need fulfillment plays in the relationship between teaching practices and students' quality of motivation.

Table 2

Theoretical Propositions for OIT from Ryan \& Deci (2017)

Proposition I) The process of organismic integration inclines humans naturally to internalize extrinsic motivations that are endorsed by significant others. However, the process of internalization can function more versus less effectively, resulting in different degrees of internalization that are the basis for regulations that differ in perceived locus of causality and thus the extent to which they are autonomous ( $p$. 182).

Proposition II) Internalization of extrinsic motivation can be described in terms of a continuum that spans from relatively heteronomous or controlled regulation to relatively autonomous self-regulation. External regulation describes extrinsic motivation that remains dependent on external controls; introjected regulation describes extrinsic motivation that is based on internal controls involving affective and self-esteem contingencies; regulations through identification describes extrinsic motivation that has been accepted as personally valued and important; and integrated regulation describes extrinsic motivation that is fully self-endorsed and has been well 
assimilated with other identifications, values, and needs. Regulations that lie further along this continuum from external toward integrated are more fully internalized, and the resulting behaviors are more autonomous (p. 191).

Proposition III) Supports for the basic needs for competence, relatedness, and autonomy facilitate the internalization and integration of non-intrinsically motivated behaviors. To the extent that the context is controlling, and/or relatedness or competence needs are thwarted, internalization, and particularly identification or integrated regulation, will be less likely (p. 203).

Proposition IV) To the degree that people's behavior is regulated through more autonomous or integrated forms of internalization, they will display greater behavioral persistence at activities, a higher quality of behavior, and more effective performance, especially for more difficult or complex actions (p. 208).

Proposition V) To the degree that people's behavior is regulated through more integrated forms of internalization, they will have more positive experiences and greater psychological health and well-being (p. 208).

\section{Basic Psychological Needs Theory}

Fundamental to the SDT framework is that people have three basic psychological needs, which are the need for autonomy, competence, and relatedness. According to Deci and Ryan (2002), the need for (a) autonomy refers to the desire to have volitional control over their own behavior, (b) competence refers to the desire to demonstrate their efficacy and abilities, and (c) relatedness refers to the desire to connect with others. BPNT focuses on the relation between basic psychological need satisfaction and well-being (Ryan \& Deci, 2017). BPNT assumes that "greater basic need satisfaction will result in enhanced wellness and greater need frustration diminish wellness" (Ryan \& Deci, 2017, p. 242). Essentially, basic psychological need satisfaction is necessary for people to flourish and to be intrinsically motivated.

As outlined by the BPNT, these three innate needs are considered the necessary nutriments for people to continue to develop and grow. In order to be qualified as a basic psychological need, Ryan and Deci $(2002,2017)$ outlined several specific criteria. First, 
Ryan and Deci (2017) stated that it is necessary that the "satisfaction of a new candidate need be strongly positively associated with psychological integrity, health, well-being, and that its frustration be negatively associated with these outcomes, over and above the variance accounted for by the existing needs" (p. 251). Second, a basic psychological need must specify the experiences and behaviors necessary for well-being. For example, the need for autonomy specifies that people have to feel that their behaviors emanate from their sense of self. Third, basic psychological needs are functional and must be able to explain the "costs and benefits from deprivation to satisfaction, respectively" (Ryan \& Deci, 2017, p. 251). Fourth, a basic psychological need must be present when people experience growth, but also when they experience decline. Finally, a basic psychological need must operate universally that applies across ages, genders, and cultures (Ryan \& Deci, 2002). Several candidates for additional needs have been presented, such as meaning, self-esteem, security, and benevolence, but have failed to meet the theoretical criteria outlined above (Ryan \& Deci, 2017).

Much of the research on BPNT has focused on examining how people's needs for autonomy, competence, and relatedness (a) fluctuate in relation to well-being and (b) operate cross-culturally. Several researchers (e.g., Lynch, La Guardia, \& Ryan, 2009; Reis, Sheldon, Gable, Roscoe, \& Ryan, 2000; Sheldon, Ryan, \& Reis, 1996) have examined how people's basic psychological needs fluctuate along with their well-being. Using diary studies across two weeks, Sheldon et al. (1996) found that students reported more positive moods and vitality on days that they felt more autonomous and competent during their daily activities. Reis et al. (2000) used a similar daily-diary method and found that people's daily basic psychological need satisfaction predicted their daily well- 
being, which included an increase in positive affect and vitality and a decrease in negative affect and symptoms (i.e., reports of a runny nose, difficulty breathing, soreness, etc.). Ryan and Deci $(2002,2017)$ argued that researchers have consistently found evidence across many life domains, such as work, education, nursing homes, and relationships, that the satisfaction of people's needs for autonomy, competence, and relatedness are conducive toward their psychological health.

SDT researchers (Deci \& Ryan, 2008) have also demonstrated that these three basic psychological needs are universal for people and extend cross-culturally. For example, previous research has supported the connection between basic psychological need satisfaction and well-being across various cultures including the United States, South Korea (Sheldon, Elliot, Kim, \& Kasser, 2001), Brazil, Canada (Chirkov, Ryan, \& Willness, 2005), China, Peru, Belgium, (Chen et al., 2015) and India (Chettiar, 2015). In regard to this dissertation, BPNT (see Table 3 for theoretical propositions) posits that students' needs for autonomy, competence, and relatedness are fundamental to their growth in the classroom, regardless if students recognize or value these needs. Importantly, BPNT acknowledges that the factors of the classroom environment can cause fluctuations in basic psychological need satisfaction and subsequently variations in psychological well-being. Thus, instructor communication behaviors can facilitate or thwart these basic needs required for development and intrinsic motivation (e.g., Baker \& Goodboy, 2018; Goldman \& Brann, 2016; Goldman, Goodboy, \& Weber, 2016). Indeed, many SDT researchers have examined how instructors and the educational environment support or thwart students' basic psychological needs and, in turn autonomous motivation. 
Table 3

Theoretical Propositions for BPNT from Ryan \& Deci (2017)

Proposition Ia) There are three basic psychological needs, the satisfaction of which is essential to optimal development, integrity, and well-being. These are the needs for autonomy, competence, and relatedness. Failure to satisfy any of these needs will be manifested in diminished growth, integrity, and wellness. In addition, need frustration, typically due to the thwarting of these basic needs, is associated with greater ill-being and more impoverished functioning (p. 242).

Proposition $\mathrm{Ib}$ ) Psychological need satisfactions and frustrations vary within persons over time, contexts, and social interactions. Any factor or event that produces variations in need satisfaction or need frustration will also produce variations in wellness, and this principle extends from highly aggregated levels of analysis down to moment-to-moment or situation-to-situation variations in functioning (p. 243).

Proposition II) Satisfaction of each of the three psychological needs is facilitated by autonomy support, whereas controlling contexts and events can disrupt not only autonomy satisfactions, but relatedness and competence need fulfillments as well (p. 247).

Proposition III) Because basic psychological need satisfactions are functional requirements for full functioning and wellness, the effects of satisfaction versus frustration of these needs will be evidenced regardless of whether or not people explicitly desire or value the needs, and regardless of their sociocultural context ( $\mathrm{p}$. 248).

Proposition IV) Basic need satisfactions of autonomy, competence, and relatedness will tend to positively relate to one another, especially at an aggregated level of analysis (i.e., across domains, situations, or time; p. 249).

Proposition V) Deficit needs (such as needs for security and self-esteem) become salient under circumstances of threat, distress, or thwarting of growth needs such as autonomy, competence, and relatedness. Satisfaction of deficit needs can stave off aspects of ill-being but do not typically contribute to enhanced wellness or flourishing. That is, deficit needs emerge as most salient under adverse conditions (threat, deprivation, exclusion, etc.), but they are not aspects of ongoing thriving, and their satisfactions may set the stage for, but do not necessarily promote, optimal human functioning (p. 255).

Proposition VI) Subjective vitality is based on more than physical nutrients; it also reflects satisfaction versus thwarting of basic psychological needs for autonomy, competence, and relatedness. Therefore, both externally controlling and selfcontrolling states are expected to deplete vitality, whereas basic psychological needs satisfactions are expected to enhance it (p. 258). 
Proposition VII) Other factors aside, meaningful exposure to living nature has a positive effect on subjective vitality relative to exposure to non-natural, built environments without living elements, and this relation is mediated in part by basic psychological needs (p. 265).

Proposition VIII) Mindfulness, defined as the open and receptive awareness of what is occurring both within people and within their context, facilitates greater autonomy and more integrated self-regulation, as well as greater basic psychological need satisfaction, which contributes to greater well-being (p. 268).

\section{Self-Determination Theoretical Perspective on Education}

Ryan and Deci (2017) noted that the educational context is a primary setting that can support or thwart students' motivation and basic psychological needs. Thus, it is no surprise that over 200 empirical studies using SDT have been applied to education, devoting considerable research toward investigating students' quality of motivation and the subsequent behavioral, cognitive, and affective outcomes (Guay et al., 2008). For example, previous research has demonstrated that students who are more autonomously motivated (compared to externally regulated) persist and stay in school (e.g., Hardre \& Reeve, 2003; Vallerand, Fortier, \& Guay, 1997), academically perform (e.g., Benware \& Deci, 1984; Black \& Deci, 2000; Vansteenkiste et al., 2004), and have more positive experiences in education (e.g., Deci, Schwartz, Sheinman, \& Ryan, 1981; Ryan \& Connell, 1989; Vallerand et al., 1992). Ultimately, decades of SDT research support Reeve's (2002) contention that autonomously motivated students thrive in the educational context. In other words, intrinsic motivation and autonomous forms of motivation (i.e., identified regulation) foster optimal student functioning. Thus, SDT researchers have focused on examining the environments that foster these types of motivation, primarily from instructors.

\section{Autonomy Support from Teachers}


SDT focuses on two major motivational styles that teachers endorse in the classroom that range in terms of being autonomy-supportive or controlling. Reeve (2009) defined autonomy-supportive instruction as the "interpersonal sentiment and behavior teachers provide during instruction to identify, nurture, and develop students' inner motivational resources" (p. 160). These inner motivational resources primarily include students' need for volitional control in the classroom (i.e., autonomy), need to connect with others (relatedness), and need to demonstrate their capacities (competence; Ryan \& Deci, 2017). Autonomy-supportive instructors not only nurture students' basic psychological needs, interests, and values, but also facilitate the internalization process for students. In other words, autonomy-supportive instructors make students feel in control of their learning and help students align their classroom behaviors with their inner motivational resources (i.e., psychological needs, interests, values, and goals). Reeve (2009) identified three conditions necessary to motivate students in an autonomy-support way, including (a) integrating students' perceptions into instruction, (b) eliciting students' thoughts, feelings, and behaviors, and (c) supporting students' development to help them regulate their own academic motivation. Put simply, an autonomy-supportive instructor should become in synch with one's students (Reeve, 2016) and create a classroom climate that conveys validation, support, development, and encouragement (Ryan \& Deci, 2017).

In contrast, Reeve (2009) defined controlling instruction as the "interpersonal sentiment and behavior teachers provide during instruction to pressure students to think, feel, or behave in a specific way" (p. 160). That is, a controlling instructor forces students to cast aside their inner motivational resources (i.e., psychological needs, interests, 
values, and goals) to follow the instructor's agenda (Reeve \& Jang, 2006). Instead of trying to foster students' psychological needs and motivation to develop, the controlling instructor relies on external demands (i.e., punishments, incentives, rewards, etc.) to get students to behave in desired ways. Reeve (2009) identified three conditions that are considered a controlling way to motivate students, including (a) focusing solely on the teacher's perspective, (b) interrupting students' thoughts, feelings, and behaviors, and (c) pressuring students to think and behave in prescribed ways. Overall, the controlling style of instruction communicates to students they are not in control of their learning, the teacher's perspective is more valuable, and that success comes from strict adherence to the teacher's pressures and demands (Reeve, 2006, 2009).

Two seminal studies (e.g., Deci, Nezlek, \& Sheinman, 1981; Deci, Schwartz et al., 1981) investigating instructors' orientations toward managing elementary students and these students' intrinsic motivation and self-esteem marked the start of the examination of autonomy support in the classroom. These studies created four orientations teachers endorse when responding to typical student problems that arise (i.e., children not preparing for lesson, bullying other children, or stealing) in the classroom: high controlling, moderately controlling, moderately autonomous, and high autonomous. High controlling instructors make decisions about what is right and use sanctions to produce desired behavior, whereas moderately controlling teachers still make the decisions but emphasize to students to behave in a certain way for their own good (i.e., guilt students to solve the problem). Moderately autonomous instructors encourage students to compare their behaviors with other students to handle problems. High autonomous instructors have students consider the relevant elements of the issue and 
have them take responsibility for coming up with a solution to the problem. As predicted in both studies, students who had an autonomously oriented teacher reported more intrinsic motivation and self-esteem in the classroom, which persisted throughout the academic year.

Almost four decades of research has been dedicated to examining the relationship between autonomy-supportive instruction and students' motivational outcomes and wellbeing (Ryan \& Deci, 2017). These findings suggest that students benefit from an autonomy-supportive instructor and suffer from a controlling instructor (Reeve, 2002). Specifically, many SDT researchers have revealed that autonomy-supportive instruction supports students' basic psychological needs, fosters more autonomous forms of motivation, and results in positive learning outcomes (Ryan \& Deci, 2017). Because the autonomy-supportive style of teaching is consistently connected to students' academic success (Reeve, 2002, 2006, 2009), SDT researchers have studied various teaching techniques that reflect this style of teaching (for most recent list, see Table 4).

Table 4

Autonomy-Supportive and Controlling Teaching Behaviors from Ryan \& Deci (2017)
Autonomy-supportive
Controlling

\begin{abstract}
Listening to students
Making time for students' independent work
\end{abstract}

Giving students an opportunity to talk

Acknowledging signs of improvement and mastery
Monopolizing the learning materials

Providing students too little time to work independently on solving problems

Telling students answers without giving them an opportunity to formulate them

Making demands and directives 
Encouraging students' effort

Offering progress-enabling hints when students seem stuck

Being responsive to students' comments and questions
Using controlling words such as should and have to

Using directed questions as a way of controlling the flow of conversation

Acknowledging students' experiences and perspectives

\section{Autonomy-Supportive Teaching Behaviors}

Reeve (2006) noted that the autonomy-supportive style of teaching is a belief that instructors endorse about their students' motivation that manifests in what they do and say in the classroom. Reeve and Jang (2006) examined 21 previously identified instructor behaviors that were either autonomy-supportive (11 behaviors) or controlling (10 behaviors) in relation to students' autonomous motivation. They reasoned that for behaviors to constitute an autonomy-supportive style of teaching, they must increase students' autonomous motivation, whereas controlling behaviors must decrease students' autonomous motivation. Of the 11 original autonomy-supportive behaviors, Reeve and Jang found that eight behaviors related positively to students' autonomous motivation: listening to students, allowing time for students to work on their own, providing students more time to talk, acknowledging students' improvement, encouraging students' efforts, providing hints when students were stuck, being responsive to students' comments and questions, and acknowledging students' experiences and perspectives. Additionally, of the 10 controlling behaviors, six behaviors related negatively to students' autonomous motivation: monopolizing learning materials (i.e., physically keeping the materials), giving students the answers without letting them work alone to formulate one, telling students the answers without letting them attempt an answer, using directives and 
demands, using controlling words (i.e., "should", “ought", and "must"), and asking controlling questions to direct instruction in a prescribed way (i.e., "can you move it like I showed you?").

Instead of studying the myriad instructor behaviors that characterize the autonomy-supportive style of teaching (see Reeve \& Jang, 2006; Ryan \& Deci, 2017), many SDT researchers have focused on the general categories of this style of teaching that subsume many of these behaviors (e.g., Jang, Reeve, \& Deci, 2010; Reeve, 2002; Reeve, Jang, Carrell, Jeon, \& Barch, 2004). Reeve (2009) identified five general categories of instructor behaviors that encompass the autonomy-supportive and controlling motivational styles. The five general categories of autonomy-supportive instruction included, nurture inner motivational resources, provide explanatory rationales, rely on noncontrolling and informational language, display patience to allow time for self-paced learning, and acknowledge and accept expressions of negative affect. Nurture inner motivational resources refers to behaviors that instructors use to gain an awareness of students' inner motivational resources (i.e., psychological needs, interests, values, and goals) and find ways to involve and develop those resources. Provide explanatory rationales refers to instructor behaviors that explain the value and utility behind their requests and for students' behaviors in the classroom. Relying on noncontrolling and informational language refers to instructional messages that minimize pressures, convey flexibility, and offer hints for students to solve problems on their own. Display patience to allow time for self-paced learning refers to giving students the necessary time and encouragement to work through the learning process, ask questions, and adjust their methods. Acknowledge and accept expressions of negative affect refers to giving students 
a voice in order to understand their perspectives and to adjust the learning environment.

In a similar vein, Reeve (2016) positioned six autonomy-supportive instructor behaviors along three critical moments within the flow of instruction: pre-lesson, lesson delivery, and addressing problems during the lesson. Though, Reeve (2016) identified six autonomy-supportive behaviors, these included the same five aforementioned behaviors from Reeve (2009) but added the behavior of taking students' perspectives. Taking students' perspectives refers to becoming in synch with students' desires, preferences, and priorities to incorporate and adjust a lesson. He argued that breaking these behaviors down into three feasible moments during instruction makes them more manageable for instructors to enact in the classroom. First, during the pre-lesson phase, Reeve (2016) mentioned that instructors should focus on taking their students' perspectives. Second, during lesson delivery where teachers introduce activities and try to engage students in the learning process, the two autonomy-supportive behaviors of nurturing students' inner motivational resources and providing explanatory rationales become critical. Third, while the lesson unfolds, student problems, such as disengagement, misbehaviors, poor performance, and resistance tend to arise. Reeve (2016) argued that the autonomysupportive behaviors of acknowledging and accepting negative affect, using noncontrolling and informational language, and displaying patience can help manage disengagement issues and these behavioral problems that arise during instruction.

\section{The Provision of Choice}

Of the various autonomy-supportive behaviors, offering students' choices is an obvious method of supporting their autonomy (Patall et al., 2008). The provision of choice in the classroom characterizes one method that instructors can use to nurture 
students' inner motivational resources (Patall et al., 2008). Recall that these inner motivational resources include students' basic psychological needs for autonomy, competence, and relatedness among other resources (i.e., interests and goals). Indeed, several decades of laboratory and field studies have found that the provision of choice leads to positive outcomes for students, such as basic psychological need fulfillment, intrinsic motivation, interest, and learning (Ryan \& Deci, 2017).

In their seminal study, Zuckerman, Porac, Lathin, Smith, and Deci (1978) manipulated whether or not participants would have choices during an interesting activity. The participants in the choice condition were given the opportunity to decide three different times which of the six puzzles to solve and allot as much time needed to solve each puzzle. However, the participants in the no choice condition were required to solve the same puzzles in the same amount of time as the individuals who were given choices. Zuckerman et al. (1978) found that giving choices to people significantly increased their intrinsic motivation. Using similar methods, Reeve et al. (2003) made an important distinction regarding offering choices. They distinguished between option choice, which is focused on allowing people to choose from an array of diverse options, and action choice, which involves offering ongoing choices during the engagement in an activity. For example, participants either decided to solve one puzzle from the six options provided (option choice) or had choice over three different puzzles to solve and allot as much time needed to solve each puzzle (action choice). Reeve et al. (2003) found that action choice was more beneficial for participants' sense of volition, internal locus of control, and intrinsic motivation.

Further differentiating choice, Moller, Deci, and Ryan (2006) offered the 
comparison between autonomous choice and controlled choice. An autonomous choice refers to unrestricted choice or a feeling that a decision is emanating from the individual, whereas controlled choice refers to subtle pressures to make a decision or feeling compelled to make one particular choice. In other words, an autonomous choice would give students the opportunity to freely choose from a number of options, whereas a controlling choice would subtly force students to choose a particular option desired by the instructor. Moller et al. (2006) argued that previous contradictory findings in the choice literature stem from the lack of differentiating between these types of choices given to participants. Therefore, they conducted three different experiments to compare unrestricted choice, which allowed people to choose any side of a debate to argue for, to controlled choice, which subtly pressured people to select one side of a debate to argue. Moller et al. (2006) demonstrated that when people were given autonomous choice, they persisted to complete the experimental tasks longer than their counterparts.

Bringing further coherence to early research, Patall and her colleagues (2008) conducted a meta-analysis of 41 choice studies and found that overall the provision of choice enhanced intrinsic motivation, effort, task performance, and perceived competence. However, Patall et al. (2008) identified several important moderators for choice to be more effective for improving intrinsic motivation. They found that the effect of choice on intrinsic motivation was stronger when the choices were irrelevant to the instructional information, included two to four successive choices during the activity, did not precede a reward, and when the study was conducted in laboratories versus natural settings. Regarding these studies, Iyengar and Lepper (2000) cautioned that prior choice research actually only demonstrates that choice among relatively limited alternatives is 
better than having no choice. In other words, Iyengar and Lepper (2000) argued that these studies have only offered participants a limited amount of options (i.e., two to about six options), but in many other real-life situations the number of options (i.e., 24 to 30 different gourmet jams and chocolates) may be overwhelming. Indeed, they demonstrated that being offered too many choices causes decision making to be demotivating and can actually become a burden for people (see also Mozgalina, 2015). More specifically, Iyengar and Lepper (2000, study 2) revealed that when students were given six (versus 30) essay topics to write about, they were more likely to complete the essay and had slightly higher quality essays. Thus, previous research supports the argument that the ideal number of choices provided to students should range somewhere between two to four successive choices.

Patall (2013) noted that providing choices is a complex process, which depends on the type of choice and/or the circumstances under which choices are provided. This begs the question: which type of choice is most effective? According to the aforementioned research, the provision of choice should be limited to a few options, autonomous, and successive (Moller et al., 2006; Patall et al., 2008; Reeve et al., 2003). That is, the choices provided to students should: (a) be simple, (b) make students feel that the choices are emanating from themselves, and (c) sequentially build off earlier choices made by students (action choice). Furthermore, Katz and Assor (2007) argued that in order to support students' basic psychological needs for autonomy, competence, and relatedness, instructors should offer choices that are relevant to students' interests, that are not too numerous or complex, and that align with students' values, respectively. Recently, Reeve and his colleagues (Jang et al., 2016; Reeve, 2016) have suggested that 
the provision of choice may be an effective way to take students' perspectives by acknowledging their preferences and allowing those preferences to be incorporated into the lesson.

As mentioned above, Reeve (2016) identified the autonomy-supportive category of taking students ' perspectives as becoming in synch with students' desires to make adjustments to a particular lesson. Thus, in addition to providing students choices as a way to nurture their inner motivational resources, offering such choices may also provide instructors a method to understand students' perspectives and adjust the lesson around those perspectives (Reeve, 2016). Jang et al. (2016) argued that any effective autonomysupportive behaviors should inherently focus on taking students' perspectives. However, Jang and his colleagues also suggested that taking students' perspective is not necessarily a behavior that instructors can easily enact; therefore, they introduced the instructional behavior of teaching in students' preferred ways as a potentially new autonomysupportive behavior to reflect this general category. Teaching in students' preferred ways includes two important methods: (1) intentionally soliciting students' preferences and (2) acting on that information to adapt instruction to align with students' preferences. Specifically, they had students rank their preferred methods of teaching and compared instruction that included the preferred methods to instruction that students' identified as not preferred. Jang et al. found that teaching in students' preferred ways (versus nonpreferred ways) increased students' self-reports of in-class engagement and observer ratings of engagement behaviors. Additionally, they showed that this method of teaching supported students' needs for autonomy, which subsequently increased their conceptual learning. 


\section{Rationale}

Having reviewed SDT and the related autonomy-supportive literature, the primary purpose of this dissertation was to extend the SDT research by examining the provision of choice during instruction using a live lecture experiment. In other words, the objective of this dissertation was to investigate the utility of the choose your own lecture method of instruction to nurture students' intrinsic motivation and understand students' desires and preferences during instruction. Putting students in control and allowing them to choose the direction of the lesson may provide instructors a useful style of teaching that supports their students' need for autonomy and their intrinsic motivation to learn in the classroom. Therefore, this dissertation examined the effect of the choose your own lecture teaching style on students' motivational resources and subsequent learning outcomes.

One contribution of this dissertation is the investigation of a different method to give students' meaningful choices during instruction. Early researchers investigating choice (see Patall et al., 2008) have focused on allowing people to choose between several interesting or uninteresting tasks (i.e., puzzles; Zuckerman et al., 1978) or have relied on manipulating the absence or presence of controlling language (i.e., "should", "must", "have to"; Deci et al., 1994). Admittedly, some researchers have extended the way choices are given to students to include choices over homework assignments (Patall et al., 2010), procedural and cognitive choices (Furtak \& Kunter, 2012), choices over the examples used for a particular topic (Reber, Hetland, Chen, Norman, \& Kobbeltvedt, 2009), and choices over students' preferred methods of instruction (Jang et al., 2016). Clearly, the provision of choice is a complex process (Patall, 2013), which has prompted many SDT researchers to examine the conditions and types of choices given to students. 
Jang et al. (2016), for example, demonstrated that allowing students to choose their preferred methods of instruction is beneficial for their learning and engagement, but providing students the opportunity to choose what information they want to learn during a lecture may also be an effective type of choice. Thus, to further extend the choice literature, this study examined the autonomy-supportive behavior of having students decide on the information presented by the instructor and how the lecture would unfold (i.e., the choose your own lecture method; Baker \& Goodboy, 2019).

\section{Autonomy-Supportive Teaching and Autonomous Motivation}

CET, BPNT, and OIT are three sub theories that frame this dissertation and support the connection between autonomy-supportive teaching and students' motivational resources and subsequent learning outcomes. According to CET (proposition IV; Table 1), the classroom climate can directly impact intrinsic motivation, such that autonomysupportive classrooms support students' needs for autonomy, competence, and relatedness and facilitate more intrinsic motivation. Additionally, BPNT (propositions Ib $\&$ II; Table 3) posits that factors of the classroom environment can cause fluctuations in basic psychological need satisfaction or frustration depending on the degree that the environment is autonomy-supportive or controlling, respectively. Furthermore, OIT (proposition III; Table 2) postulates that the classroom context that support students' psychological needs fosters the internalization of external regulations and promotes more autonomous forms of motivation (i.e., identified regulation and intrinsic motivation). In other words, as outlined by the theoretical propositions of CET, BPNT, and OIT the choose your own lecture method of instruction should enhance intrinsic motivation.

\section{Consequences of Autonomous Motivation}


Moreover, CET, BPNT, and OIT suggest that students' basic psychological need fulfillment and autonomous forms of motivation represent optimal student functioning (Ryan \& Deci, 2017). That is, according to BPNT (proposition Ia \& III; Table 3), students' needs for autonomy, competence, and relatedness are required for development and well-being, regardless if students recognize or value these needs. Additionally, OIT (propositions IV \& V) posits that because basic psychological need fulfillment facilitates autonomous motivation, students will "display greater behavioral persistence at activities, a higher quality of behavior, and more effective performance, especially for more difficult or complex actions," and will "have more positive experiences and greater psychological health and well-being" (Ryan \& Deci, 2017, p. 208). Therefore, the following hypotheses will examine how students' intrinsic motivation in response to autonomy-supportive instruction would increase students' interest in the topic of information taught, free-choice persistence, cognitive learning, and likelihood of enrolling in a future course with the instructor, and decrease expressive dissent.

The first hypothesis will determine if the choose your own lecture method of instruction will increase students' interest in the topic of the lecture, indirectly through students' intrinsic motivation to learn. Hidi and Renninger (2006) defined interest as a "psychological state of engaging or the predisposition to reengage with particular classes of objects, events, or ideas over time" (p. 112). Specifically, they described situational interest as interest that can be momentarily triggered or activated by an environment. Schraw, Flowerday, and Lehman (2001) suggested that students who are given choices in the classroom make decisions based on their preferences and become more involved in the teaching process. They also argued that students' curiosity may be a driving force 
behind their interests in certain topics. Flowerday, Schraw, and Stevens (2004) found that the provision of choice not only increased students' situational interest in the topic they were learning, but also increased situational interest for students who had low personal interest in the topic (see also Patall, 2013). Thus, it is likely that students who are driven by a natural inclination to challenge themselves and explore new ideas (i.e., intrinsically motivated) are more likely to be interested in the lecture information (Figure 2).

Figure 2

Hypothesized Conceptual Model of Hypothesis 1

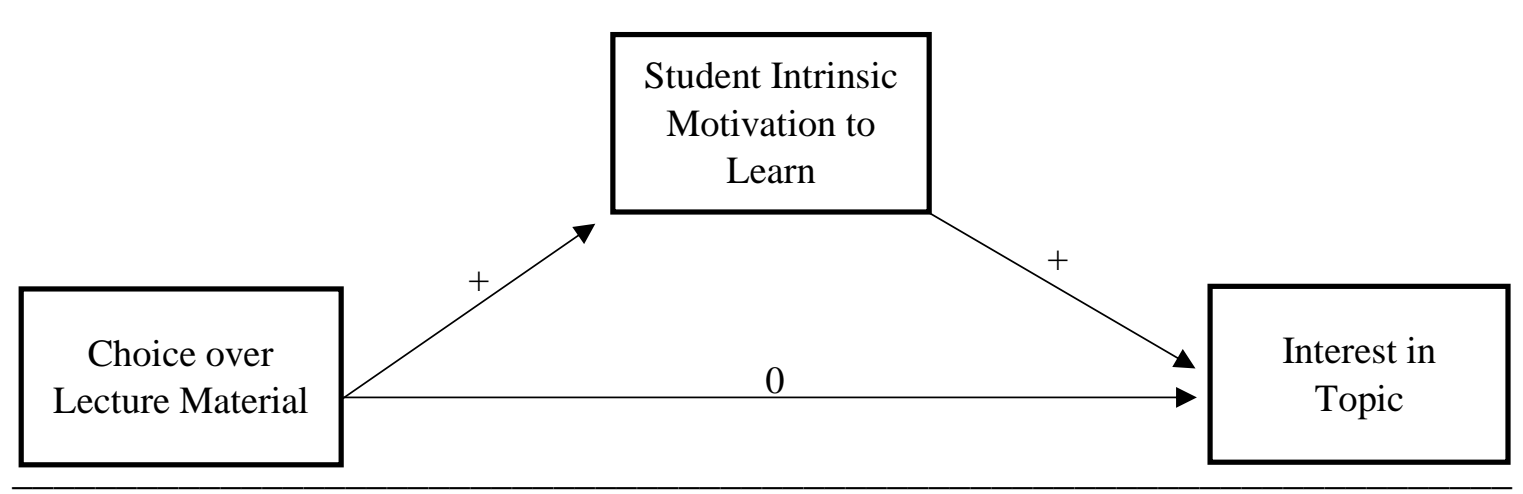

Note. Choice over Lecture Material is indicator coded $(0=$ control, $1=$ treatment $)$ to reflect the mean difference between the two lecture conditions. The instructor behaviors of Clarity, Humor, Nonverbal Immediacy, and Enthusiasm; and students' past experience with the instructor and perception of choices met were included as covariates in the models of M (Intrinsic Motivation) and Y (Interest in Topic).

The second hypothesis will examine if offering students' choices over the material may vitalize their intrinsic motivation to learn and subsequently make students persist when given free-choice. As noted above, SDT researchers from the free-choice paradigm (e.g., Deci, 1971), have demonstrated that using controlling language and expected tangible rewards (engagement-contingent, completion-contingent, and performance-contingent) diminish people's free-choice persistence. Recall that freechoice persistence is people's motivation to continue to attempt or complete the target 
activity when left to freely choose what to do (e.g., Deci, 1971). In conjunction with the free-choice paradigm and SDT, Vansteenkiste et al. (2004) revealed, in three separate experiments, that using autonomy-supportive language increased students' autonomous motivation, and subsequently, their free-choice persistence (i.e., visiting the library, joining the campus-wide visit to the recycling plant, additional reading materials, and volunteered to demonstrate exercises). Thus, because giving students the opportunity to choose during a lecture makes them feel a sense intrinsic motivation, these students will likely choose to persist to learn more about the topic of the lecture when given freechoice to anything else (Figure 3).

Figure 3

Hypothesized Conceptual Model of Hypothesis 2

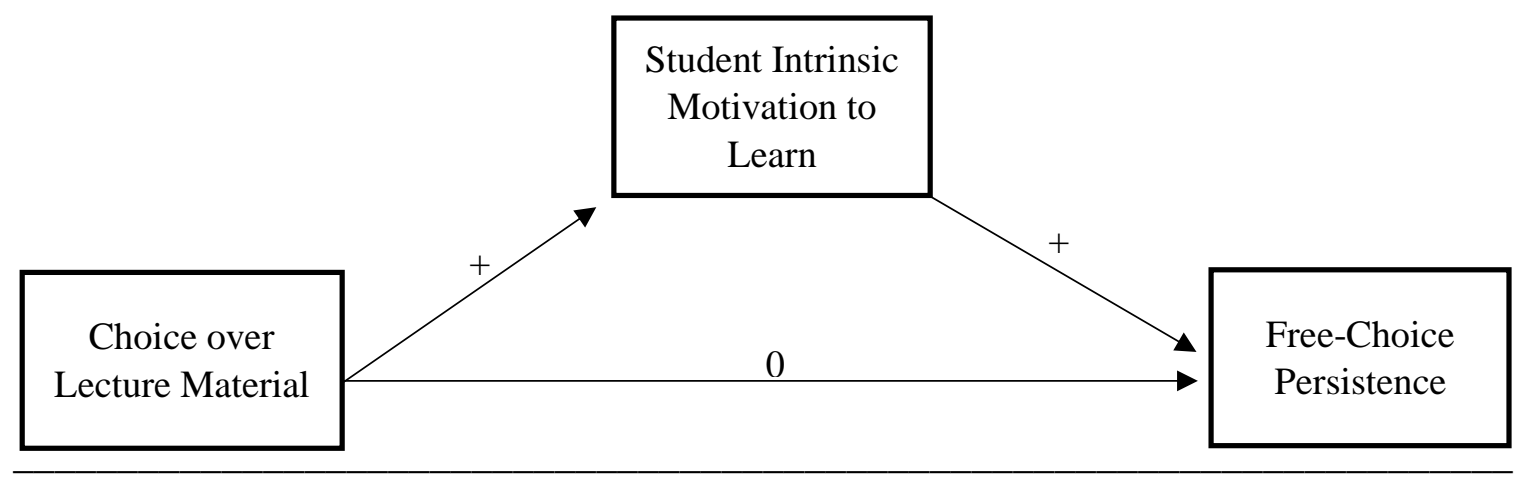

Note. Choice over Lecture Material is indicator coded $(0=$ control, $1=$ treatment $)$ to reflect the mean difference between the two lecture conditions. The instructor behaviors of Clarity, Humor, Nonverbal Immediacy, and Enthusiasm; and students' past experience with the instructor and perception of choices met were included as covariates in the models of M (Intrinsic Motivation) and Y (Free-Choice Persistence).

The third hypothesis will determine if students' cognitive learning will increase as a result of their intrinsic motivation from choosing the direction of the lesson. Anderson and Krathwohl (2001) refer to cognitive learning as a taxonomy of cognitive domains that ranges from lower levels like remembering and understanding to more complex 
processes like evaluation and creation. Several SDT studies have also found that autonomy-supportive instruction is responsible for student gains in cognitive learning (Benware \& Deci, 1984; Black \& Deci, 2000; Grolnick \& Ryan, 1987; Sheldon \& Krieger, 2007; Vansteenkiste, Zhou, Lens, \& Sioenens, 2005). However, some researchers (e.g., Jang, 2008; Vansteenkiste et al., 2004) have demonstrated that students' autonomous motivation plays an important explanatory role between this style of teaching and students' learning. One likely reason for these gains in cognitive learning is because autonomous motivation is linked positively to students' deep cognitive processing, self-regulation strategies, and metacognitive strategies (Baleghizadeh \& Rahimi, 2011; Vansteenkiste et al., 2004; Wang, Ng, Liu, \& Ryan, 2016). Therefore, in line with SDT, students' inner motivational resources (i.e., intrinsic motivation) should be the mechanism through which the provision of choice over the lecture material fosters an increase in students' performance on a short test of cognitive learning (Figure 4). 
Figure 4

Hypothesized Conceptual Model of Hypothesis 3

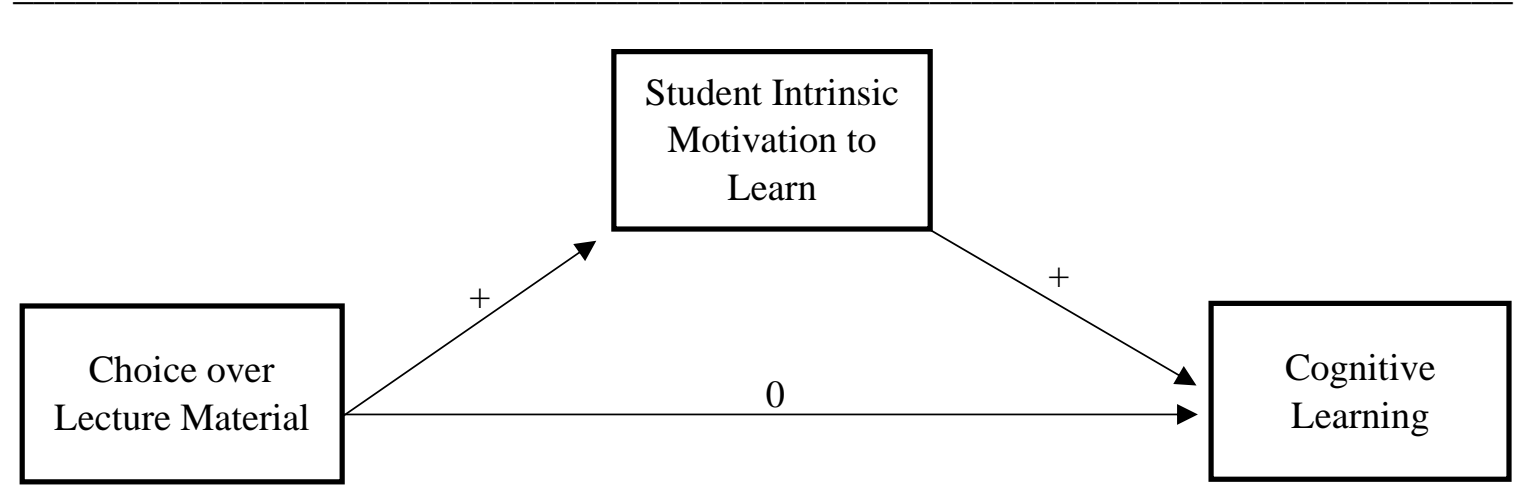

Note. Choice over Lecture Material is indicator coded $(0=$ control, $1=$ treatment $)$ to reflect the mean difference between the two lecture conditions. The instructor behaviors of Clarity, Humor, Nonverbal Immediacy, and Enthusiasm; and students' perceived familiarity with, and difficulty of, the lecture material; and students' past experience with the instructor and perception of choices met were included as covariates in the models of $\mathrm{M}$ (Intrinsic Motivation) and $\mathrm{Y}$ (Cognitive Learning).

The fourth and fifth hypotheses will examine how students' affect toward the course and communication (i.e., expressive dissent) will be influenced by their intrinsic motivation in response to the choose your own lecture method of instruction. Students' affect in the course refers to their likelihood of taking another course with the same instructor. Goodboy (2011) identified expressive dissent as students' expressed frustrations with a particular course or instructor to their friends or classmates as a way to cope with their dissatisfaction and garner sympathy. One major triggering agent of dissent is the lack of fairness in a particular course such as unfair grading, testing, course policies, and course procedures (Bolkan \& Goodboy, 2013).

Ryan and Deci (2017) noted that students tend to rate autonomy-supportive instructors as being more effective than controlling instructors. Indeed, Griffin (2016) found that students who were intrinsically motivated and perceived their instructors to be autonomy-supportive, gave these instructors an overall positive rating and specifically 
rated them as being able to present and organize the material clearly, share students' ideas, help students, show concern for students, give helpful feedback, and demonstrate their knowledge. Similarly, Filak and Sheldon (2008) found that students' needsatisfaction increased their likelihood of recommending the course and instructor to friends and their overall evaluation of the course and instructor. Additionally, Williams et al. (2015) noted that instructors who offer choices in the classroom communicate trust, respect, and worth to students, which influence their engagement. In other words, allowing students to choose how the lecture will unfold give them ownership over the material and the direction of the learning process. It is likely that the intrinsic motivation students' report in response to being given the opportunity to choose how the lecture unfolds should increase their intentions to take the course with the instructor in the future and diminish their intentions to talk negatively about their instructor (i.e., expressively dissent; Goodboy, 2011; See Figures 5 and 6).

Figure 5

Hypothesized Conceptual Model of Hypothesis 4

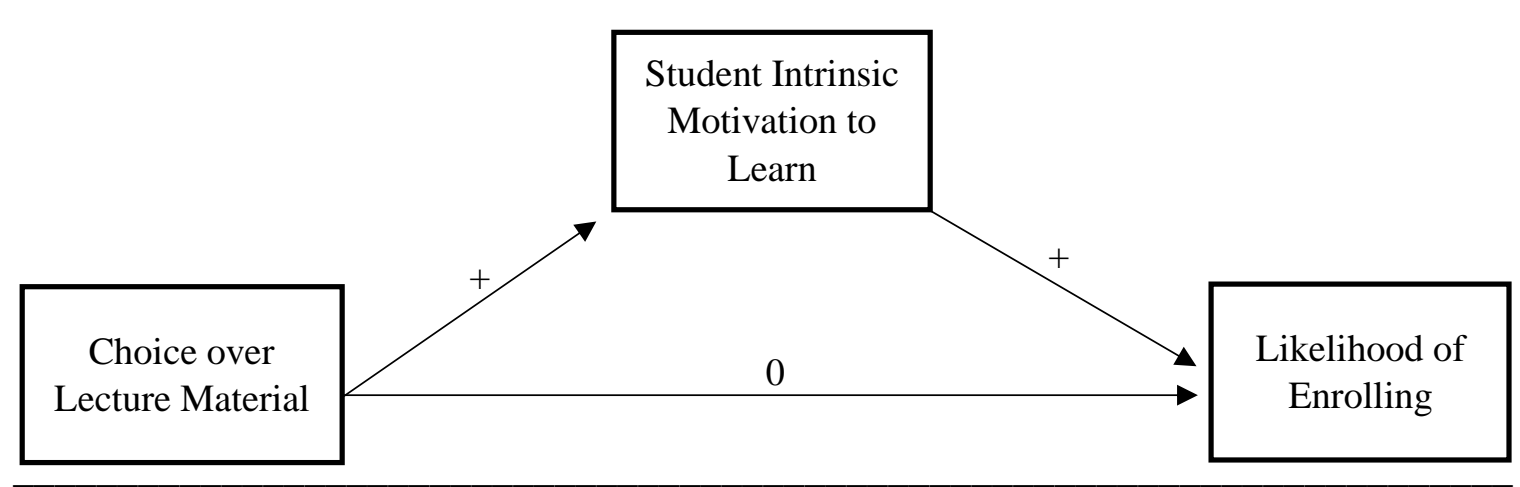

Note. Choice over Lecture Material is indicator coded $(0=$ control, $1=$ treatment $)$ to reflect the mean difference between the two lecture conditions. The instructor behaviors of Clarity, Humor, Nonverbal Immediacy, and Enthusiasm; and students' past experience with the instructor and perception of choices met were included as covariates in the models of M (Intrinsic Motivation) and Y (Likelihood of Enrolling). 
Figure 6

Hypothesized Conceptual Model of Hypothesis 5

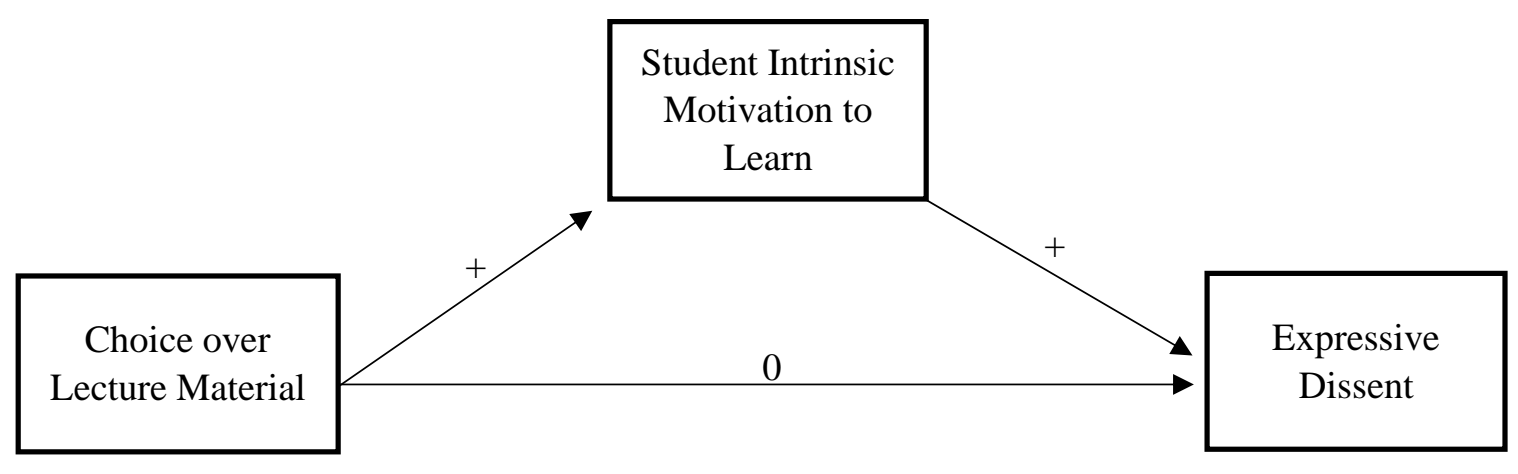

Note. Choice over Lecture Material is indicator coded $(0=$ control, $1=$ treatment $)$ to reflect the mean difference between the two lecture conditions. The instructor behaviors of Clarity, Humor, Nonverbal Immediacy, and Enthusiasm; and students' past experience with the instructor and perception of choices met were included as covariates in the models of M (Intrinsic Motivation) and Y (Expressive Dissent).

\section{Serial Mediation Claim of SDT}

The aforementioned hypotheses argue that students' intrinsic motivation is the mechanism responsible for the influence that the choose your own lecture method of instruction has on students' learning outcomes. However, as previously stated, SDT makes a claim that students' type of motivation relies upon their basic psychological need fulfillment. More specifically, according to Ryan and Deci (2017), the "social contexts that support satisfaction of all three psychological needs also facilitate more autonomous functioning, which in turn yields more effective performance and greater wellness" ( $p$. 16). Thus, it seems very likely that the autonomy-supportive behavior of giving students' choices over the lecture material they learn, will promote their intrinsic motivation (Baker \& Goodboy, 2019; Deci et al., 1991; Patall et al., 2008) because this teaching behavior supports their need for autonomy (Patall, Vasquez, Steingut, Trimble, \& Pituch, 2017; Ryan \& Deci, 2017). In fact, CET (proposition I) states that "external events 
relevant to the initiation or regulation of behavior will affect a person's intrinsic motivation to the extent that they influence the perceived locus of causality for the behavior" (Ryan \& Deci, 2017, p. 129). It seems that SDT makes an argument for serial mediation, such that the choose your own lecture method of instruction should increase students' learning outcomes, indirectly through students' autonomy-need satisfaction, and subsequently, intrinsic motivation to learn. Thus, the following research question is posed to explore this claim of serial mediation:

RQ: Will the choose your own lecture method of instruction influence students' (a) interest in the topic, (b) free-choice persistence, (c) cognitive learning, (d) likelihood of enrollment, and (e) expressive dissent through serial mediation via students' autonomy-need satisfaction and intrinsic motivation to learn?

\section{Summary}

This chapter provided an overview of SDT, particularly focusing on autonomysupportive instruction, to examine a different way of giving students choices during instruction in the form of the choose your own lecture method of teaching. Using assumptions from three sub theories of SDT, this dissertation hypothesized that offering students the opportunity to choose how a lecture unfolds would support one causal mechanism - their intrinsic motivation to learn - of SDT. In turn, this intrinsic motivation to learn should promote students' interest in the topic of lecture, free-choice persistence, cognitive learning, affect for the course, as well as decrease their intentions to expressively dissent. Additionally, this dissertation posed a research question to explore the serial mediation claim of SDT: the choose your own lecture method of instruction will cause students' autonomy-need satisfaction and subsequently students' 
intrinsic motivation to learn, which in turn, will result in the aforementioned learning outcomes. 


\section{CHAPTER II}

\section{Methodology}

\section{Pilot Study 1}

\section{Participants}

The first set of participants were recruited to pilot test the teaching scripts and the short test developed for this dissertation. Participants were 46 (10 Men and 36 Women) undergraduate students enrolled in two communication theory courses at a large MidAtlantic university. Participant ages ranged from 18 to 33 years $(M=20.20, S D=2.32)$.

\section{Procedures}

Part one of this study included developing live lecture teaching materials and scripts. Environmental communication, specifically climate change, was the topic of the lecture because this material was not part of the participants' communication curriculum at West Virginia University. Although the topic of environmental communication was chosen to limit the amount of previous experience students have with the lecture information, it is entirely possible that students may have some experience with this material and the topic of climate change in other coursework; therefore, this dissertation included students' familiarity with the material as a covariate (see below). Prezi presentation software was used to display the lecture material (see Appendix N). Prezi was used because this software allows for a nonlinear presentation style to create userdefined paths to illustrate information (Good \& Bederson, 2002). Prezi allowed the instructor to display the lecture information in a nonlinear form and provide the experimental group (i.e., choice condition) with the ability to choose the information discussed and have the presentation software follow those choices. Although there is a 
total of 18 potential paths for the experimental condition to have gone down for the lecture (see Figure 7), students were provided with no more than three options to choose from at a time. For example, when it came time for the first and third opportunity for students to choose the direction of the lesson (see Figure 7), students made a choice between only two options. Additionally, the provision of the second choice allowed students the opportunity to choose from three options: risk communication, communicating sustainability, or advocacy campaigns. Thus, the amount of choices provided to the experimental condition followed Patall et al.'s (2008) recommendation that the number of options to choose from should range from two to four successive choices.

Figure 7

Flowchart of Prezi Presentation and Student Choices

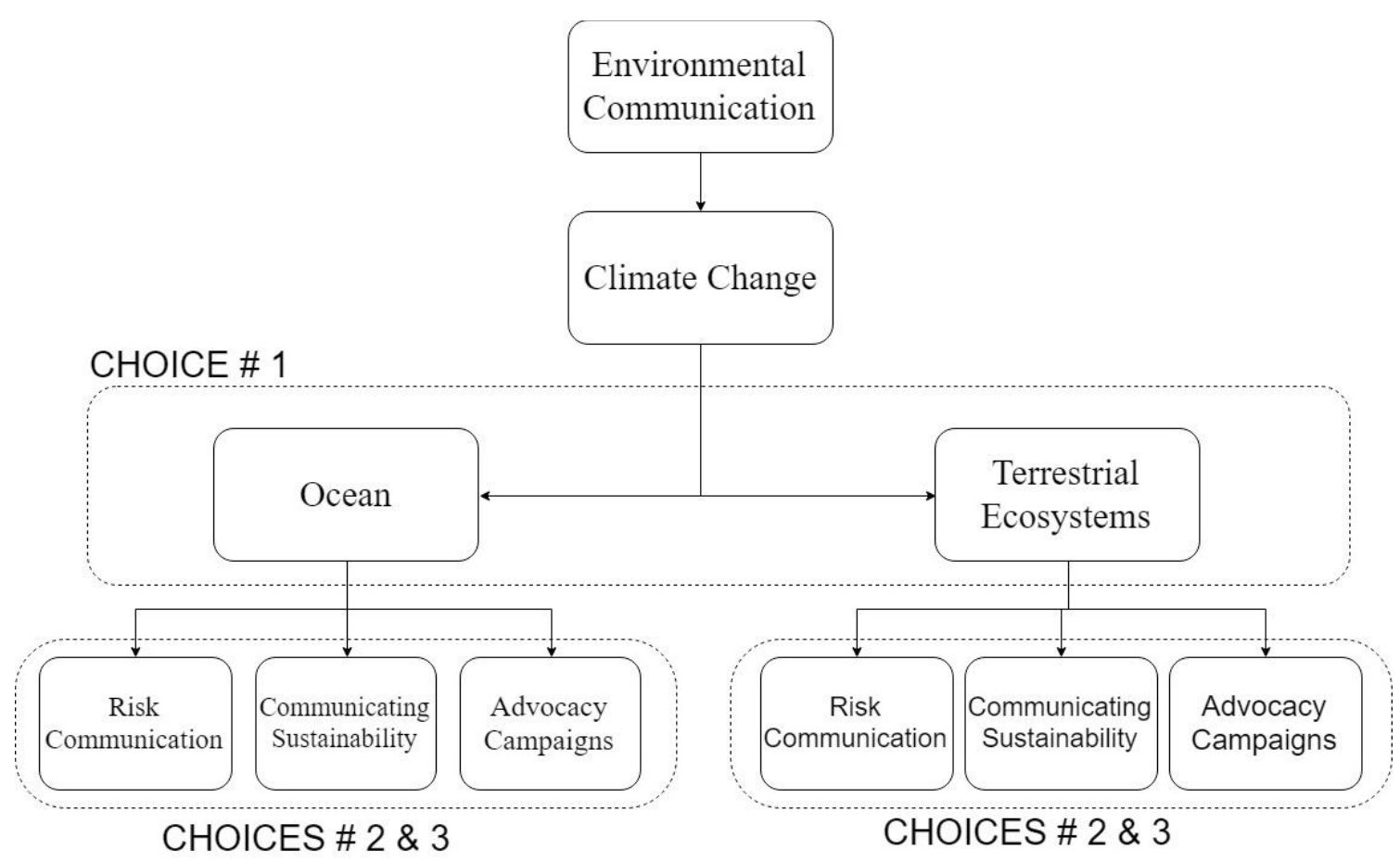

To facilitate the choices, two lecture scripts were developed on the topic of environmental communication. These lecture scripts focused on teaching the following 
topics: (1) environmental communication, (2) climate change, (3) risk communication, (4) communicating sustainability, and (5) advocacy campaigns. The lecture content presented within the two conditions remained exactly the same, except for the choice manipulations (see Appendix K).

After receiving Institutional Review Board (IRB) approval, the researcher visited two undergraduate communication theory courses during the $15^{\text {th }}$ week of the fall 2018 semester to confirm that the choice manipulations were adequate for both lecture scripts. Students were given either the control or treatment lecture script, which focused on environmental communication concepts. After reading the lecture script, participants completed a short survey that contained demographic questions, a 5-item measure to assess the provision of choice (Belmont, Skinner, Wellborn, \& Connell, 1988), a 4-item measure to assess their confidence in understanding the main points of the lesson (King $\&$ Witt, 2009), and a short 13-item test (developed for this dissertation). To measure students' lower levels of cognitive learning, a 13-item multiple-choice test was developed. The items were taken from the main points (i.e., climate change, risk communication, risk assessment, green marketing, greenwashing, and features of advocacy campaigns) of the lesson on environmental communication (see Appendix E). The researcher chose to create 13 test questions to ensure that the test would have an adequate number of items if poor performing items needed to be dropped during analysis. After completing the short survey, students were thanked for their assistance in helping the researcher and no course extra credit was given for their participation in the pilot study.

Additionally, the researcher wanted to assess the validity of the test that was 
developed for this dissertation. More recently, researchers have advocated for a unified view of validity focused on the accumulation of evidence to support the interpretation of measurements (Bandalos, 2018). Rather than focusing on any one "type" of validity, Bandalos (2018) argued that validity is a process that includes several different types of evidence that best support the argument for interpreting test scores. Therefore, this dissertation took several steps to provide evidence that the created 13-item test was indeed measuring students' lower levels of cognitive learning. More specifically, this dissertation sought to provide validity evidence based on the content of the test, the internal structure of the test, and the relations of the test to other variables.

First, to provide evidence that the content included on the test adequately represented students' lower levels of cognitive learning, the researcher had an environmental science instructor, who was consulted during the development of the lecture scripts, review the short 13-item test for question clarity, readability, and to ensure the questions tested students on the main points of the lesson. This process revealed minor issues with the response choices for questions $1,4,8$, and 12 . The expert reviewer provided the following suggestions to improve the test: (a) question one contained multiple responses that could be perceived as correct, (b) question four included responses that seemed too similar, (c) question eight's responses needed to mirror the responses of the prior question that was similar, and (d) question 12's responses should be a compatible length. Additionally, the expert reviewer provided corrections to improve the clarity and readability for questions $2,6,7,8$, and 11 . In addition to making the suggested corrections for clarity, the researcher made sure the response items were distinct answers, similar in length, and contained only one clear correct answer (see 


\section{Appendix E).}

Second, to provide further validity evidence based on content, the researcher created two coding sheets (see Appendix F) to examine which test questions aligned with the learning outcomes for the lesson and which questions tapped into the different levels of cognitive learning specified by Anderson and Krathwohl (2001). The cognitive learning coding sheet was created using Anderson and Krathwohl's (p. 67) revised taxonomy to define and provide coders with keywords for each level of cognitive learning ranging from remember to create. The researcher and environmental science instructor read the test questions and coded which learning outcome each question assessed and which level of cognitive learning was being measured.

Third, this dissertation focused on providing validity evidence based on the internal structure of the test and relation with students' confidence testing. King and Witt (2009) demonstrated that students' confidence in understanding the main points of a lesson plan was positively linked to their course grades. Thus, a positive relationship between students' percentage on the test and perceived confidence in their answers and understanding the main points of the lesson would provide initial validity evidence for the created 13 -item test.

\section{Instrumentation}

To assess the successfulness of the choice manipulation in the lecture scripts, the choice subscale (5-items) from the Teacher as Social Context Questionnaire - Student Report (Belmont et al., 1988) was used (see Appendix G). This measure was modified from focusing on assessing students' perceptions of the choices an instructor provides over students' schoolwork and assignments to choices an instructor provides over the 
lesson and information. Sample items included "The teacher gave students a lot of choices during the lesson," "When it comes to the lesson, the teacher gave students all kinds of things to choose from," and "The teacher did not give students much choice over the information discussed during the lesson." Participant responses were solicited using a 5-point Likert scale ranging from 1 (strongly disagree) to 5 (strongly agree) $(\alpha=.93, M$ $=4.15, S D=.88)$.

This dissertation developed a 13-item multiple choice test focused on assessing students' recollection of the main points (i.e., climate change, risk communication, risk assessment, green marketing, greenwashing, advocacy campaigns) of the lesson (see Appendix E). Sample test questions included “ describes an upward temperature trend, whereas describes a scientific phenomenon responsible for sea level rises and shifts in growing seasons." and "Organizations such as the environmental protection agency (EPA) assess risk from environmental stressors like ocean acidification and desertification. To these organizations, risk is a function of and ." Every test question had four potential answers and were scored as either correct (1) or incorrect (0). The test scores were summed and converted into a percentage $(\mathrm{KR}-20=.53, M=50.26, S D=18.09)$.

To measure students' confidence testing, King and Witt's (2009) Confidence Testing Instrument was used (see Appendix G). This instrument asked participants to recall significant information from the lesson they just finished reading: "'List (no need to explain) the three most important theoretical concepts you recall learning from the lesson you just read. In other words, focus on general (theoretical or conceptual) principles about communication rather than specific do's and don'ts. Do this from memory. Please 
do not review the lecture scripts.', (p. 116). Three spaces were provided for students to write in their responses. Following these spaces students read the following stem: "Please indicate (circle) on the scale below how confident you feel that the three principles that you listed are, in fact, the three most important principles from the lesson.' Participant responses were solicited using three, 10-point bipolar adjective response format (e.g., "not confident/highly confident," "certain/not at all certain," and "not at all sure/highly assured") $(\alpha=.71, M=5.45, S D=1.84)$. In addition to King and Witt's measure, the researcher had students rate, on a scale ranging from $0 \%$ to $100 \%$, their confidence in their answer for each of the 13 test questions (see Appendix E). For example, after each test question students were asked to answer the following question: "On a scale ranging from $0 \%$ to $100 \%$, how confident are you that you provided the correct answer to question $1 ? \ldots$

\section{Pilot Study 1 Results}

To test the successfulness of the choice manipulations, a Welch's t-test was conducted to compare the two lecture scripts and students' perceptions of the provision of choice. The results revealed that the choice manipulations in the lecture scripts were successful, $t(29.73)=-6.13, p<.001, d=1.78$. Students perceived significantly more choices $(M=4.76, S D=.32)$ offered in the treatment condition and less choices $(M=$ $3.60, S D=.86)$ in the control condition.

Regarding the validity of the 13 -item test, results from the coding process revealed that the researcher and environmental science instructor were in general agreement that the test was measuring students lower levels of cognitive learning, specifically the remember, understand, and apply domains (Cohen's kappa $=.64, \mathrm{SE}=$ 
$.18, p=.001)$ and measuring the learning objectives for the lesson (Cohen's kappa $=.91$, $\mathrm{SE}=.09, p<.001)$. However, examining the descriptive test statistics revealed that a majority of participants failed the 13-item test with an average score of approximately $50 \%(M=50.26)$. The results also revealed that students' test percentage was not associated with their confidence in their understanding of the main points of the lesson ( $r$ $=-.03, p=.857)$, but was associated positively with their overall confidence in their answers on the quiz $(r=.34, p=.026)$.

These preliminary results suggested a successful manipulation of the provision of choice, but validity issues with the 13 -item test. That is, even though the coding process provided evidence that the test was measuring students' cognitive learning and that students were confident in having correct answers, their scores on the test were poor and did not reflect learning much information from the lesson. Arguably, this could have been because students were required to read a nine-page (single spaced) lecture script on environmental communication. According to students' confidence reports, the results indicated that most students were undecided or unsure $(M=5.45, S D=1.84)$ of their understanding of the main points of the lesson. Thus, having students read the lecture scripts may have created a daunting and confusing task prior to taking the test.

\section{Pilot Study 2}

Given the fact that most students from the first pilot study failed the 13-item test, the researcher wanted to examine if the delivery of the lesson (i.e., having students read the lecture scripts) was the reason for this failure. Therefore, a second pilot study was conducted to assess the validity of the test using an audio delivery format of the lesson.

\section{Participants}


Participants were 57 (20 Men and 37 Women) undergraduate students enrolled in two communication theory courses at a large Mid-Atlantic university. Participant ages ranged from 18 to 25 years $(M=19.86, S D=1.71)$.

\section{Procedures}

After IRB approval, the researcher visited the two sections of the undergraduate communication theory course during the second week of the spring 2019 semester to further assess the validity of the test and provide more evidence for the strength of the manipulations. The researcher announced to the students that they would listen to an audio recording of a lesson on environmental communication and receive a short survey to assess their perceptions of the lesson and take a short test on the information. In each section, the researcher either played the control or treatment audio recording ( 24 minutes and 38 seconds for treatment and 24 minutes and 21 seconds for control) for students and asked students to pay close attention. After listening to the lecture, participants completed a short survey that contained demographic questions, a measure to assess the provision of choice (Belmont et al., 1988), the same 13-item test from pilot study one, a measure to assess their confidence in their individual answers on the test (developed in the first pilot study), a measure of perceived difficulty of the test questions (developed for this pilot study similar to the confidence measure), the cognitive learning measure (Frisby \& Martin, 2010), and the cognitive interest subscale of the student interest scale (Mazer, 2012).

In addition to assessing the manipulations, the primary goal of the second pilot study was to provide validity evidence based on the internal structure of the test and the relationship between the short test and students' self-reports of cognitive learning, 
cognitive interest, and confidence testing. To create a better link between the conceptual definition and operational definition of student's cognitive learning, Frisby and Martin (2010) introduced the cognitive learning measure. This specific measure was used for this dissertation, because previous research has provided initial evidence that the cognitive learning measure captures students' lower levels of cognitive learning (i.e., acquisition, recall, and application; Frisby, Mansson, \& Kaufman, 2014). Therefore, a positive relationship between the 13-item test and students' self-reports of their lower levels of cognitive learning would provide initial validity evidence for the test. Furthermore, Weber, Corrigan, Fornash, and Neupauer (2003) found that students who watched a video lecture that was designed to elicit higher interest in the material, compared to students who watched a low interest video, performed better on a cognitive recall test. Arguably, students who are more interested in the material of the lesson should perform better on a test of recall. Therefore, a positive relationship between the 13-item test and students' cognitive interest would provide additional validity evidence (based on relations to other variables) for the test.

\section{Instrumentation}

The same modified version of the choice subscale $(\alpha=.93, M=3.88, S D=1.07)$ and the 13 -item test $(\mathrm{KR}-20=.44, M=48.90, S D=16.94)$ from pilot study 1 were used in pilot study two.

To measure students' confidence testing, the researcher had students rate, on a scale ranging from $0 \%$ to $100 \%$, their confidence in their answers $(M=62.48, \mathrm{SD}=$ $15.82)$ and perceived difficulty $(M=36.99, \mathrm{SD}=13.30)$ for each of the 13 test questions. For example, after each test question students were asked to answer the following two 
questions: "On a scale ranging from $0 \%$ to $100 \%$, how confident are you that you provided the correct answer to question 1 ? " and "On a scale ranging from 0 to 100 , how difficult was question 1 ?

To measure students' perceived cognitive learning from the lesson, a slightly modified version of the Cognitive Learning Measure (Frisby \& Martin, 2010) was used (see Appendix E). The original measure (10-items) was modified from focusing on perceived cognitive learning in a particular class to perceived cognitive learning from the lesson. Sample items included "I have learned a great deal from this lesson," "My knowledge on this topic has increased since the beginning of the lesson," and "I would be unable to use this information from this lesson." Participant responses were solicited using a 5-point Likert scale ranging from 1 (strongly disagree) to 5 (strongly agree) $(\alpha=$ $.78, M=3.68, S D=.67)$.

To measure students' cognitive interest, the cognitive interest subscale of the Student Interest Scale (Mazer, 2012) was used. Participants were given the following stem before responding to the 7-item subscale "I am interested in this lesson because..." Sample items included “... I can remember the lesson material,” “... I feel like I am learning topics covered in the lesson," and "... I can understand the flow of ideas." Participant responses were solicited using a 5-point Likert scale ranging from 1 (strongly disagree) to 5 (strongly agree) $(\alpha=.82, M=3.61, S D=.68)$.

\section{Pilot Study 2 Results}

A Welch's t-test was conducted to assess the successfulness of the choice manipulations in the lecture scripts. The results revealed that the choice manipulations were once again successful, $t(33.47)=-4.20, p<.001, d=1.16$. Students perceived 
significantly more choices $(\mathrm{M}=4.37, \mathrm{SD}=.61)$ being offered in the treatment condition and less choices $(\mathrm{M}=3.25, \mathrm{SD}=1.21)$ in the control condition.

However, most participants still failed $(M=48.90)$ the 13 -item test regardless of how the information was presented (i.e., written or audio provided). Additionally, the results revealed that students' test percentage was unrelated to their cognitive interest ( $r=$ $.07, \mathrm{p}=.596)$, perceived cognitive learning $(r=.04, \mathrm{p}=.765)$, and confidence in their answers on the quiz $(r=.15, \mathrm{p}=.263)$. Although these results suggested the manipulations held for the audio delivery of the lesson, the issues with the test remained. After examining the descriptive test statistics from pilot study one and two, the results indicated that a majority of participants reported incorrect answers for questions 3, 5, 6, 8,12 , and 13; whereas a majority of participants reported correct answers for questions 1 , 2, 7, 9, and 10 (see Table 5). Additionally, examining the average difficulty participants reported for each question revealed that the third test item $(M=54.67)$ was perceived as the most difficult followed by item five $(M=50.31)$.

\section{Post Hoc Modifications}

To further tease out where the issues were within the 13-item test, the researcher revisited one of the undergraduate communication theory courses (treatment condition) to gauge students' perceptions of the clarity and difficulty of each test question. The researcher provided students with three lines to write comments on clarity and three lines to write comments on difficulty for each test question. Students were instructed to make comments on the clarity and difficulty for each test question and note any issues or provide suggestions for improvements for each test question. The researcher tallied the total number of positive and negative statements made by students that related to clarity 
and difficulty for each question (see Table 5). When the number of negative tallies, for either clarity or difficulty, exceeded the number of positive tallies, the researcher inspected the comments to make the appropriate adjustments to the test question. Using this procedure, the following adjustments were made to questions $2,3,4,5,7,8,12$, and 13.

Upon further inspection of the comments for question two, participants mentioned the question was too long and that the terms climate change and global warming were too similar, which created confusion. Since question one focused on climate change, the second question was shortened to focus solely on global warming and removed the portion focused on contrasting climate change with global warming. Regarding the comments for question three, students mentioned that the question was inquiring about details that were not touched on often enough in the lecture (i.e., the EPA example) making it difficult to remember. Since this question is similar to question number six (i.e., recalling the definition of risk communication) and students did not have trouble with number six, this question was removed. Students took issue with question number four being too long and having responses that seemed interchangeable. Therefore, question four was shortened from a two-sentence statement to a one-sentence statement and the responses were changed to be more distinct (i.e., the incorrect responses were changed to be drastically different from terms severity and likelihood). Upon further inspection of the comments for question five and 12 , students mentioned that the negative form (e.g., "which of the following was NOT") used in the question was tricky and confusing. Thus, these questions were rewritten and stated in a positive form. Student comments for questions seven and eight suggested that the questions were too long, and 
the responses were too similar (i.e., over using the word "green"), which made the questions unclear and difficult. To shorten these questions, the original statements used to provide an example of these concepts were modified to simply ask students to recall the definition of green marketing and greenwashing, respectively. Additionally, the responses were modified by removing the word "green" from two of the responses ("green" had to remain for the other two responses because these questions mirrored each other and were pulled directly from the lesson). Finally, students took issue with the length of question 13 and mentioned the length made it hard to focus and maintain their attention. This question was shortened from three sentences to one simplified sentence and included distinct clues in the question to help students focus on the point of the question.

Although the tallies of students' open-ended responses did not reveal an issue with question six, students' abilities to answer this question correctly on the test suggested otherwise. Thus, the question was made easier by using a simpler definition of risk communication for students to recall that was emphasized in the lecture.

Additionally, question number one was slightly modified to mirror the adjustments made to question number two. After examining the student comments for questions nine and ten, the comments suggested that these two questions were too long. Therefore, these questions were shortened to one sentence each. Finally, to give the researcher more flexibility to drop (potentially) poor test questions, two more test items were written that mirrored question 12 (i.e., inquired about the features of advocacy campaigns and used the same response format). 
Table 5

Descriptive information for the 13-item and 15-item test

\begin{tabular}{|c|c|c|c|c|c|c|c|c|c|c|c|c|c|c|c|}
\hline Test Questions & Q1 & Q2 & Q3 & Q4 & Q5 & Q6 & Q7 & Q8 & Q9 & Q10 & Q11 & Q12 & Q13 & Q14 & Q15 \\
\hline \multicolumn{16}{|l|}{ Pilot Study 1} \\
\hline Correct & 82.2 & 60.0 & 33.3 & 48.9 & 17.8 & 22.2 & 68.9 & 40.0 & 75.6 & 68.9 & 53.3 & 40.0 & 40.0 & -- & -- \\
\hline Incorrect & 17.8 & 40.0 & 66.7 & 51.1 & 82.2 & 77.8 & 31.1 & 60.0 & 24.4 & 31.1 & 46.7 & 60.0 & 60.0 & -- & -- \\
\hline \multicolumn{16}{|l|}{ Pilot Study 2} \\
\hline Correct & 73.2 & 57.1 & 35.7 & 48.2 & 17.9 & 25.0 & 57.1 & 39.3 & 78.6 & 73.2 & 46.4 & 39.3 & 44.6 & -- & -- \\
\hline Incorrect & 26.8 & 42.9 & 64.3 & 51.8 & 82.1 & 75.0 & 42.9 & 60.7 & 21.4 & 26.8 & 53.6 & 60.7 & 55.4 & -- & -- \\
\hline Difficulty & 26.36 & 32.09 & 54.67 & 44.71 & 50.31 & 42.96 & 38.58 & 23.90 & 24.95 & 22.68 & 37.95 & 39.20 & 46.35 & -- & -- \\
\hline \multicolumn{16}{|c|}{ Pilot Study 2 Revisit } \\
\hline \multicolumn{16}{|l|}{ Clarity } \\
\hline Positive & 12 & 12 & 10 & 10 & 9 & 11 & 7 & 6 & 9 & 9 & 13 & 8 & 7 & -- & -- \\
\hline Negative & 2 & 3 & 6 & 3 & 4 & 2 & 7 & 8 & 4 & 4 & 2 & 3 & 7 & -- & -- \\
\hline \multicolumn{16}{|l|}{ Difficulty } \\
\hline Positive & 14 & 6 & 3 & 6 & 5 & 10 & 7 & 3 & 8 & 9 & 7 & 7 & 5 & -- & -- \\
\hline Negative & 0 & 8 & 12 & 8 & 9 & 4 & 8 & 10 & 8 & 7 & 6 & 10 & 10 & -- & -- \\
\hline \multicolumn{16}{|l|}{ Pilot Study 3} \\
\hline Correct & 93.8 & 87.5 & 25.0 & 93.8 & 81.2 & 56.2 & 75.0 & 87.5 & 75.0 & 93.8 & 87.5 & 37.5 & 31.2 & 75.0 & 50.0 \\
\hline Incorrect & 6.2 & 12.5 & 75.0 & 6.2 & 18.2 & 43.8 & 25.0 & 12.5 & 25.0 & 6.2 & 12.5 & 62.5 & 68.8 & 25.0 & 50.0 \\
\hline Difficulty & 9.53 & 11.75 & 42.44 & 19.06 & 29.99 & 29.21 & 16.94 & 27.44 & 26.44 & 9.31 & 19.00 & 49.56 & 39.69 & 33.19 & 32.31 \\
\hline
\end{tabular}

Note. Correct and Incorrect reflect the percent correct and incorrect for each test question. Difficulty reflects the mean score for each test question. Positive and Negative reflect the total tally marks for positive and negative feedback from the participants. 


\section{Pilot Study 3}

Pilot studies one and two demonstrated that the manipulations were successful, but each time the students failed the 13-item test on average. The primary purpose of the third pilot study, then, was to examine the validity of the new 15 -item test that was modified using the open-ended data from the second pilot study. Thus, students should be able to, on average, pass the new test for the researcher to claim that the modified 15 -item test measures students' cognitive learning (specifically the remember and understand domains of Bloom's taxonomy).

\section{Participants}

Participants were 16 (2 Male and 14 Female) students enrolled in one upper level undergraduate communication course at a large Mid-Atlantic university. Participant ages ranged from 18 to 26 years $(M=20.81, S D=1.60)$. No other demographic information was collected from the third pilot study participants.

\section{Procedures}

After IRB approval, the researcher visited one upper level communication course during the fifth week of the spring 2019 semester to assess the validity of the modified test (see Appendix J). The researcher announced to the students they would attend a lesson on environmental communication and take a short test on the information. The researcher delivered the treatment lecture condition that offered students choices throughout the lesson. Since the lesson was being delivered in a small classroom (with a few students) and the researcher did not want to take too much class time, the choices were handled by having students raise their hands for their choices instead of using the voting app planned for the main study. That is, whenever the researcher offered students 
the opportunity to dictate the direction of the lesson the researcher presented each of the available options and allowed students to raise their hands for their desired choice. The researcher counted the number of hands for each option and moved the lesson in the direction that received the most hands.

After the researcher finished teaching the lecture, participants completed a short survey that contained demographic questions, the new 15-item test, and a measure of perceived difficulty of the test questions. Students were thanked for their assistance in helping the researcher and no course extra credit was given for their participation in the pilot study.

Since the test was modified, the researcher wanted to reassess the validity evidence for the new test based on content, therefore the coding sheets from pilot study one were used again (see Appendix F). These coding sheets were used to examine which test questions aligned with the new learning outcomes for the lesson and which questions tapped into the different levels of cognitive learning (specifically remember and understand) specified by Anderson and Krathwohl (2001). Similar to pilot study one, the researcher and environmental science instructor read the test questions and coded which learning outcome each question assessed and which level of cognitive learning was being measured.

\section{Instrumentation}

The same measure of perceived difficulty of the test questions $(M=25.68, S D=$ 18.59) from pilot study two and the 15 -item test $(\mathrm{KR}-20=.64, M=72.50, S D=16.67)$ were used. 


\section{Pilot Study 3 Results}

The results revealed that a majority of participants passed the new 15 -item test $(M$ $=72.50, S D=16.67)$. Additionally, results from the coding process revealed that the researcher and environmental science instructor were in general agreement that the test measured students' lower levels of cognitive learning, specifically the remember and understand domains (Cohen's kappa $=.73, \mathrm{SE}=.17, p=.003$ ) and the new learning objectives for the lesson (Cohen's kappa $=.91, \mathrm{SE}=.08, p<.001$ ). Furthermore, after examining the descriptive statistics for each of the test questions, the results suggested that the modifications improved the students' abilities to answer the test questions correctly and decreased their perceptions of the difficulty for each test question (see Table 5). Since students on average passed the test, the researcher was more confident that the modified and simplified 15-item test was a more valid measurement of students' lower levels of cognitive learning.

\section{Main Study}

\section{Participants}

The fourth set of participants were recruited from several undergraduate communication courses at a large Mid-Atlantic university to take part in the live lecture experiment in return for minimal extra credit. Participants were 207 undergraduate students $($ men $=101$, women $=102$, nonbinary $=1$, three participants did not report their sex) who ranged in age from 18 to $37(M=20.13, S D=2.03)$. A majority of participants were first-year students $(n=82,39.6 \%)$, followed by sophomores $(n=56,27.1 \%)$, juniors $(n=35,16.9 \%)$, and seniors $(n=29,14 \%)$. Four participants did not report their class rank and one participant reported that he or she was completing a second degree. 
The primary ethnicity reported by participants was White/Caucasian $(n=159,76.8 \%)$, followed by Middle Eastern $(n=26,12.6 \%)$, Black/African American $(n=9,4.3 \%)$, Asian American $(n=6,2.9 \%)$, and Hispanic $(n=1, .5 \%)$. Two participants $(1 \%)$ reported being biracial and four participants did not report their ethnicity. A majority of the participants never had the researcher (who delivered the live-lecture) as a previous instructor $(n=170,82.1 \%)$ and believed climate change to be a real scientific phenomenon $(n=199,96.1 \%)$. No additional demographic information was collected from the participants.

\section{Procedures}

Since the choice manipulations were successful and a more valid test was created through several pilot tests, part two of this dissertation consisted of practicing the lecture scripts and delivering the live lecture. The researcher practiced delivering the lecture several times with a fellow doctoral student from the same institution who followed along and timed the lecture (see Appendix K). These practice sessions helped the researcher pace the material to fit the time allotted for the lecture and make final adjustments to the lecture materials. More specifically, these practice sessions revealed that the Prezi presentation was difficult to see, and the lecturer needed to slow down when giving students the directions for the voting application. With these suggestions in mind, the researcher adjusted the background color and the color of the font to make sure students could clearly see the lesson. Additionally, the researcher made sure to pause several times whenever instructions regarding the voting application was given to participants.

Participants for the live lecture lesson were recruited using two methods. First, an advertisement was placed on the departmental virtual and physical bulletin board to 
solicit undergraduate students to participate in this study (see Appendix A). Second, the researcher asked course instructors of undergraduate communication courses to email their students an IRB approved recruitment script (see Appendix B). The advertisement and recruitment script described the study and notified participants of the requirements to successfully complete the study. That is, participants were notified that this study required them to have a smartphone and be available on two separate evenings to attend a lecture in Eiesland Hall G24 on environmental communication. Participants were then guided to a Qualtrics pre-survey (see Appendix L) to report demographic information, create a unique identifier code, and be randomly assigned to one of the lecture conditions. Specifically, this pre-survey had students report on their initial interest in the topic of environmental communication (specifically climate change), provide their demographic information, and create a unique identifier code that was used later to match their presurvey with their post (feedback) survey. The unique identifier code was participants' initials followed by their birth date (e.g., JPB12281992). To ensure participants' anonymity, these identifier codes were only used to pair the pre-survey with the feedback survey and were removed before data analysis.

After completing the pre-survey, participants were randomly assigned to sign-up for one of the lecture conditions. This sign-up process had participants provide their unique identifier code and their university email. Participants were presented with the day, time, and location of the lecture they were assigned to complete part two of the study and were told to only show up on their assigned day or they would not be able to receive credit for participating in the study. Participants were emailed a reminder the day of their assigned lecture date (see Appendix C). 
After being randomly assigned to one of the two lecture conditions, participants attended the live lecture in a large classroom that seats approximately 230 people. This classroom has two projectors that were used to display the Prezi presentation at the front of the classroom. Each of the lecture conditions were video recorded with the camera pointed solely at the instructor. The lectures were recorded to provide video content to compare the conditions if major discrepancies in the delivery of the scripts were to arise during the lesson (which did not happen). The procedures for each class session included the following: (1) students arrived to their designated lecture day; (2) the researcher introduced himself and the study; (3) students were given a feedback survey; (4) the researcher taught a 38-minute lecture; (5) students were asked to complete and submit their feedback survey in one of two sealed boxes in the front of the classroom. The feedback survey (see Appendix M) included a cover letter, a blank page for potential notes, and the instruments described below. After the teaching experiment was complete, students were debriefed through an email (see Appendix D) from the researcher to inform them of the deception used in the study (i.e., choice manipulation and the free-choice opportunities) and that their participation would in no way affect their university standing. More specifically, the debrief email included language to notify students that the instructor of the lesson was trained to either provide choices or refrain from providing choices to students and that the five free opportunities to learn more about environmental communication were all created by the researcher and would not take place during the semester. Although no student decided to withdraw their data from the study, they were provided this opportunity in the debrief email. 
To assess the choices students made throughout the lecture, the polleverywhere.com website was used. This website allows instructors to create live polling questions that students can answer on their smartphones, which can be visually displayed for students. For this dissertation, polls were created to measure the participants' successive choices over the material and display those choices on the projector screen in the front of the classroom. For instance, to capture the first choice students made over the direction of the lecture they were presented with the following question "What topic of climate change would you like to talk about?" on their smartphone and were instructed to choose whichever answer they preferred "Ocean ecosystems" or "Terrestrial ecosystems." The instructor, then, displayed these results in the front of the room and moved the lecture toward the topic which received the most votes (e.g., Ocean Ecosystems). The second and third choices provided to students used a similar procedure, but students were presented with the following question "What do you want to talk about next?" followed by three options to choose from: "risk communication," "communicating sustainability," and "advocacy campaigns." Again, the instructor displayed the results in the front of the room and moved the lecture toward the topic which received the most votes. See Table 6 for the choices made in the treatment condition each time data were collected.

Table 6

Paths the treatment group chose for each data collection

Topics from the lesson

Data Collection \# 1 Ocean Ecosystems $\rightarrow$ Risk Communication $\rightarrow$ Communicating 3/18/19 \& 3/20/19 Sustainability $\rightarrow$ Advocacy Campaigns

Data Collection \# 2 Ocean Ecosystems $\rightarrow$ Risk Communication $\rightarrow$ Advocacy Campaigns $\rightarrow$ 4/1/19 \& 4/3/19 Communicating Sustainability 
Data Collection \# 3 Ocean Ecosystems $\rightarrow$ Risk Communication $\rightarrow$ Communicating 4/15/19 \& 4/17/19 Sustainability $\rightarrow$ Advocacy Campaigns

Note. For each data collection, the control group successfully followed the same path as the treatment group.

Additionally, to ensure the polleverywhere.com website was not responsible for influencing students' perceptions of the instructor and their learning outcomes, the website was also used in the control condition. However, instead of capturing students' choices, the polls required students to answer opinion questions related to the material. For instance, the first question students saw on their smartphones in the control condition was "What topic of climate change do you think is more valuable for scientists to devote efforts to?" along with the answers of either "Ocean ecosystems" or "Terrestrial ecosystems." The instructor, then, displayed these results in the front of the room to show students which topic received the most votes. Using a similar procedure, but different questions, students were presented with two of the four following questions (this depended on the choices of the treatment condition): "Have you heard of ocean acidification/desertification before today?," "Do you think the EPA, NOAA, and FDA do a good job of communicating risk to the public?," "In your opinion, was the video provided by BP a good example of greenwashing?," and "Which feature of advocacy campaigns do you think is the most important?" In order remain similar to the treatment condition, students were presented with three options to choose from. Again, the instructor displayed the results in the front of the room to show students which answer received the most votes.

\section{Instrumentation}

The choice subscale from the Teacher as Social Context Questionnaire - Student Report (Belmont et al., 1988) was used to assess the choice manipulation of the teaching 
conditions (see items 58 to 62 of Appendix M). The original 5-item subscale was modified from focusing on choices over course assignments in general to focusing on choices over the lesson. For example, the original item "My teacher gives me a lot of choices about how I do my schoolwork" was changed to "The teacher gave me a lot of choices during the lesson." Sample items included "When it comes to the lesson, the teacher gave me all kinds of things to choose from," "The teacher did not give me a chance to choose anything about the lesson," and "The teacher did not give me much choice over the information discussed during the lesson." Participant responses were solicited using a 5-point Likert scale ranging from 1 (strongly disagree) to 5 (strongly agree).

The autonomy need subscale of the Basic Psychological Need Satisfaction and Frustration Scale (BPNSFS; Chen et al., 2015) was used to measure students' autonomyneed satisfaction (see items 63 to 70 of Appendix M). This scale has been used by previous SDT researchers to capture students' basic psychological need fulfillment (e.g., Aelterman, Vansteenkiste, Van Keer, \& Haerens, 2016). Although the measure includes items to capture students' needs for competence and relatedness, eight items were used to assess students' autonomy satisfaction and frustration. Participants were given the following stem before responding to the 8-item subscale: "During this lesson:". The original 8-item subscale was modified from focusing on autonomy need satisfaction during a specific training session to autonomy satisfaction during a classroom lesson. For example, the original item "I felt like the way the training was delivered reflected how I wanted it myself." was changed to "I felt like the way the information was delivered reflected how I wanted it myself." Sample items included "I felt a sense of choice and 
freedom in the things I thought and did," "I felt forced to do things I would not choose to do," and "I felt like the suggestions given reflected what I want myself." Participant responses were solicited using a 5-point Likert-type scale ranging from 1 (not at all true) to 5 (totally true).

The Intrinsic Motivation to Learn Scale (IMLS; Goldman et al., 2016) was used to measure students' intrinsic motivation to learn course materials (see items 23 to 32 of Appendix M). The 10-item measure was modified from focusing on one class in general to focusing on students' intrinsic motivation to learn in response to the lesson of the experiment. For example, the original item "Learning new concepts in this class is fulfilling to me" was changed to "Learning new concepts during this lesson was fulfilling to me." Sample items included "Developing my understanding of the content was rewarding to me," "Learning new things from this lesson makes me feel better about myself," and "Understanding new concepts from this lesson was enjoyable to me." Participant responses were solicited using a 7-point Likert scale ranging from 1 (strongly disagree) to 7 (strongly agree).

The interest/enjoyment subscale of the Intrinsic Motivation Inventory (Ryan, 1982) was used to measure students' interest in the material before (see items 5 to 11 of Appendix L) and after the live lecture material (see items 33 to 39 of Appendix M). The 7-item subscale has been used by previous SDT researchers (e.g., Patall, 2013) to capture students' interest toward the activities and/or tasks used during experiments. Therefore, the measure was modified to assess students' interest in the topic of the lecture (i.e., environmental communication specifically climate change). The tense of some items was adjusted for the pre-survey and the feedback survey. Sample items included "The topic of 
climate change is (was) quite enjoyable," "I would describe the topic of climate change as very interesting," and "I enjoy (enjoyed) the topic of climate change very much." Participant responses were solicited using a 7-point Likert-type scale to respond to these items that ranged from 1 (not at all true of me) to 7 (very true of me). Since students' interest in the topic was measured before and after the lesson, an interest change score was computed by subtracting students' pre-interest score from their post-interest score.

Test. Based on the pilot study revisions, a 15-item multiple choice test (see Appendix J) was administered to assess students' recall of the lecture material. Each quiz item was created from the main points of the lesson on environmental communication and climate change. For example, questions focused on the main points of risk communication, communicating sustainability (i.e., green marketing and green washing), advocacy campaigns, and defining climate change. These 15 questions included both recall questions (e.g., “ describes long term changes in weather patterns and how the atmosphere "behaves" over a relatively long period of time.") and understand questions (e.g., " describes the third step of risk assessment focused on calculating the potential impact of an environmental issue.”). For each question, students were provided with four possible answers. Correct answers were scored as 1 and incorrect answers as 0 , which was summed and converted it to a percentage.

Additionally, one prompt at the end of the test had students respond to the following open-ended question: "In the space provided below, please walk me through the three features necessary to make an advocacy campaign successful AND make sure to provide an example of each feature." This question was used to assess students' 
conceptual understanding of the lesson material. Similar to Jang et al. (2016), two objective raters (the researcher and one fellow doctoral student) scored participants' answers on a 0 to 3 scale $(0=$ no conceptual understanding, $1=$ low conceptual understanding, $2=$ moderate conceptual understanding, and $3=$ high conceptual understanding). These coders content analyzed (Neuendorf, 2002) 100\% of the students' responses to the prompt.

The open-ended question required students to provide three different parts to fully answer the question and demonstrate their understanding of the material. The researcher created a codebook (see Appendix F) based on how students answered each part of the question. That is, if students did not answer any part of the question or their answers were unrelated to the prompt they were scored as no conceptual understanding (0). A low conceptual learning (1) code was given to students who only answered one part of the question, whereas a moderate conceptual understanding (2) code was given to students who answered two of the three parts of the question. Finally, a high conceptual understanding (3) code was given to students who answered all three parts of the question correctly. Additionally, the researcher taught the one rater the portion of the lecture in which the question was derived and extracted specific student examples from the data to represent each potential code. The two raters coded all the responses and general agreement was established (Cohen's kappa $=.83, \mathrm{SE}=.04, p<.001)$. In total, there were 18 instances in which the researcher and the coder had a discrepancy in the students' level of conceptual learning. These discrepancies were discussed among the coders and were resolved by revisiting the grading rubric and talking through the reasons for giving students a certain score. 
Like Vansteenkiste et al. (2004), to measure Free-Choice Persistence, students were given several options to sign-up to learn more about environmental communication, namely climate change. Specifically, these five opportunities were focused on university (West Virginia University) sponsored events related to climate change, including: (1) training at the university's geographic information systems center, (2) film screening on renewable energy related to climate change, (3) guided tour of the university's greenhouse, (4) receive information on the effects of climate change on local water supplies, and (5) university sponsored debate over the consequences of climate change. The final page of the feedback survey included a description of each of these options (see Appendix M) followed by a blank line for students to sign-up for as many options as they choose. This page was a different color than the rest of the feedback survey and was clipped to the feedback survey using a paper clip. Students were instructed to remove this final page and submit this sheet to a separate box at the front of the room. The sign-up sheet was a different color and paper clipped to the survey because the researcher wanted to separate this task from the survey and make this task require slightly more effort if students desired to learn more about the lesson. Students were only required to provide their unique identifier code (created for the pre-survey) to sign-up for the options. The researcher created a count variable for each participant by summing the total number of free-choice options they chose to take advantage of (ranging from 0 to 5).

The affect toward the likelihood of enrolling in another course with the instructor subscale of the Instructional Affect Assessment Instrument (Course Forum; McCroskey, 1994) was used to measure students' intentions to enroll in another course (see items 40 to 43 of Appendix M). The 4-item subscale used a 7-point bipolar adjective response 
format (e.g., "unlikely/likely," "impossible/possible," and "improbable/probable") to the following stem: "Your likelihood of actually enrolling in another course with this instructor if your schedule would permit would be:"

The expressive dissent subscale of the Instructional Dissent Scale (IDS; Goodboy, 2011) was used to measure students' intentions to express their dissatisfaction and frustration with the lecturer (see items 44 to 53 of Appendix M). Participants were given the following stem before responding to the 10-item subscale: "If James were my regular instructor I would...”. Sample items included "complain to others to express my frustrations with this course," "express my disappointment about this course to other people because it helps me feel better," and "talk to other students to see if they also have complaints about this teacher." Participant responses were solicited using a 7-point Likert scale ranging from 1 (strongly disagree) to 7 (strongly agree).

Covariates. To ensure that the quality of teaching was held constant between the two lecture conditions, the researcher measured four effective instructor behaviors: humor, nonverbal immediacy, clarity, and enthusiasm. Additionally, this dissertation included a live lecture on new material and assessed students' learning, therefore, students' perceived familiarity with, and difficulty of, the lecture material was used as covariates.

The Instructor Humorousness Scale (IHS: Wanzer, Frymier, \& Irwin, 2010) was used to assess students' perceptions of the instructor's overall humor (see items 1 to 3 of Appendix M). The 3-item scale included the following items: the instructor was "humorous," "not a funny instructor," and "one of the funniest instructors I know". Participant responses were solicited using a 7-point Likert scale ranging from 1 (strongly 
disagree) to 7 (strongly agree).

The Revised Nonverbal Immediacy Measure (McCroskey, Richmond, Sallinen, Fayer, \& Barraclough, 1995) was used to assess students' perceptions of the lecture's nonverbal immediacy behaviors (see items 9 to 18 of Appendix M). Sample items from the 10-item measure included: the instructor "looked at the class while talking," "used a monotone/dull voice when talking to the class," and "moved around the classroom while teaching." Participant responses were solicited using a 7-point Likert scale ranging from 1 (strongly disagree) to 7 (strongly agree).

The shortened version (e.g., Bolkan, Goodboy, \& Kelsey, 2016) of the Teacher Clarity Inventory (TCI; Chesebro \& McCroskey, 1998) was used to measure the instructor's overall clarity (see items 4 to 8 of Appendix M). Sample items from the 5item measure included: the lesson today "made sense," "was easy to understand," and “was clear." Participant responses were solicited using a 7-point Likert scale ranging from 1 (strongly disagree) to 7 (strongly agree).

The Perceptions of Teacher Enthusiasm scale (Patrick, Hisley, \& Kempler, 2000) was used to measure the instructor's enthusiasm (see items 19 to 22 of Appendix M). Sample items from the 5-item measure included: "The instructor is full of dynamic energy when he teaches," "The instructor just lights up the room when he teaches," and “The instructor is a bit dull." Participant responses were solicited using a 7-point Likert scale ranging from 1 (strongly disagree) to 7 (strongly agree).

The Perceived Familiarity scale (Bolkan et al., 2016) was used to assess students' familiarity with the lecture material (see items 54 to 56 of Appendix M). The 3-item scale included the following items: "How familiar were you with this topic before today?" 
"How much did you already know about the subject being discussed?" and "To what extent had you been exposed to the material in this lesson in the past?" Participant responses were solicited using a 5-point Likert-type scale ranging from 1 (not at all) to 5 (very much).

The Mental Effort Rating Scale (Paas, 1992) was be used to measure students' perceived difficulty of the lecture material (see item 57 of Appendix M). This 1-item scale used the following question: "How difficult would the material have been to understand if it was taught in an ideal manner (e.g., by an ideal teacher, in a way that was simple to comprehend, etc.)?" Students answered this question using a 9-point response option that ranged from 1 (very, very low) to 9 (very, very much).

Additionally, the researcher had students vote to decide on the direction of the lecture and move the lecture toward the topic which received the most votes. Thus, even though students may feel that they were offered choices, if their choices did not have many votes the lecture may move against their desires. Therefore, a 1-item covariate to assess if students believed their choices were met was included (see item 72 Appendix M). The live lecture was taught by the researcher who has some experience teaching undergraduate students in communication studies courses at the university in which the study took place. Thus, it is likely that some participants may have been students in the researcher's past courses. Therefore, a 1-item covariate to assess if James Baker was their instructor in the past was included (see item 71 Appendix M). Finally, the researcher taught a lesson on climate change, which some students may have trouble believing or believe to be false. However, during the lecture the instructor will be sure to distinguish between climate change and global warming for students. That said, the 1-item question 
to assess students' perceptions toward climate change was included as a covariate in all five estimated models (see item 73 Appendix M). However, a total of eight individuals reported that climate change is not a real scientific phenomenon, therefore these individuals were removed from data and the climate change attitude covariate was removed from the analyses to test the hypotheses and answer the research question outlined below.

\section{Data Analysis}

Power analysis. Before the main study was conducted, a statistical power analysis was performed for sample size estimation, based on data from three studies conducted by Vansteenkiste et al. (2004). These studies examined the effect of autonomy-supportive teaching on students' test performance mediated through students' reports of autonomous motivation (i.e., intrinsic motivation). Since all three studies included variables similar to the ones under examination and in order to produce a conservative sample size estimation, the researcher used the lowest parameters for each path in the mediation model for the power analysis $\left(\right.$ e.g., a path $=.41, \mathrm{~b}$ path $=.31, \mathrm{c}^{\prime}=$ .15). Following previous researchers' recommendations (e.g., Thoemmes, Mackinnon, \& Reiser, 2010; Wolf, Harrington, Clark, \& Miller, 2013), estimated power was set to be $80 \%(.80)$ or greater with an alpha level of .05 for all parameters in the mediation model (e.g., choice, intrinsic motivation, and learning). Using Kenny’s (2016) MedPower application to calculate the projected sample size to detect a direct and an indirect effect revealed 359 and 91 participants, respectively, were necessary for sufficient power. Thus, the sample size for the main study of 207 participants was deemed adequate for the hypothesized mediation models. 
Confirmatory factor analyses. In order to test the psychometric properties of each of the instruments used in the hypothesized models (besides the 15-item test and measures with three scale items or fewer), confirmatory factor analyses (CFAs) using maximum-likelihood robust estimation (MLR) in Mplus Version 8.2 (Muthén \& Muthén, 2017) was conducted before testing the aforementioned hypotheses. According to $\mathrm{Hu}$ and Bentler (1999; see also Kline, 2016), the global fit criteria for a CFA model to be retained includes: (1) non-significant chi-square, (2) comparative fit index (CFI) $\geq .95$, (3) root mean square error of approximation $($ RMSEA) $\leq .08$ accompanied by a $90 \%$ confidence interval with an upper bound of .10 or less, and (4) standardized root-mean-residual $(\mathrm{SRMR}) \leq .08$. Additionally, following Kline's (2016) recommendation, local fit was assessed by examining the normalized residual covariance matrix for values that exceed the critical value of +/- 2.58 needed for a .99 confidence level (see also Bandalos, 2018). Finally, factor loadings (pattern coefficients) were examined to further determine goodness-of-fit for the CFA models, which should be above the .70 minimum threshold (Kline, 2016). Since hypothesis testing used path analysis and not a structural regression model with latent variables and with a sample size of 207, CFA models were conducted on each individual instrument. Overall, due to poor local and global fit, two CFA models were not retained: (1) autonomy-need satisfaction and (2) instructor nonverbal immediacy. Global fit results from CFA analyses can be found in Table 7 and the standardized factor loadings for each scale can be found in Table 8. 
Table 7

CFA Goodness of Fit for Predicted Model Variables

\begin{tabular}{|c|c|c|c|c|c|}
\hline Model & $\chi^{2}(d f)$ & RMSEA & $\begin{array}{c}\text { RMSEA } \\
90 \% \text { CI } \\
\text { LL, UL }\end{array}$ & CFI & SRMR \\
\hline 1. Choice Manipulation Check & $42.27(5)^{* *}$ & .19 & $.14, .25$ & .85 & .06 \\
\hline 2. Autonomy Need & $226.88(20) * *$ & .22 & $.20, .25$ & .21 & .18 \\
\hline 3. Intrinsic Motivation to Learn & $142.96(35)^{* *}$ & .12 & $.10, .14$ & .90 & .06 \\
\hline 4. Pre-Interest/Enjoyment & $72.73(14) * *$ & .14 & $.11, .18$ & .89 & .06 \\
\hline 5. Post-Interest/Enjoyment & $45.89(14) * *$ & .11 & $.07, .14$ & .95 & .05 \\
\hline 5. Likelihood of Enrollment & $9.95(2)^{*}$ & .14 & $.06, .23$ & .95 & .02 \\
\hline 6. Expressive Dissent & $98.34(35)^{* *}$ & .09 & $.07, .12$ & .91 & .05 \\
\hline 7. Instructor Clarity & $6.939(5)$ & .004 & $.00, .11$ & .99 & .02 \\
\hline 8. Nonverbal Immediacy & $166.212(35)^{* * *}$ & .14 & $.11, .16$ & .59 & .10 \\
\hline 9. Enthusiasm & $4.839(2)$ & .08 & $.00, .18$ & .99 & .02 \\
\hline
\end{tabular}

Note. ${ }^{*} p<.01 .{ }^{* *} p<.001$. The CFA models flagged in bold reflect the models that were not retained.

Table 8

Pattern Coefficients and Variance Estimates for each Scale

\begin{tabular}{lcc}
\hline \multicolumn{1}{c}{ Scale \& Items } & $\begin{array}{c}\text { Standardized Loadings (SE) } \\
\text { (pattern coefficients) }\end{array}$ & $R^{2}(\mathrm{SE})$ \\
\hline Choice & $.712(.055)^{\wedge}$ & $.506(.079)$ \\
Choice 1 & $.872(.035)^{\wedge}$ & $.760(.060)$ \\
ReChoice 2 & $.592(075)^{\wedge}$ & $.351(.089)$ \\
Choice 3 & $.806(.056)^{\wedge}$ & $.649(090)$ \\
ReChoice 4 & $.774(061)^{\wedge}$ & $.600(095)$ \\
ReChoice 5 & & \\
Autonomy-Need Satisfaction & $.450(.092)^{\wedge}$ & $.202(.083)$ \\
Aut 1 & $.114(.194)^{\wedge}$ & $.013(.044)$ \\
ReAut2 & $.541(.101)^{\wedge}$ & $.293(109)$ \\
Aut3 & $-.023(.193)^{\wedge}$ & $.001(.009)$ \\
ReAut4 & $.739(.097)^{* *}$ & $.546(.144)$ \\
Aut5 & $.105(.215)^{\wedge}$ & $.011(.045)$ \\
ReAut6 & $.155(.182)^{\wedge}$ & $.024(.056)$ \\
ReAut 7 & $.615(077)^{\wedge}$ & $.379(.095)$ \\
Aut 8 & & \\
Intrinsic Motivation to Learn & $.844(.027)^{\wedge}$ & $.711(.046)$ \\
IML 1 & $.875(.023)^{\wedge}$ & $.766(.041)$ \\
IML 2 & $.779(.036)^{\wedge}$ & $.607(.056)$ \\
IML 3 & $.888(.022)^{\wedge}$ & $.788(.039)$ \\
IML 4 & & \\
& &
\end{tabular}


ReIML 5

IML 6

IML 7

ReIML 8

IML 9

IML 10

Pre-Interest/Enjoyment

INT 1

ReINT 2

INT 3

INT 4

INT 5

INT 6

ReINT 7

Post-Interest/Enjoyment

INT 1

ReINT 2

INT 3

INT 4

INT 5

INT 6

ReINT 7

Likelihood of Enrollment

Enroll 1

Enroll 2

Enroll 3

Enroll 4

Expressive Dissent

EXP 1

EXP 2

EXP 3

EXP 4

EXP 5

EXP 6

EXP 7

EXP 8

EXP 9

EXP 10

Covariates

Instructor Clarity

Clarity 1

Clarity 2

Clarity 3

Clarity 4

Clarity 5

Instructor Nonverbal Immediacy

NVI 1

ReNVI 2

NVI 3

NVI 4

ReNVI 5

\begin{tabular}{|c|c|}
\hline $.226(.087)^{* * *}$ & $.051(.039)$ \\
\hline $.838(.030)^{\wedge}$ & $.702(.050)$ \\
\hline $.869(.026)^{\wedge}$ & $.755(.045)$ \\
\hline $.472(.076)^{\wedge}$ & $.223(.072)$ \\
\hline $.731(.039)^{\wedge}$ & $.534(.057)$ \\
\hline $.825(.025)^{\wedge}$ & $.681(.042)$ \\
\hline $.858(.026)^{\wedge}$ & $.736(.045)$ \\
\hline $.594(.072)^{\wedge}$ & $.352(.086)$ \\
\hline $.895(.017)^{\wedge}$ & $.802(.031)$ \\
\hline $.905(.027)^{\wedge}$ & $.819(.049)$ \\
\hline $.809(.046)^{\wedge}$ & $.654(.075)$ \\
\hline $.858(.041)^{\wedge}$ & $.736(.070)$ \\
\hline $.602(.066)^{\wedge}$ & $.362(.080)$ \\
\hline $.821(.037)^{\wedge}$ & $.674(.061)$ \\
\hline $.597(.073)^{\wedge}$ & $.356(.087$ \\
\hline $.888(.020)^{\wedge}$ & $.788(.036)$ \\
\hline $.954(.011)^{\wedge}$ & $.911(.021)$ \\
\hline $.795(.032)^{\wedge}$ & $.632(.050)$ \\
\hline $.877(.021)^{\wedge}$ & $.768(.036)$ \\
\hline $.604(.061)^{\wedge}$ & $.364(.074)$ \\
\hline $.879(.045)^{\wedge}$ & $.772(.079)$ \\
\hline $.817(.052)^{\wedge}$ & $.667(.085)$ \\
\hline $.883(.035)^{\wedge}$ & $.780(.062)$ \\
\hline $.840(.041)^{\wedge}$ & $.706(.070)$ \\
\hline $.703(.047)^{\wedge}$ & $.495(.065)$ \\
\hline $.780(.037)^{\wedge}$ & $.609(.058)$ \\
\hline $.798(.031)^{\wedge}$ & $.637(.050)$ \\
\hline $.766(.036)^{\wedge}$ & $.587(.056)$ \\
\hline $.768(.038)^{\wedge}$ & $.590(.059)$ \\
\hline $.687(.050)^{\wedge}$ & $.472(.068)$ \\
\hline $.787(.034)^{\wedge}$ & $.619(.053)$ \\
\hline $.693(.050)^{\wedge}$ & $.480(.069)$ \\
\hline $.724(.042)^{\wedge}$ & $.523(.061)$ \\
\hline $.599(.050)^{\wedge}$ & $.359(.059)$ \\
\hline $.820(.033)^{\wedge}$ & $.673(.055)$ \\
\hline $.884(.030)^{\wedge}$ & $.782(.053)$ \\
\hline $.799(.040)^{\wedge}$ & $.638(.064)$ \\
\hline $.876(.025)^{\wedge}$ & $.768(.044)$ \\
\hline $.777(.039)^{\wedge}$ & $.603(.061)$ \\
\hline $.504(.078)^{\wedge}$ & $.254(.079)$ \\
\hline $.356(.109)^{* *}$ & $.127(.078)$ \\
\hline $.456(.091)^{\wedge}$ & $.208(.083)$ \\
\hline $.526(.076)^{\wedge}$ & $.277(.079)$ \\
\hline $.373(.111)^{* *}$ & $.139(.083)$ \\
\hline
\end{tabular}


NVI 6

$.395(.089)^{\wedge}$

$.156(.070)$

ReNVI 7

$.110(.090)$

$.012(.020)$

NVI 8

$.757(.049)^{\wedge}$

$.574(.074)$

Re NVI 9

$.098(.106)$

NVI 10

$.602(.069)^{\wedge}$

$.010(.083)$

Instructor Enthusiasm

Enth 1

Enth 2

$.843(.039)^{\wedge}$

$.363(.083)$

Enth 3

$.924(.026)^{\wedge}$

$.710(.066)$

$.846(.036)^{\wedge}$

$.854(.047)$

$.715(.060)$

ReEnth 4

$.535(.077)^{\wedge}$

$.286(.083)$

Note. ${ }^{* *} p<.01 . \wedge p<.001$.

Hypothesis testing. To test all five hypotheses (see Figures 2 to 6), PROCESS

version 3.0 in SPSS (Hayes, 2018) was used to estimate mediation models. Six different ordinary least squares path analyses were estimated in which the dichotomous experimental conditions (indicator coded as 0 for the no choice condition and 1 for the choice condition) were entered into the model as the independent variable and student's intrinsic motivation to learn was entered as the continuous mediator. Indirect effects were estimated using $95 \%$ percentile confidence intervals with 10,000 bootstrap resamples.

Research question. To answer the research question, PROCESS in SPSS (Hayes, 2018) was used to estimate six serial multiple mediation models. According to Hayes (2018), serial multiple mediation models are used to "investigate the direct and indirect effects of $X$ [choose your own lecture] on $Y$ [e.g., student interest] while modeling a process in which $X$ causes $M_{1}$ [students' autonomy-need satisfaction], which in turn causes $M_{2}$ [students' intrinsic motivation to learn], and so forth, concluding with $Y$ as the final consequent" (p. 167). In other words, estimating serial mediation models allowed the researcher to examine a causal chain responsible for the effect of the choose your own lecture (versus control) method of instruction $(X)$ on students' interest in the topic of lecture $\left(Y_{1}\right)$, free-choice persistence $\left(Y_{2}\right)$, cognitive learning $\left(Y_{3}\right)$, affect for the course $\left(Y_{4}\right)$, and expressive dissent $\left(Y_{5}\right)$. Six different ordinary least squares serial mediation 
models were estimated in which the dichotomous experimental conditions (indicator coded as 0 for the no choice condition and 1 for the choice condition) were entered into the model as the independent variable, and student's autonomy-need satisfaction and intrinsic motivation to learn was entered as the continuous serial mediators. Indirect effects were estimated using $95 \%$ percentile confidence intervals with 10,000 bootstrap resamples.

\section{Summary}

The second chapter reviewed the methodology that was used to test the hypotheses and research question of this dissertation. This chapter reviewed the procedures to conducting a live-lecture experiment in one of two teaching conditions that manipulated autonomy-supportive choices in a large college classroom. Participants were undergraduate students who either attended a lecture where the instructor gave students choices over how the lecture on environmental communication would unfold (experimental condition) or attended another lecture where the instructor refrained from allowing students to choose the direction of the lecture (control condition). Along with the procedures of the live lecture experiment, this chapter also included a description of the participants, an overview of the instruments, and a plan for analyzing the data. 


\section{Chapter III}

\section{Results}

Table 9 contains a correlation matrix of all the variables along with the means, the standard deviations, the Cronbach alpha reliability coefficients, and the Omega coefficients and $95 \%$ confidence intervals of each variable.

\section{Teaching Effectiveness Check}

To ensure that the quality of teaching was held constant between lecture conditions, the four effective instructor behaviors were compared between the two conditions. Results from the MANOVA revealed that there were no overall differences among instructor clarity, humor, nonverbal immediacy, and enthusiasm, Wilks' $\Lambda=.95$, $F(4,200)=2.393, p=.052$, suggesting that the quality of teaching did not differ between the teaching conditions. However, results from the follow-up ANOVAs revealed significant differences between the two teaching conditions and students' perceptions of the instructor's nonverbal immediacy $\left[F(1,204)=5.45, p=.021, \eta^{2}=.03\right]$ and enthusiasm $\left[F(1,204)=9.56, p=.002, \eta^{2}=.05\right]$. Specifically, students believed the instructor in the treatment condition displayed slightly more immediacy behaviors $(M=$ $4.71, S D=.71)$ and enthusiasm $(M=4.31, S D=1.29)$ compared to the instructor's immediacy behaviors $(M=4.46, S D=.78)$ and enthusiasm $(M=3.75, S D=1.30)$ in the control condition. Moreover, the follow-up ANOVAs also revealed that there were no significant differences between the two teaching conditions and students' perceptions of the instructors' humor $\left[F(1,204)=3.02, p=.084, \eta^{2}=.02\right]$ and clarity $[F(1,205)=.226$, $\left.p=.635, \eta^{2}=.001\right]$. That being said, these teaching effectiveness variables (clarity, humor, nonverbal immediacy, enthusiasm) were still included as covariates in every 
hypothesized model to ensure that above and beyond the instructors' clarity, humor, nonverbal immediacy, and enthusiasm, the provision of choice contributed to students' motivational resources, as well as their learning outcomes.

\section{Manipulation Check}

A Welch's t-test was conducted to assess the successfulness of the choice manipulations between the two teaching conditions. The results revealed that the choice manipulations were successful, $t(172.81)=-5.40, p<.001, d=.76$ with a mean difference of $-.602,95 \%$ CI [-.823, -.382]. Students perceived significantly more choices $(M=4.29, S D=.67)$ being offered in the choose your own lecture condition and less choices $(M=3.69, S D=.89)$ in the control condition. 
Table 9:

\section{Correlation Matrix}

\begin{tabular}{|c|c|c|c|c|c|c|c|c|c|c|c|c|c|c|}
\hline Variables & $M$ & $S D$ & $\alpha$ & $\begin{array}{c}\omega \\
(\mathrm{LL}, \mathrm{UL})\end{array}$ & 1 & 2 & 3 & 4 & 5 & 6 & 7 & 8 & 9 & 10 \\
\hline 1. Choice Manipulation & -- & -- & -- & -- & -- & & & & & & & & & \\
\hline 2. Choice & 4.02 & .84 & .87 & $\begin{array}{c}.87 \\
(.84, .91)\end{array}$ & $.36^{\wedge}$ & -- & & & & & & & & \\
\hline 3. Exam Percentage & 61.77 & 19.16 & .66 & -- & -.01 & .07 & -- & & & & & & & \\
\hline 4. Conceptual Learning & .50 & .82 & -- & -- & .08 & .02 & $.30^{\wedge}$ & -- & & & & & & \\
\hline 5. Autonomy Need Satisfaction & 3.82 & .56 & .64 & $\begin{array}{c}.58 \\
(.46, .70)\end{array}$ & .04 & $.45^{\wedge}$ & .14 & .12 & -- & & & & & \\
\hline 6. Intrinsic Motivation to Learn & 4.99 & 1.12 & .92 & $\begin{array}{c}.89 \\
(.88, .92)\end{array}$ & .03 & $.33^{\wedge}$ & $.14^{*}$ & $.16^{*}$ & $.47^{\wedge}$ & -- & & & & \\
\hline 7. Pre-Interest & 4.12 & 1.40 & .92 & $\begin{array}{c}.93 \\
(.91, .95)\end{array}$ & .00 & $.26^{\wedge}$ & .06 & .14 & $.28^{\wedge}$ & $.45^{\wedge}$ & -- & & & \\
\hline 8. Post-Interest & 4.59 & 1.42 & .92 & $\begin{array}{c}.93 \\
(.91, .95)\end{array}$ & -.03 & $.31^{\wedge}$ & .05 & .13 & $.50^{\wedge}$ & $.67^{\wedge}$ & $.57^{\wedge}$ & -- & & \\
\hline 9. Interest Change Score & .46 & 1.31 & -- & -- & -.03 & .07 & .01 & .01 & $.24 * *$ & $.27^{\wedge}$ & $-.45^{\wedge}$ & $.48^{\wedge}$ & -- & \\
\hline 10. Likelihood of Enrollment & 5.13 & 1.43 & .92 & $\begin{array}{c}.92 \\
(.89, .95)\end{array}$ & $.19 * *$ & $.39^{\wedge}$ & .02 & .13 & $.43^{\wedge}$ & $.46^{\wedge}$ & $.14^{*}$ & $.35^{\wedge}$ & $.24 * *$ & -- \\
\hline 11. Expressive Dissent & 2.26 & .82 & .92 & $\begin{array}{c}.90 \\
(.89, .92) \\
\end{array}$ & -.13 & $-.36^{\wedge}$ & -.02 & -.07 & $-.49^{\wedge}$ & $-.30^{\wedge}$ & -.06 & $-.32^{\wedge}$ & $-.28^{\wedge}$ & $-.49^{\wedge}$ \\
\hline
\end{tabular}

Note. ${ }^{*} p<.05 .{ }^{* *} p<.01 .{ }^{\wedge} p<.001$. Variables correlated with Choice Manipulation reflect Point-Biserial correlations. 


\section{Correlation Matrix Continued}

\begin{tabular}{|c|c|c|c|c|c|c|c|c|c|c|c|}
\hline Variables & $M$ & $S D$ & $\alpha$ & $\begin{array}{c}\omega \\
(\mathrm{LL}, \mathrm{UL})\end{array}$ & 11 & 12 & 13 & 14 & 15 & 16 & 17 \\
\hline 12. Free-Choice Persistence & .55 & 1.31 & -- & -- & -.12 & -- & & & & & \\
\hline 13. Clarity & 6.02 & .81 & .91 & $\begin{array}{c}.92 \\
(.89, .94)\end{array}$ & $-.36^{\wedge}$ & -.05 & -- & & & & \\
\hline 14. Nonverbal Immediacy & 4.59 & .75 & .68 & $\begin{array}{c}.71 \\
(.61, .80)\end{array}$ & $-.47^{\wedge}$ & .11 & $.32^{\wedge}$ & -- & & & \\
\hline 15. Humor & 3.50 & 1.15 & .72 & $\begin{array}{c}.73 \\
(.64, .82)\end{array}$ & $-.32^{\wedge}$ & .03 & $.19 * *$ & $.49^{\wedge}$ & -- & & \\
\hline 16. Enthusiasm & 4.06 & 1.32 & .86 & $\begin{array}{c}.87 \\
(.84, .91)\end{array}$ & $-.38^{\wedge}$ & .08 & $.25^{\wedge}$ & $.68^{\wedge}$ & $.59^{\wedge}$ & -- & \\
\hline 17. Familiarity & 2.83 & .96 & .89 & $\begin{array}{c}.89 \\
(.86, .92)\end{array}$ & -.01 & .08 & $.28^{\wedge}$ & .07 & .06 & .06 & -- \\
\hline 18. Difficulty & 4.37 & 1.88 & -- & -- & -.01 & .06 & -.11 & $.20 * *$ & $.22 * *$ & $.22 *$ & .04 \\
\hline
\end{tabular}

Note. ${ }^{*} p<.05 . * * p<.01 .{ }^{\wedge} p<.001$. 


\section{Correlation Matrix Continued}

\begin{tabular}{|c|c|c|c|c|c|c|c|c|c|c|}
\hline Variables & 1 & 2 & 3 & 4 & 5 & 6 & 7 & 8 & 9 & 10 \\
\hline 12. Free-Choice Persistence & .07 & .04 & $-.20 * *$ & -.04 & -.001 & $.18^{* *}$ & $.15^{*}$ & $.19 * *$ & .06 & .08 \\
\hline 13. Clarity & .03 & $.27^{\wedge}$ & .09 & .09 & $.40^{\wedge}$ & $.43^{\wedge}$ & $.19 * *$ & $.33^{\wedge}$ & $.16^{*}$ & $.38^{\wedge}$ \\
\hline 14. Nonverbal Immediacy & $.16^{*}$ & $.35^{\wedge}$ & -.01 & .05 & $.41^{\wedge}$ & $.37^{\wedge}$ & .09 & $.27^{\wedge}$ & $.20 * *$ & $.54^{\wedge}$ \\
\hline 15. Humor & .12 & $.21^{* *}$ & -.06 & .12 & $.20 * *$ & $.29^{\wedge}$ & .10 & $.24^{\wedge}$ & $.16^{*}$ & $.44^{\wedge}$ \\
\hline 16. Enthusiasm & $.21 * *$ & $.25^{\wedge}$ & -.10 & $.15^{*}$ & $.28^{\wedge}$ & $.46^{\wedge}$ & $.19^{* *}$ & $.33^{\wedge}$ & $.17^{*}$ & $.53^{\wedge}$ \\
\hline 17. Familiarity & .09 & $.23^{* *}$ & .06 & -.04 & $.16^{*}$ & $.24 * *$ & $.37^{\wedge}$ & $.34^{\wedge}$ & -.04 & .03 \\
\hline 18. Difficulty & .07 & -.01 & -.05 & -.01 & -.09 & .01 & -.02 & .05 & .06 & .10 \\
\hline
\end{tabular}

Note. ${ }^{*} p<.05 . * * p<.01 .{ }^{\wedge} p<.001$. Variables correlated with Choice Manipulation reflect Point-Biserial correlations. 


\section{Hypothesis Testing}

The first hypothesis predicted that the choose your own lecture method of instruction would increase students' interest in the topic of the lecture, indirectly through students' intrinsic motivation to learn. To test this hypothesis, a simple mediation model (Model 4; Hayes, 2018) was estimated which included the teaching effectiveness covariates (Clarity, Humor, Nonverbal Immediacy, and Enthusiasm) as well as the students' past experience with the instructor and perception of choices met covariates. The results revealed no direct effect of the choose your own adventure method of instruction on students' interest in the lecture topic $\left(c^{\prime}=-.084, p=.658\right)$. Additionally, results revealed no indirect effect $\left(a b=-.035, \mathrm{CI}:-.129, .026, a b_{p s}=-.027, \mathrm{CI}:-.098\right.$, .020) of the choose your own adventure method of instruction on students' interest in the topic through their intrinsic motivation to learn. Thus, hypothesis one was not supported (see Table 10).

Table 10

Unstandardized Model Estimates for Hypothesis 1 using PROCESS Model 4

\begin{tabular}{|c|c|c|c|c|c|c|}
\hline \multirow{3}{*}{$\begin{array}{l}\mathrm{H} 1-\text { Interest in Topic } \\
a b=-.035, \mathrm{CI}:-.129, .026 \\
c^{\prime}=-.084, p=.658\end{array}$} & \multicolumn{6}{|c|}{$\underline{\text { Consequent }}$} \\
\hline & \multicolumn{3}{|c|}{$F(7,184)=13.03, p<.001, R^{2}=.33$} & \multicolumn{3}{|c|}{$F(8,183)=2.45, p=.015, R^{2}=.10$} \\
\hline & \multicolumn{3}{|c|}{ Intrinsic Motivation to Learn } & \multicolumn{3}{|c|}{ Interest in the Topic } \\
\hline Antecedent & Estimate & $S E$ & $p$ & Estimate & $S E$ & $p$ \\
\hline Choices & -.150 & .139 & .282 & -.084 & .188 & .658 \\
\hline Intrinsic Motivation to Learn & --- & --- & --- & .233 & .099 & .020 \\
\hline Clarity & .528 & .099 & $<.001$ & .068 & .143 & .636 \\
\hline Humor & .040 & .074 & .591 & .071 & .099 & .475 \\
\hline Nonverbal Immediacy & -.042 & .130 & .746 & .185 & .175 & .291 \\
\hline Enthusiasm & .333 & .078 & $<.001$ & -.041 & .110 & .706 \\
\hline Previous Instructor & -.222 & .187 & .238 & .043 & .253 & .864 \\
\hline Number of Choices Met & .073 & .084 & .389 & .114 & .113 & .317 \\
\hline
\end{tabular}

Note. Estimates flagged in bold represent significant unstandardized regression slopes. 
The second hypothesis predicted that the choose your own lecture method of instruction would increase students' persistence when given free-choice, indirectly through students' intrinsic motivation to learn. To test this hypothesis, a simple mediation model (Model 4; Hayes, 2018) was estimated which included the teaching effectiveness covariates (Clarity, Humor, Nonverbal Immediacy, and Enthusiasm) as well as the students' past experience with the instructor and perception of choices met covariates. The results revealed no direct effect of the provision of choice influencing students' likelihood to persist when given free-choice $\left(c^{\prime}=-.161, p=.380\right)$. Additionally, results revealed no indirect effect $\left(a b=-.041, \mathrm{CI}:-.134, .036, a b_{p s}=-.033, \mathrm{CI}:-.106, .028\right)$ of the choose your own adventure method of instruction influencing students' likelihood to persist when given free-choice through their intrinsic motivation to learn. Thus, hypothesis two was not supported (see Table 11).

Table 11

Unstandardized Model Estimates for Hypothesis 2 using PROCESS Model 4

\begin{tabular}{|c|c|c|c|c|c|c|}
\hline H2 - Free-Choice Persistence & \multicolumn{6}{|c|}{ Consequent } \\
\hline \multirow{3}{*}{$\begin{array}{l}a b=-.041, \mathrm{CI}:-.134, .036 \\
c^{\prime}=-.161, p=.380\end{array}$} & \multirow{2}{*}{\multicolumn{3}{|c|}{$\begin{array}{c}F(7,188)=13.35, p<.001, R^{2}=.33 \\
\underline{\text { Intrinsic Motivation to Learn }}\end{array}$}} & \multicolumn{3}{|c|}{$F(8,187)=2.45, p=.068, R^{2}=.07$} \\
\hline & & & & Free- & ice Pe & \\
\hline & Estimate & $S E$ & $p$ & Estimate & $S E$ & $p$ \\
\hline Choices & -.141 & .138 & .311 & .161 & .183 & .380 \\
\hline Intrinsic Motivation to Learn & --- & --- & --- & .295 & .096 & .003 \\
\hline Clarity & .525 & .099 & $<.001$ & -.244 & .139 & .081 \\
\hline Humor & .031 & .073 & 672 & -.057 & .096 & .554 \\
\hline Nonverbal Immediacy & -.031 & .130 & .810 & .194 & .171 & .259 \\
\hline Enthusiasm & .329 & .077 & $<.001$ & -.029 & .106 & .781 \\
\hline Previous Instructor & -.120 & .186 & .285 & -.195 & .246 & .430 \\
\hline Number of Choices Met & .073 & .084 & .388 & -.133 & .111 & .231 \\
\hline
\end{tabular}

Note. Estimates flagged in bold represent significant unstandardized regression slopes.

The third hypothesis predicted that the choose your own lecture method of instruction would increase students' cognitive learning, indirectly through students' 
intrinsic motivation to learn. To test this hypothesis, a simple mediation model (Model 4; Hayes, 2018) was estimated which included the teaching effectiveness covariates (Clarity, Humor, Nonverbal Immediacy, and Enthusiasm) as well as the students' past experience with the instructor and perception of choices met covariates. Additionally, this model included students' perceived familiarity with, and difficulty of, the lecture material as covariates. The results revealed no direct effect of the provision of choice on students' exam percentage $\left(c^{\prime}=.449, p=.875\right)$ and conceptual learning score $\left(c^{\prime}=.117, p=.341\right)$. Additionally, results revealed no indirect effect of the choose your own adventure method of instruction influencing students' exam percentage $\left(a b=-.427, \mathrm{CI}:-1.894, .408, a b_{p s}=\right.$ -.022 , CI: $-.097, .022)$ and conceptual learning score $\left(a b=-.014, \mathrm{CI}:-.057, .017, a b_{p s}=-\right.$ $.016, \mathrm{CI}:-.066, .020)$ through their intrinsic motivation to learn. Thus, hypothesis three was not supported (see Table 12).

Table 12

Unstandardized Model Estimates for Hypothesis 3 using PROCESS Model 4

\begin{tabular}{|c|c|c|c|c|c|c|}
\hline \multirow{4}{*}{$\begin{array}{l}\mathrm{H} 3-\text { Exam Percent } \\
\begin{array}{l}a b=-.427, \mathrm{CI}:-1.894, .408 \\
c^{\prime}=.449, p=.875\end{array} \\
\text { Antecedent }\end{array}$} & \multicolumn{6}{|c|}{ Consequent } \\
\hline & \multirow{2}{*}{\multicolumn{3}{|c|}{$\begin{array}{c}F(9,182)=11.11, p<.001, R^{2}=.36 \\
\text { Intrinsic Motivation to Learn }\end{array}$}} & \\
\hline & & & & \multicolumn{3}{|c|}{$\begin{array}{c}F(10,181)=1.10, p=.363, R^{2}=.06 \\
\text { Exam Percentage }\end{array}$} \\
\hline & Estimate & $S E$ & $p$ & Estimate & $S E$ & $p$ \\
\hline Choices & -.125 & .139 & .367 & .449 & 2.847 & .875 \\
\hline Intrinsic Motivation to Learn & --- & --- & --- & 3.405 & 1.521 & .026 \\
\hline Clarity & .471 & .104 & $<.001$ & 1.137 & 2.253 & .615 \\
\hline Humor & .037 & .073 & 611 & -.042 & 1.505 & .978 \\
\hline Nonverbal Immediacy & -.018 & .130 & .888 & 1.189 & 2.672 & .657 \\
\hline Enthusiasm & .340 & .077 & $<.001$ & -3.185 & 1.651 & .055 \\
\hline Previous Instructor & -.183 & .191 & .338 & -3.824 & 3.925 & .331 \\
\hline Number of Choices Met & .051 & .086 & .551 & 1.413 & 1.765 & .424 \\
\hline Familiarity with Material & 154 & .074 & .038 & -.112 & 1.531 & 942 \\
\hline Difficulty of Material & -.042 & .038 & .275 & .040 & .780 & .959 \\
\hline
\end{tabular}

Note. Estimates flagged in bold represent significant unstandardized regression slopes. 
Table 12 continued

\begin{tabular}{|c|c|c|c|c|c|c|}
\hline \multirow{4}{*}{$\begin{array}{l}\mathrm{H} 3 \text { - Conceptual Learning } \\
a b=-.014, \mathrm{CI}:-.057, .017 \\
c^{\prime}=.117, p=.341 \\
\text { Antecedent }\end{array}$} & \multicolumn{6}{|c|}{ Consequent } \\
\hline & \multirow{2}{*}{\multicolumn{3}{|c|}{$\begin{array}{c}F(9,184)=10.90, p<.001, R^{2}=.35 \\
\underline{\text { Intrinsic Motivation to Learn }}\end{array}$}} & \multirow{2}{*}{\multicolumn{3}{|c|}{$\begin{array}{c}F(10,183)=2.23, p=.277, R^{2}=.06 \\
\text { Conceptual Learning }\end{array}$}} \\
\hline & & & & & & \\
\hline & Estimate & $S E$ & $p$ & Estimate & $S E$ & $p$ \\
\hline Choices & -.144 & .138 & 298 & .117 & .123 & .341 \\
\hline Intrinsic Motivation to Learn & --- & --- & --- & .094 & .067 & .154 \\
\hline Clarity & .453 & .103 & $<.001$ & .038 & .096 & .691 \\
\hline Humor & .036 & .073 & .629 & .058 & .65 & .380 \\
\hline Nonverbal Immediacy & -.030 & .132 & .820 & -.180 & .117 & .126 \\
\hline Enthusiasm & .343 & .077 & $<.001$ & .087 & .072 & .226 \\
\hline Previous Instructor & -.197 & .186 & .292 & .010 & .166 & .955 \\
\hline Number of Choices Met & .051 & .084 & .542 & .034 & .075 & .648 \\
\hline Familiarity with Material & .159 & .073 & .032 & -.093 & .066 & .159 \\
\hline Difficulty of Material & -.039 & .038 & .305 & -.010 & .034 & .771 \\
\hline
\end{tabular}

Note. Estimates flagged in bold represent significant unstandardized regression slopes.

The fourth hypothesis predicted that the choose your own lecture method of instruction would increase students' likelihood of taking another course with the same instructor, indirectly through students' intrinsic motivation to learn. To test this hypothesis, a simple mediation model (Model 4; Hayes, 2018) was estimated which included the teaching effectiveness covariates (Clarity, Humor, Nonverbal Immediacy, and Enthusiasm) as well as the students' past experience with the instructor and perception of choices met covariates. The results revealed no direct effect of the provision of choice influencing students' likelihood of enrolling with the instructor in the future $\left(c^{\prime}=.224, p=.169\right)$. Additionally, results revealed no indirect effect $(a b=-.035$, CI: $\left.-.121, .041, a b_{p s}=-.024, \mathrm{CI}:-.083, .028\right)$ of the choose your own adventure method of instruction influencing students' likelihood to enroll with the same instructor through their intrinsic motivation to learn. Thus, hypothesis four was not supported (see Table 13). 
Table 13

Unstandardized Model Estimates for Hypothesis 4 using PROCESS Model 4

\begin{tabular}{|c|c|c|c|c|c|c|}
\hline \multirow{4}{*}{$\begin{array}{l}\text { H4 - Likelihood of Enrollment } \\
\begin{array}{l}a b=-.035, \mathrm{CI}:-.121, .041 \\
c^{\prime}=.224, p=.169\end{array} \\
\text { Antecedent }\end{array}$} & \multicolumn{6}{|c|}{ Consequent } \\
\hline & \multirow{2}{*}{\multicolumn{3}{|c|}{$\begin{array}{c}F(7,185)=13.29, p<.001, R^{2}=.34 \\
\underline{\text { Intrinsic Motivation to Learn }}\end{array}$}} & \multirow{2}{*}{\multicolumn{3}{|c|}{$\begin{array}{c}F(8,184)=18.90, p<.001, R^{2}=.45 \\
\underline{\text { Likelihood of Enrollment }}\end{array}$}} \\
\hline & & & & & & \\
\hline & Estimate & $S E$ & $p$ & Estimate & $S E$ & $p$ \\
\hline Choices & -.130 & .140 & .355 & .224 & .162 & .169 \\
\hline Intrinsic Motivation to Learn & --- & --- & --- & .269 & .085 & .002 \\
\hline Clarity & .527 & .099 & $<.001$ & .252 & .123 & .042 \\
\hline Humor & .022 & .073 & .762 & .147 & .085 & .086 \\
\hline Nonverbal Immediacy & -.046 & .130 & .727 & .386 & .151 & .011 \\
\hline Enthusiasm & .337 & .077 & $<.001$ & .152 & .093 & .106 \\
\hline Previous Instructor & -.208 & .187 & .267 & .406 & .217 & .063 \\
\hline Number of Choices Met & .082 & .084 & .335 & .116 & .098 & .237 \\
\hline
\end{tabular}

Note. Estimates flagged in bold represent significant unstandardized regression slopes.

The fifth hypothesis predicted that the choose your own lecture method of instruction would decrease students' expressive dissent, indirectly through students' intrinsic motivation to learn. To test this hypothesis, a simple mediation model (Model 4; Hayes, 2018) was estimated which included the teaching effectiveness covariates (Clarity, Humor, Nonverbal Immediacy, and Enthusiasm) as well as the students' past experience with the instructor and perception of choices met covariates. The results revealed no direct effect of the provision of choice influencing students' likelihood to expressively dissent about the instructor $\left(c^{\prime}=-.045, p=.661\right)$. Additionally, results revealed no indirect effect $\left(a b=.005, \mathrm{CI}:-.020, .032, a b_{p s}=.006, \mathrm{CI}:-.025, .039\right)$ of the choose your own adventure method of instruction influencing students' likelihood to expressively dissent through their intrinsic motivation to learn. Thus, hypothesis five was not supported (see Table 14). 
Table 14

Unstandardized Model Estimates for Hypothesis 5 using PROCESS Model 4

\begin{tabular}{|c|c|c|c|c|c|c|}
\hline \multirow{4}{*}{$\begin{array}{l}\text { H5 - Expressive Dissent } \\
a b=-.0051, \mathrm{CI}:-.018, .033 \\
c^{\prime}=-.045, p=.661 \\
\text { Antecedent }\end{array}$} & \multicolumn{6}{|c|}{ Consequent } \\
\hline & \multirow{2}{*}{\multicolumn{3}{|c|}{$\begin{array}{c}F(7,188)=13.35, p<.001, R^{2}=.33 \\
\underline{\text { Intrinsic Motivation to Learn }}\end{array}$}} & \multirow{2}{*}{\multicolumn{3}{|c|}{$\begin{array}{c}F(8,187)=10.81, p<.001, R^{2}=.32 \\
\text { Expressive Dissent }\end{array}$}} \\
\hline & & & & & & \\
\hline & Estimate & $S E$ & $p$ & Estimate & $S E$ & $p$ \\
\hline Choices & -.141 & .138 & .311 & -.045 & .103 & .661 \\
\hline Intrinsic Motivation to Learn & --- & --- & --- & -.037 & .054 & .498 \\
\hline Clarity & .525 & .099 & $<.001$ & -.282 & .078 & $<.001$ \\
\hline Humor & .031 & .073 & .672 & -.049 & .054 & .372 \\
\hline Nonverbal Immediacy & -.031 & .130 & .810 & -.389 & .096 & $<.001$ \\
\hline Enthusiasm & .329 & .077 & $<.001$ & .006 & .059 & .927 \\
\hline Previous Instructor & -.200 & .186 & .285 & .008 & .139 & .956 \\
\hline Number of Choices Met & .073 & .084 & .388 & -.005 & .062 & .935 \\
\hline
\end{tabular}

Note. Estimates flagged in bold represent significant unstandardized regression slopes.

\section{Research Question}

The research question inquired about the effect of the choose your own lecture method of instruction influencing students' (a) interest in the topic, (b) free-choice persistence, (c) cognitive learning, (d) likelihood of enrollment, and (e) expressive dissent through serial mediation via students' autonomy-need satisfaction and intrinsic motivation to learn. Unfortunately, due to the measurement issues with the autonomyneed scale, these research questions could not be answered. First, results from the CFA suggested (according to global and local fit) that the factor structure of the autonomyneed scale was problematic with a majority of the factor loadings below Kline's (2016) .70 cutoff recommendation (factor loadings ranged from -.02 to .74). In addition to validity issues, the autonomy-need scale struggled with reliability $(\alpha=.64, \omega=.58,95 \%$ CI: .46, .70). Kline (2016) argued that measures with poor reliability and validity can jeopardize the results and render any findings meaningless. Therefore, due to the poor psychometrics of the autonomy-need scale, the researcher refrained from estimating 
serial mediation models to answer the research question.

\section{Summary}

The results from this dissertation indicate that the choose your own adventure method of instruction did not directly or indirectly (through students' intrinsic motivation to learn) influence students' (a) interest in the topic of lecture, (b) free-choice persistence, (c) cognitive learning, (d) affect for the course, or (e) decrease their intentions to expressively dissent. These findings are primarily due to the lack of the provision of choice contributing to students' intrinsic motivation to learn (i.e., a-path in the mediation analyses). However, in conjunction with SDT, the results still illuminate the importance of supporting students' intrinsic motivation to learn. In other words, even though the provision of choice did not increase students' intrinsic motivation to learn, their natural inclination to learn in a course increased their interest in the topic of the lesson, likelihood of signing up for free opportunities to learn more about the topic, affect for the course, and minimally increased their exam percentage $(3.41 \%)$ and conceptual understanding of the material. Not only do these results reveal important implications for the (in)effectiveness of choices in the classroom, but further bolster the connection between students' intrinsic motivation and their success in the classroom. 


\section{Chapter IV}

\section{Discussion}

The goal of this dissertation was to examine the autonomy-supportive behavior of giving students' choices over what they were learning using a live lecture experiment. More precisely, this dissertation investigated the effect of allowing students to control the direction of a lesson on their intrinsic motivation to learn, and consequently, their learning outcomes. In contrast to the predictions, the provision of choice during the lesson did not indirectly (through students' intrinsic motivation to learn) or directly influence students' interest in the topic of the lesson, free-choice persistence, cognitive learning, affect for the course, or expressive dissent. In fact, the provision of choice did not influence students' intrinsic motivation at all, therefore, this style of teaching may not be worthwhile to bring into the classroom. Although offering students choices did not influence students' learning outcomes, their intrinsic motivation to learn did influence their interest in the topic, likelihood of signing up for free opportunities to learn more about environmental communication, affect for the course, and slightly increased their cognitive learning. The implications for these findings as well as recommendations for teaching and future research are discussed next.

\section{Choose Your Own Lecture Method Did Not Motivate Students}

The choose your own lecture style of teaching did not intrinsically motivate students to learn. Looking at the findings from this study, one might conclude that the choose your own lecture style of instruction is an ineffective method of teaching. Such conclusions may be premature, especially in the context of Schneider, Nebel, Beege, and Rey's (2018) study that examined the provision of choice, like the choose your own 
lecture style of teaching, but in an online setting. They used several webpages to deliver two separate lessons. In one lesson (study 1) students were either given the opportunity to choose the topic of the lesson or were not given a choice over the topic. In the second lesson (study 2) students were given some combination of relevant choices (over the topic) and/or irrelevant choices (over the music playing) during the lesson. Results from both studies revealed that choices in general (both relevant and irrelevant) positively contributed to students' autonomy, learning (retention and transfer), and intrinsic motivation, and decreased their cognitive load. Importantly, Schneider et al. (2018) found that students' autonomy need satisfaction mediated the relationship between choices given in this online context and students' retention. It seems that the choose your own lecture style of teaching may be more beneficial in an online classroom setting. That said, the results of this dissertation revealed that the choose your own lecture style of teaching did not intrinsically motivate students to learn nor did this style of teaching contribute to students' learning and affect for the course and lecture information.

These findings may best be understood by considering the differential effects of instructionally relevant versus instructionally irrelevant choices. Previous research (Reeve et al., 2003) has identified instructionally relevant choices as the manipulations of choice that allow people to make more meaningful decisions during a task (e.g., the pace of working on the activity, method for completing activity, goals for the activity, etc.). In contrast, instructionally irrelevant choices are the manipulations of choice that give people decisions that have no bearing on learning or the activity (e.g., the name of a character, choosing between different topics, the song playing during the activity, etc.). Patall et al.'s (2008) meta-analysis on the provision of choice, revealed that 
instructionally irrelevant choices were superior to instructionally relevant choices for facilitating people's intrinsic motivation. In line with the findings of this meta-analysis, the researcher created the lesson to strictly provide students the choice between the topics of information (e.g., the choice between oceans or terrestrial), which would be consistent with instructionally irrelevant choices. However, it is entirely possible that students believed that having the opportunity to vote and dictate the direction of the lesson was an instructionally relevant choice. That is, although the choices provided to students had little consequence for what the students were going to learn, allowing them the ability to decide the direction of the lesson may have allowed students to express their personal interest. Considering the SDT literature, these types choices may seem beneficial, but Patall et al.'s (2008) findings suggests that having these meaningful choices may be responsible for the choose your own adventure style of teaching not influencing students' intrinsic motivation to learn. Similarly, Moller et al. (2006) suggested that the reason why choice researchers find inconsistent findings is because of the subtle pressures imposed on people to decide when given a choice, referred to as controlled choices. Therefore, it may be likely that the choices made by students may have not been perceived as truly autonomous (i.e., unrestricted) choices. In other words, if students perceived the choices given to them as instructionally relevant and/or controlling, it is possible that these choices did not contribute to students' intrinsic motivation to learn.

Alternatively, if students did perceive the choices provided as instructionally irrelevant, the question remains: why did these choices not contribute to their intrinsic motivation to learn? The logical and likely explanation for these results is that the students may not have cared about making the choices provided to them during the 
lesson. Williams (1998) argued that inconsequential choices may cause people to feel ambivalent about their choices rather than intrinsically motivated to persist in the future. According to Schwartz (2004), giving people meaningless choices that do not allow them to reflect on their decisions or adjust their goals causes people to feel like pickers, instead of choosers. Being a picker often means people will follow the herd or make the same inconsequential decision similar to those around them (Schwartz, 2004). Thus, by having students use the polling application to solicit their choices and displaying the live polling on the projector in the front of the room may have inadvertently caused a picking effect where students made choices based on the popularity of other votes. Therefore, instead of taking the time to reflect on a decision that would be personally important for themselves, students may have chosen a direction for the lesson that followed most of their peers. That is, students likely did not care about the choices they were making and picked an option based on popularity. Similarly, the disappointing effects found in this dissertation may simply be due to the fact that students made several choices over the topic of the lesson but were not satisfied with their choices later when the topic was discussed in further detail.

In a similar vein, these findings may also be interpreted by examining Stefanou, Perencevich, DiCintio, and Turner's (2004) hierarchy of autonomy-supportive choices. Stefanou et al. (2004) argued that there are three qualitatively different types of choices given to students, each of which have differing implications for students' motivation and learning. That is, choices can be administered through organizational autonomy support (e.g., students choose evaluation procedures, group members, due dates, classroom rules, and seating arrangement), procedural autonomy support (e.g., students choose the 
materials for displaying their work, methods of assessment, and allowing them the opportunity to discuss their desires), or cognitive autonomy support (e.g., asking students to justify their argument and generate their own solution, give students time for decision making, allow students to ask questions, and reevaluate their answers/errors). Arguably, organizational autonomy-supportive choices provide students with the least amount on personal investment in their decision making (e.g., seating arrangement) whereas cognitive choices facilitate more meaningful decision making for students (e.g., justifying or reevaluating answers). In other words, although the provision of organizational choices can be slightly beneficial for students, providing cognitive choices may be the necessary type of choice to enhance students' intrinsic motivation to learn (Stefanou et al., 2004). In this experiment, students were allowed a short amount of time to dictate the direction of the lesson, which reflects more of an organizational/procedural choice rather than cognitive choices. It is likely that incorporating more cognitive choices, such as giving students time to reflect or adjust their decisions, receive feedback on their choices, debate about the different available topics, and/or ask questions about the choices (Stefanou et al., 2004), into the choose your own lecture style of teaching may facilitate more intrinsic motivation.

Similar to adding more cognitive choices to the choose your own lecture style of teaching, the provision of rationales (specifically regarding the choices students make) may be the key component that contributes to the effectiveness of choices in the classroom. Recall that Baker and Goodboy (2019) introduced the choose your own lecture method of teaching, but also complemented this style of teaching by providing meaningful rationales to the students about their choices. More specifically, they 
conducted a live lecture experiment where the instructor allowed students to make choices over the material and explained the importance of the choices they made by attempting to connect the chosen material to students' experiences. They found that offering choices accompanied with rationales for their choices increased students' intrinsic motivation toward the in-class activities, and consequently, increased their effort toward completing the activities, attention during the lesson, and participation; and decreased their intentions to spread negative comments about the instructor. However, Baker and Goodboy (2019) did not find that this method of teaching contributed to students' performance on a short quiz. It seems that expressing to students why their choices matter and how their choices impact their daily lives may be the driving force as to why choices foster more intrinsic motivation.

Indeed, several SDT researchers have demonstrated that providing rationales for doing a task is an important way to support people's autonomy and intrinsic motivation (Deci et al., 1994; Koestner, Ryan, Bernieri, \& Holt, 1984; Vansteenkiste, Aelterman, Muynck, Harens, Patall, \& Reeve, 2018). Katz and Assor (2007) discussed the conditions under which choices would be most effective, and concluded choices are only effective to the degree they support students' basic psychological needs for autonomy, competence, and relatedness. For instance, they argued that for choices to support students' basic psychological needs the choice options should be relevant to students' interests and goals (autonomy), simple and offer very few options (competence), and consistent with students' values and culture (relatedness). Importantly, Katz and Assor (2007) suggested that instructors should demonstrate the value of the choice options to the students to empower students to work on tasks that interest them and that align with their personal 
goals. It is likely that because the choose your own lecture method of teaching did not include statements that expressed the importance and value of students' decisions, this style of teaching did not meaningfully facilitate students' intrinsic motivation to learn.

\section{Intrinsic Motivation to Learn and Student Learning Outcomes}

The second conclusion that can be drawn from the results is the positive influence of students' intrinsic motivation on their affect for the course and topic, free-choice persistence, and cognitive learning. More specifically, students' intrinsic motivation to learn increased their interest in climate change, likelihood of signing up for free opportunities to learn more about environmental communication, likelihood of enrolling in another course with the instructor, and their performance on the short test. SDT scholars have consistently demonstrated that intrinsically motivated students are high performers in education (see Ryan \& Deci, 2017). Thus, it is not surprising that the intrinsically motivated students reported these beneficial learning outcomes following the lesson.

The question, then, becomes: if the provision of choice did not contribute to students' intrinsic motivation, why did some students report high quality motivation? One answer to this question may be students' individual interest in the topic of the lesson. Krapp (2002) defined individual interest as a relatively enduring characteristic of a person that represents preferences for certain topics (e.g., environmental science or climate change) or learning tasks (e.g., attending a live-lecture on environmental communication). In other words, some of the participants may have had a relatively enduring preference for the topic of environmental communication, specifically climate change. Shiefele (2009) argued that having high levels of individual interest in a subject 
area relates to positive feelings (e.g., excitement and enjoyment) and valuing that specific subject area (e.g., personal importance). Thus, it is likely that students who had positive feelings toward the topic of the lesson and intrinsically valued the information were likely to be intrinsically motivated to learn. In fact, Shiefele (2009) suggested that when students' individual interest is activated in the classroom, this interest may lead to students' intrinsic motivation. Echoing this argument, this dissertation revealed a positive correlation between students' pre-interest in the topic and their intrinsic motivation to learn $(r=.45, p<.001)$. According to the theoretical propositions of OIT, students' individual interest likely fostered the internalization process, which in turn facilitated students' intrinsic motivation and their learning outcomes.

Recall, OIT focuses on the degree to which people internalize extrinsic regulations (e.g., instructor requests, external rewards, etc.), which contributes to the different types of motivation people experience. Based on the degree of internalization, people's motivation will range from amotivation to intrinsic motivation. According to OIT, intrinsic motivation to learn reflects highly autonomous motivation and represents students' desire to learn information simply because learning is inherently interesting and enjoyable (Ryan \& Deci, 2017). Further, Ryan and Deci (2017) argued that people continue to engage in intrinsically motivated behaviors, such as learning, because these behaviors are driven by a pure desire to experience a natural feeling of satisfaction and curiosity. In other words, intrinsically motivated learning represents the learning that students are excited and interested in doing at a specific time. In line with the fourth and fifth theoretical propositions of OIT (see Table 2), students who experience more autonomous motivation (i.e., intrinsic motivation) will have more behavioral persistence, 
quality behaviors, effective performance, and positive experiences. Therefore, the positive connection between students' intrinsic motivation to learn and their interest in the topic, affect for the course, and free-choice persistence echoes much of the SDT literature. For example, previous researchers have demonstrated that intrinsically motivated students are more likely to give instructors a positive evaluation (e.g., students report the instructor presents material clearly, shows concern, provides helpful feedback, and is knowledgeable; Griffin, 2016) and persist to learn more about a topic when given free-choice to do anything else (Vansteenkiste et al., 2004). Our findings align with the claims of OIT that students who are motivated to learn, likely due to their individual interest in the topic, are more prone to experience beneficial learning outcomes.

In addition to increasing students' affect and persistence, the results revealed a small association between students' intrinsic motivation to learn and their cognitive learning. This finding is not too surprising given Taylor et al.'s (2014) meta-analysis that found a positive connection ( $d=.27$, CI: $.23, .32)$ between students' intrinsic motivation and their academic achievement. Benware and Deci (1984) reasoned that intrinsically motivated students are academically successful because these students are more likely to genuinely process the information with a sense curiosity. For example, Vansteenkiste et al. (2004) not only found a positive link between students' autonomous motivation and their test performance, but also found that autonomously motivated students were more likely to use deep mental processing to engage with the reading material. Furthermore, Ryan and Deci (2017) stated that autonomous motivation, such as intrinsic motivation, is "associated with less internal conflict and a greater holistic dedication of self to actions, thus more fully engaging the individual's cognitive, affective, and energetic resources." 
(p. 208). In other words, intrinsically motivated students are learning for the sake of curiosity and using their available cognitive resources to engage with learning activities, which would explain why these students perform better on a test of recall and demonstrate more conceptual understanding of the lesson.

\section{The Importance of Instructor Clarity and Enthusiasm (Covariates)}

An additional noteworthy finding is the positive influence of two of the four instructor covariates, specifically instructor clarity and enthusiasm, on students' intrinsic motivation to learn. Many researchers have demonstrated the value of clear teaching in the classroom (Titsworth, Mazer, Goodboy, Bolkan, \& Myers, 2015) and being an enthusiastic instructor (Patrick et al., 2000). The connection between instructor clarity and student intrinsic motivation may best be understood by considering the SDT literature focused on classroom structure (e.g., Hospel \& Galand, 2016; Mouratidis, Vansteenkiste, Michou, \& Lens, 2013; Vansteenkiste et al., 2012). Reeve (2006) considered classroom structure to include presenting clear expectations, offering help during learning activities (e.g., hints), and providing constructive feedback. Jang et al. (2009) reasoned that the provision of structure in the classroom is beneficial for students because this clarity supports students' need to demonstrate their competence and understanding. Additionally, this dissertation revealed that there is also a positive connection between instructor clarity and students' autonomy-need satisfaction $(r=.40, p$ $<.001)$. Moreover, Kunter, Frenzel, Nagy, Baumert, and Pekrun (2011) argued that enthusiastic teaching is often reflected in instructor behaviors such as stating the value of the learning material, conveying one's interest in the material, and/or having a dynamic teaching style. Patrick et al. (2000) posited that instructor enthusiasm may serve as a 
catalyst for students' curiosity and enjoyment of the material. Thus, it is likely that instructor enthusiasm has a spillover effect, such that instructors who genuinely express their own interest in the material and excitement for teaching spills over to their students and fosters their students' intrinsic motivation to learn. Indeed, previous researchers have found that instructor enthusiasm positively contributes to students' intrinsic motivation (Patrick et al., 2000) and mastery goal orientation (Zhang, 2014). Therefore, it is no surprise that clear and enthusiastic teaching fosters students' basic psychological needs and has the potential to spark the interests of some students to enjoy the learning process.

\section{Implications for Theory and (Online) Teaching}

One theoretical implication that can be drawn from this dissertation is the complexity of the provision of choice in the classroom. Previous researchers (e.g., Patall et al., 2008; Reeve et al., 2003) have found that choices can be beneficial for students, but at the same time, other researchers have cautioned against choices in the classroom (Iyengar \& Lepper, 2000; Mozgalina, 2015). Patall and her colleagues (2008) suggested that productive choices should limit the amount of options (2-4 options), be instructionally irrelevant, and successively build off one another. The choose your own lecture style of teaching used in this dissertation adhered to these recommendations, but this style of teaching did not contribute to students' intrinsic motivation to learn. Again, this may be because the choose your own lecture style of teaching did not provide rationales to demonstrate the importance of the choices offered to students. Therefore, it seems the choose your own lecture style of teaching is conducive to students' intrinsic motivation only to the degree that students recognize the importance of the information they choose (Baker \& Goodboy, 2019). Indeed, Vansteenkiste et al. (2018) argued that 
students must clearly recognize the value and importance of an activity to help facilitate the internalization process (i.e., intrinsic motivation). Furthermore, Vansteenkiste et al. (2018) suggested that choices (and other autonomy-supportive behaviors) are often embedded in other autonomy-supportive behaviors, such as rationales (e.g., Flunger, Mayer, \& Umbach, 2019). Vansteenkiste and his colleagues (2018) reasoned that the autonomy-supportive behaviors of providing students with several rationales and allowing students to choose a rationale to endorse could be combined to optimally support students' basic psychological needs and foster students' intrinsic motivation. Therefore, the choose your own lecture style of teaching can be embedded with other autonomy-supportive teaching behaviors (e.g., providing rationales, acknowledging negative affect, offering hints, or providing informational feedback) to ensure students' feel a sense of volitional control over what they are learning in the classroom.

Creating and preparing a lesson that reflects the choose your own lecture style of teaching may be a daunting task for classes that meet consistently face-to-face. This method of teaching requires the instructor to prepare lesson plans for an array of possible topics and directions that students can choose from. Additionally, instructors may be hesitant of allowing students to choose the direction of the learning environment, because students may not have the expertise to make the "correct" decision regarding how the lesson or semester should progress. In fact, our findings seem to suggest that incorporating this style of teaching (compared to teaching without the provision of choice) is probably not worth instructors' time. The aforementioned results from Schneider et al. (2018) seem to suggest that this style of teaching may be more suitable for an online classroom context, which gives instructors more freedom to create 
opportunities for students to have structured choices over the information. More importantly, in online contexts, instructors have more time and resources to prepare several units of information to create a classroom environment where students can choose the direction in which they would like to interact with the material. That is, online instructors may be able to personalize their courses for students by having several units of information available to students to choose from and allowing students to choose the order in which they complete these units. Thus, the choose your own lecture style of teaching may have more potential in an online context that takes the burden off the instructor to have several lesson plans prepared for a single class meeting. That is, online instructional designers can take the planned lessons for the semester and create an environment that allows students the opportunity to choose the information to learn on a week-to-week or day-to-day basis.

\section{Limitations and Future Research}

This dissertation was primarily concerned with testing the impact of offering students choices in the classroom, but as with any study the results must be interpreted in the context of its limitations. The primary limitation of this study was the issues with the short test that was developed for this dissertation. The researcher used three pilot studies and consulted an environmental science instructor to create a short test to assess students' recall of the lesson. Although evidence was provided to suggest the test was reliably asking students to recall the major points from the lesson, students still struggled to perform well on the test $(M=61.77, S D=19.16)$. In other words, the researcher and the external environmental science expert generally agreed the test was assessing students' recollection of the main lecture points and assessing the learning objectives developed for 
the lesson. However, students on average received a D on the test. Similarly, students on average struggled answering the open-ended conceptual learning question $(M=.50, S D=$ .82). Therefore, the researcher cannot be truly confident that the final short 15 -item test and the conceptual learning question accurately captured students' learning.

Another major limitation of the dissertation was the frequency of participants who reported that their choices were met in both the treatment and control condition. In other words, the manipulation check for choices was successful, but the frequency for which participants believed the instructor had listened/implemented their choices was present even in the control condition. In fact, a Welch's t-test between the lecture conditions and the number of choices participants believed the instructor implemented revealed no significant differences, $t(160.073)=-1.56, p=.120, d=.224$. That is, the number of choices participants believed the instructor listened to did not differ between the choose your own lecture condition $(M=2.47, S D=.69)$ and the control lecture condition $(M=$ $2.28, S D=.98)$. Clearly, participants in the control condition should have reported having none of their choices being implemented by the instructor, but on average across the conditions participants reported that approximately two of their choices were met $(M=$ $2.38, S D=.84)$. Perhaps, the polling system used in both conditions is the culprit for this finding. Although students in the control condition were not given a choice over the direction of the lesson, they were still provided with the opportunity to select answers to questions related to the lesson. That is, students in the control condition still had the opportunity to use their smartphones and select an answer that expressed their feelings toward the material. Even though students' perceptions of choices met was included as a covariate, having students use the voting application may have amplified their 
perceptions of choices being offered in both lectures. Thus, using the voting application in the control condition may have provided the researcher with an interactive way to capture students' decisions, but also likely dampened the effect of the provision of choice on students' intrinsic motivation to learn.

An additional limitation of this dissertation is the validity and reliability issues with the autonomy-need scale that prevented the estimation of the serial mediation models to answer the research question. The CFA and reliability analysis revealed that the eight-item measurement lacked psychometric stability. Many researchers (e.g., Chen et al., 2015) have used the eight-item measure and created two separate scales to reflect autonomy-need satisfaction (4 items) and autonomy-need frustration (4 items). Although a CFA of the two factor measurement model improved local (normalized residuals did not exceed the recommended 2.58 cutoff value) and global fit $\left[\chi^{2}(19)=26.42, p=.119\right.$; RMSEA $=.04,90 \% \mathrm{CI}: .00, .08 ; \mathrm{CFI}=.97 ; \mathrm{SRMR}=.05]$, three of the four factor loadings for the autonomy-need satisfaction scale were below the recommended .70 value (Kline, 2016), and the reliability of the four-item measure only slightly improved $(\omega=$ $.69,95 \%$ CI: .61, .78). Chen et al. (2015) examined the psychometrics of the basic psychological need satisfaction and need frustration scale (BPNSNF) and concluded that across four different cultures (U.S., China, Peru, and Belgium) this scale was valid and reliable. Thus, the poor findings of this dissertation must not overshadow the comprehensive findings from previous SDT researchers (e.g., Aelterman et al., 2016; Chen et al., 2015) that support the psychometrics of the BPNSNF scale.

The fourth limitation of this dissertation was the low stakes nature of the lesson and the low number of students who signed up for the live-lecture. Many steps were 
taken to create an environment that reflected a normal class session, such as using a typical large lecture classroom and timing the live-lecture portion of the experiment to take approximately 50 minutes to complete (a typical class period at the university). However, students were provided with a cover letter (included in the survey) and the instructor made an announcement at the beginning of the lesson that explained that students' university standing would in no way be impacted by the information they provided for the study. These comments may have emphasized to students the low stakes nature of the experiment. Similar to the low stakes nature of the study, students were hesitant to sign up to attend the live lecture. Due to the low amount of sign ups and low number of students who attended each live lecture lesson, the researcher had to conduct the experiment three different times. These low numbers reflect that students did not care about the lesson and demonstrate that the extra-credit provided for the study may have led to a sample that is not representative of all types of undergraduate students. Thus, any interpretations made from this dissertation must be tempered with both methodological limitations.

The fifth limitation of this study was the use of extra credit provided to students for attending the live-lecture lesson. SDT researchers (e.g., Deci et al., 1999) have demonstrated that providing external rewards, especially performance contingent rewards, can undermine people's intrinsic motivation. According to CET (Ryan \& Deci, 2000a), these external rewards, such as extra credit, are responsible for thwarting students' basic psychological needs for autonomy and competence. Because these rewards diminish students' autonomy and competence, CET posits that students would view their behaviors in this live-lecture experiment as instrumental means of receiving 
their extra credit points, which is perceived as controlling. Thus, using extra credit to motivate students to attend the live-lecture portion of the study may have undermined the autonomy-supportiveness of the choose your own lecture style of teaching.

In addition to making the adjustments to the measurement of autonomy-need satisfaction and removing the polling application from the control condition, there are three directions future research could examine the choose your own lecture style of teaching. First, future research would benefit from removing the extra credit component by taking over an entire class (e.g., Baker \& Goodboy, 2019) for a few weeks or the entire semester to manipulate parts of the classroom environment. In other words, the findings of this dissertation may have been different if the experiment took place during the normal learning environment for students. Similarly, adopting a longitudinal design (e.g., Black \& Deci, 2000) to examine the ebb and flow of students' basic psychological need satisfaction, intrinsic motivation to learn, and learning outcomes would benefit future researchers interested in examining the impact of the choose your own lecture style of teaching. Using these methodological changes may reveal the number, when in the semester, and the different types of choices students desire to have in the classroom.

Second, future research should examine the influence of incorporating meaningful choices into the choose your own lecture style of teaching. For example, previous researchers have demonstrated that providing students the choice over their homework assignments (Patall et al., 2010) and allowing them to pick their preferred method of instruction (Jang et al., 2016) fosters their intrinsic motivation and autonomy-need satisfaction, respectively. The choose your own lecture style of teaching used in this dissertation gave students the opportunity to decide on the direction of the lesson, but 
students were still exposed to all the information. Instead, future research should consider manipulating choices in the classroom that have bigger implications for students, such as allowing students to choose the type of activity to work on during or following the lesson, the context in which the lecture information is discussed (e.g., deception in romantic relationships versus families), and/or the examples or rationales used to explain the information. Additionally, future investigations may want to examine how the inclusion of cognitive autonomy-supportive choices (i.e., giving students time to reflect or adjust their decisions, allowing students to debate the different available options, etc.) may increase the effectiveness of the choose your own lecture style of teaching. Researchers should investigate why students may or may not desire to have choices during a lesson and what types of choices, if any, do students want to have in the classroom.

Third, building on Baker and Goodboy's (2019) study, this dissertation isolated the unique effect of the choose you own lecture style of teaching without rationales. Previous researchers (e.g., Assor et al., 2002; Vansteenkiste et al. 2018) have demonstrated the importance of providing rationales to foster students' motivational resources (i.e., basic psychological needs and autonomous motivation). Therefore, future research should investigate how these autonomy-supportive behaviors work in isolation and in tandem to allow for the comparison between the choose your own lecture style of teaching with or without demonstrating the importance of students' choices. That is, future investigations should compare the consequences of the choose your own lecture style of teaching and the choose your own lecture style of teaching coupled with meaningful rationales. In fact, Assor and his colleagues (Assor et al., 2002; Katz \& Assor, 2007) have demonstrated that communicating the value and importance of choices 
is necessary to make the provision of choice motivating.

\section{Summary}

The results of this dissertation revealed that the choose your lecture style of teaching did not intrinsically motivate students (a-path). In other words, putting students in control and allowing them to dictate the direction of a lesson seems to be ineffective in intrinsically motivating students. However, as SDT literature has consistently found, students' intrinsic motivation to learn beneficially contributed to their learning outcomes (b-path). That is, students who were intrinsically motivated, potentially due to their inherent individual interest in the subject matter, reported more positive affect for the course and topic, free-choice persistence, and perform slightly better on a short test. These results may suggest that the choose your own lecture style of teaching may not be worth instructors' time and effort to intrinsically motivate their students to learn. Perhaps, instructors should focus their efforts on implementing the other autonomy-supportive behaviors in the classroom that have been established to facilitate students' higher quality motivation. 


\section{References}

Aelterman, N., Vansteenkiste, M., Van Keer, H., \& Haerens, L. (2016). Changing teachers' beliefs regarding teacher autonomy support and structure: The role of experienced psychological need satisfaction in teacher training. Psychology of Sport and Exercise, 23, 64-72. doi:10.1016/j.psychsport.2015.10.007

Anderson, L. W., \& Krathwohl, D. R. (Eds.). (2001). A taxonomy for learning, teaching, and assessing: A revision of Bloom's taxonomy of educational objectives. New York, NY: Addison Wesley Longman.

Assor, A., Kaplan, H., \& Roth, G. (2002). Choice is good, but relevance is excellent: Autonomy-enhancing and suppressing teacher behaviours predicting students' engagement in schoolwork. British Journal of Educational Psychology, 72, 261278. doi:10.1348/000709902158883

Baker, J. P., \& Goodboy, A. K. (2018). Students' self-determination as a consequence of instructor misbehaviors. Communication Research Reports, 35, 68-73. doi:10.1080/08824096.2017.1366305

Baker, J. P., \& Goodboy, A. K. (2019). The choice is yours: The effects of autonomysupportive instruction on students' learning and communication. Communication Education, 68, 80-102. doi:10.1080/03634523.2018.1536793

Baleghizadeh, S., \& Rahimi, A. H. (2011). The relationship among listening performance, metacognitive strategy use and motivation from a self-determination theory perspective. Theory and Practice in Language Studies, 1, 61-67. doi:10.4304/tpls.1.1.61-67

Bandalos, D. B. (2018). Measurement theory and applications for the social sciences. 
New York, New York: Guilford Press.

Belmont, M., Skinner, E., Wellborn, J., \& Connell, J. (1988). Teacher as social context: A measure of student perceptions of teacher provision of involvement, structure, and autonomy support. Rochester, NY: University of Rochester.

Benware, C. A., \& Deci, E. L. (1984). Quality of learning with an active versus passive motivational set. American Educational Research Journal, 21, 755-765. doi:10.3102/00028312021004755

Black, A. E., \& Deci, E. L. (2000). The effects of instructors' autonomy support and students' autonomous motivation on learning organic chemistry: A selfdetermination theory perspective. Science Education, 84, 740-756. doi:10.1002/1098-237X200011

Bolkan, S., Goodboy, A. G., \& Kelsey, D. (2016). Instructor clarity and student motivation: Academic performance as a product of students' ability and motivation to process instructional material. Communication Education, 65, 129148. doi:10.1080/03634523.2015.1079329

Bolkan, S., \& Goodboy, A. K. (2013). No complain, no gain: Students' organizational, relational, and personal reasons for withholding rhetorical dissent from their college instructors. Communication Education, 62, 278-300. doi:10.1080/03634523.2013.788198

Brophy, J. (1987). Synthesis of research on strategies for motivating students to learn. Educational Leadership, 45, 40-48. doi:10.1080/00461528309529274

Chen, B., Vansteenkiste, M., Beyers, W., Boone, L., Deci, E. L., Van der Kaap-Deeder, J., ... Verstuyf, J. (2015). Basic psychological need satisfaction, need frustration, 
and need strength across four cultures. Motivation and Emotion, 39, 216-236. doi:10.1007/s11031-014-9450-1

Chesebro, J. L., \& McCroskey, J. C. (1998). The development of the teacher clarity short form inventory (TCSI) to measure clear teaching in the classroom. Communication Research Reports, 15, 262-266.

doi:10.1080/08824099809362122

Chettiar, C. (2015). A study of need satisfactions, causality, orientations and subjective well-being. Indian Journal of Mental Health, 2, 48-55.

Chirkov, V. I., Ryan, R. M., \& Willness, C. (2005). Cultural context and psychological needs in Canada and Brazil: Testing a self-determination theory perspective on internalization of cultural practices, identity, and well-being. Journal of CrossCultural Psychology, 36, 423-443. doi:10.1177/0022022105275960

Christophel, D. M. (1990). The relationships among teacher immediacy behaviors, student motivation, and learning. Communication Education, 39, 323-340. doi:10.1080/03634529009378813

Cooper, J. L., \& Robinson, P. (2000). The argument for making large classes seem small. In J. MacGregor, J. L. Cooper, K. A. Smith, \& P. Robinson (Eds.), Strategies for energizing large classes: From small groups to leaning communities. New directions for teaching and learning, No. 81 (pp. 5-16). San Francisco, CA: Jossey-Bass.

Cuseo, J. (2007). The empirical case against large class size: Adverse effects on the teaching, learning, and retention of first-year students. Journal of Faculty Development, 21, 5-21. 
Deci, E. L. (1971). Effects of externally mediated rewards on intrinsic motivation. Journal of Personality and Social Psychology, 18, 105-115. doi: $10.1037 / \mathrm{h} 0030644$

Deci, E. L. (1975). Intrinsic motivation. New York, NY: Plenum.

Deci, E. L., Eghrari, H., Patrick, B. C., \& Leone, D. (1994). Facilitating internalization: The self-determination theory perspective. Journal of Personality, 62, 119-142. doi:10.1111/j.1467-6494.1994.tb00797.x

Deci, E. L., Koestner, R., \& Ryan, R. M. (1999). A meta-analytic review of experiments examining the effects of extrinsic rewards on intrinsic motivation. Psychological Bulletin, 125, 627-668. doi:10.1037/0033-2909.125.6.627

Deci, E. L., Koestner, R., \& Ryan, R. M. (2001). Extrinsic rewards and intrinsic motivation in education: Reconsidered once again. Review of Educational Research, 71, 1-27. doi:10.2307/3516064

Deci, E. L., Nezlek, J., \& Sheinman, L. (1981). Characteristics of the rewarder and intrinsic motivation of the rewardee. Journal of Personality and Social Psychology, 40, 1-10. doi:10.1037/0022-3514.40.1.1

Deci, E. L., \& Ryan, R. M. (1980). The empirical exploration of intrinsic motivational processes. In L. Berkowitz (Ed.), Advances in experimental social psychology (Vol. 13, pp. 39-80). New York, NY: Academic Press.

Deci, E. L., \& Ryan, R. M. (1985a). Intrinsic motivation and self-determination in human behavior. New York, NY: Plenum Press.

Deci, E. L., \& Ryan, R. M. (1985b). The general causality orientations scale: Selfdetermination in personality. Journal of Research in Personality, 19, 109-134. 
doi:10.1016/0092-6566(85)90023-6

Deci, E. L., \& Ryan, R. M. (2002). Handbook of self-determination research. Rochester, NY: University of Rochester Press.

Deci E. L., \& Ryan, R. M. (2008). Self-determination theory: A macrotheory of human motivation, development, and health. Canadian Psychology, 49, 182-185. doi:10.1037/a0012801

Deci E. L., Schwartz, A. J., Sheinman, L., \& Ryan, R. M. (1981). An instrument to assess adults' orientations toward control versus autonomy with children: Reflections on intrinsic motivation and perceived competence. Journal of Educational Psychology, 73, 642-650. doi:10.1037/0022-0663.73.5.642

Deci, E. L., Vallerand, R. J., Pelletier, L. G., \& Ryan, R. M. (1991). Motivation and education: The self-determination perspective. Educational Psychologist, 26, 325346. doi:10.1207/s15326985ep2603\&4_6

Filak, V. F., \& Sheldon, K. M. (2008). Teacher support, student motivation, student need satisfaction, and college teacher course evaluations: testing a sequential path model. Education Psychology, 28, 711-724. doi:10.1080/01443410802337794

Flowerday, T., Schraw, G., \& Stevens, J. (2004). The role of choice and interest in reader engagement. The Journal of Experimental Education, 72, 93-114. doi:10.2307/20157361

Flunger, B., Mayer, A., \& Umbach, N. (2019). Beneficial for some or for everyone? Exploring the effects of an autonomy-supportive intervention in the real-life classroom. Journal of Educational Psychology, 111, 210-234. doi:10.1037/edu0000284 
Frisby, B. N., Mansson, D. H., \& Kaufmann, R. (2014). The cognitive learning measure: A three-study examination of validity. Communication Methods and Measures, 8, 163-176. doi:10.1080/19312458.2014.903389

Frisby, B. N., \& Martin, M. M. (2010). Instructor-student and student-student rapport in the classroom. Communication Education, 59, 146-164. doi:10.1080/03634520903564362

Frymier, A. B. (2016). Students' motivation to learn. In P. L. Witt (Ed.), Handbooks of communication science - Vol. 16: Communication and learning (pp. 378-396). Berlin, Germany: De Gruyter Mouton.

Furtak, E. M., \& Kunter, M. (2012). Effects of autonomy-supportive teaching on student learning and motivation. The Journal of Experimental Education, 80, 284-316. doi:10.1080/00220973.2011.573019

Goldman, Z. W., \& Brann, M. (2016). Motivating college students: An exploration of psychological needs from a communication perspective. Qualitative Research Reports in Communication, 17, 7-14. doi:10.1080/17459435.2015.1088890

Goldman, Z. W., Goodboy, A. K., \& Weber, K. (2016). College students' psychological needs and intrinsic motivation to learn: An examination of self-determination theory. Communication Quarterly, 65, 167-191. doi:10.1080/01463373.2016.1215338

Good, L., \& Bederson, B. B. (2002). Zoomable user interfaces as a medium for slide show presentations. Information Visualization, 1, 35-49. doi:10.1057/palgrave.ivs.9500004

Goodboy, A. K. (2011). The development and validation of the instructional dissent 
scale. Communication Education, 60, 422-440.

doi:10.1080/03634523.2011.569894

Griffin, B. W. (2016). Perceived autonomy support, intrinsic motivation, and student ratings of instruction. Studies in Educational Evaluation, 51, 116-125. doi:10.1016/j.stueduc.2016.10.007

Grolnick, W. S., \& Ryan, R. M. (1987). Autonomy in children's learning: An experimental and individual difference investigation. Journal of Personality and Social Psychology, 52, 890-898. doi:10.1037/0022-3514.52.5.890

Grouzet, F. M. E., Otis, N., \& Pelletier, L. G. (2006). Longitudinal cross-gender factorial invariance of the academic motivation scale. Structural Equation Modeling, 13, 73-98. doi:10.1207/s15328007sem1301_4

Guay, F., Ratelle, C. F., \& Chanal, J. (2008). Optimal learning in optimal contexts: The role of self-determination in education. Canadian Psychology, 49, 233-240. doi:10.1037/a0012758

Hardre, P. L., \& Reeve, J. (2003). A motivational model of rural students' intentions to persist in, versus drop out of, high school. Journal of Educational Psychology, 95, 347-356. doi:10.1037/0022-0663.95.2.347

Hayes, A. F. (2018). Introduction to mediation, moderation, and conditional process analysis: A regression-based approach (2nd ed.). New York, NY: Guilford Press.

Hidi, S., \& Renninger, K. A. (2006). The four-phase model of interest development. Educational Psychologist, 41, 111-127. doi:10.1207/s15326985ep4102_4

Hospel, V., \& Galand, B. (2016). Are both classroom autonomy support and structure equally important for students' engagement? A multilevel analysis. Learning and 
Instruction, 41, 1-10. doi:10.1016/j.learninstruc.2015.09.001

Hu, L. T., \& Bentler, P. M. (1999). Cutoff criteria for fit indexes in covariance structure analysis: Conventional criteria versus new alternatives. Structural Equation Modeling: A Multidisciplinary Journal, 6, 1-55. doi:10.1080/10705519909540118

Hull, C. L. (1943). Principles of behavior: An introduction to behavior theory. Oxford, UK: Appleton-Century.

Iyengar, S. S., \& Lepper, M. R. (2000). When choice is demotivating: Can one desire too much of a good thing? Journal of Personality and Social Psychology, 79, 9951006. doi:10.1037/0022-3514.79.6.995

Jang, H. (2008). Supporting students' motivation, engagement, and learning during and uninteresting activity. Journal of Educational Psychology, 100, 798-811. doi:10.1037/a0012841

Jang, H., Reeve, J., \& Deci, E. L. (2010). Engaging students in learning activities: It is not autonomy support or structure but autonomy support and structure. Journal of Educational Psychology, 102, 588-600. doi:10.1037/a0019682

Jang, H., Reeve, J., \& Halusic, M. (2016). A new autonomy-supportive way of teaching that increases conceptual learning: Teaching in students' preferred ways. The Journal of Experimental Education, 84, 686-701. doi:10.1080/00220973.2015.1083522

Jang, H., Reeve, J., Ryan, R. M., \& Kim, A. (2009). Can self-determination theory explain what underlies the productive, satisfying learning experiences of collectivistically oriented Korean students?. Journal of Education Psychology, 101, 644-661. doi:10.1037/a0014241 
Kasser, T., \& Ryan, R. M. (1993). A dark side of the American dream: Correlates of financial success as a central life aspiration. Journal of Personality and Social Psychology, 65, 410-422. doi:10.1037/0022-3514.65.2.410

Kasser, T., \& Ryan, R. M. (1996). Further examining the American dream: Differential correlates of intrinsic and extrinsic goals. Personality and Social Psychology Bulletin, 22, 280-287. doi:10.1177/0146167296223006

Katz, I., \& Assor, A. (2007). When choice motives and when it does not. Educational Psychology Review, 19, 429-442. doi:10.1007/s10648-006-9027-y

Kenny, D. A. (2018). Power analsis app MedPower. Learn how you can do a mediation analysis and output a text description of your results: Go to mediational analysis using DataToText using SPSS or R. Power. Retrieved from http://www.davidakenny.net/cm/mediate.htm

King, P., \& Witt, P. (2009). Teacher immediacy, confidence testing, and the measurement of cognitive learning. Communication Education, 58, 110-123. doi:10.1080/03634520802511233

Kline, R. B. (2016). Principles and practice of structural equation modeling ( $4^{\text {th }} \mathrm{ed}$.). New York, NY: Guilford Press.

Koestner, R., Ryan, R. M., Bernieri, F., \& Holt, K. (1984). Setting limits on children's behavior: The differential effects of controlling vs. informational styles of intrinsic motivation and creativity. Journal of Personality, 52, 233-248. doi:10.1111/j.1467-6494.1984.tb00879.x

Krapp, A. (2002). An educational-psychological theory of interest and its relation to SDT. In E. L. Deci \& R. M. Ryan (Eds.), Handbook of self-determination 
research (pp. 183-204). Rochester, NY: University of Rochester Press.

Kunter, M., Frenzel, A., Nagy, G., Baumert, J., \& Pekrun, R. (2011). Teacher enthusiasm: Dimensionality and context specificity. Contemporary Educational Psychology, 36, 289-301. doi:10.1016/j.cedpsych.2011.07.001

Lynch, M. F., La Guardia, J. G., \& Ryan, R. M. (2009). On being in different cultures: Ideal and actual self-concept, autonomy-support, and well-being, in China, Russia, and the United States. Journal of Positive Psychology, 4, 290-304. doi:10.1080/17439760902933765

Mazer, J. P. (2012). Development and validation of the student interest and engagement scales. Communication Methods and Measure, 6, 99-125. doi:10.1080/19312458.2012.679244

McCroskey, J. C. (1994). Assessment of affect toward communication and affect toward instruction in communication. In S. Morreale \& M. Brooks (Eds.), Assessing college student competency in communication (pp. 56-70). Annandale, VA: Speech Communication Association.

McCroskey, J. C., Richmond, V. P., Sallinen, A., Fayer, J. M., \& Barraclough, R. A. (1995). A cross-cultural and multi-behavioral analysis of the relationship between nonverbal immediacy and teacher evaluation. Communication Education, 44, 281-291. doi:10.1080/03634529509379019

Moller, A. C., Deci, E. L., \& Ryan, R. M. (2006). Choice and ego-depletion: The moderating role of autonomy. Personality and Social Psychology Bulletin, 32, 1024-1036. doi:10.1177/0146167206288008

Mozgalina, A. (2015). More or less choice? The influence of choice on task motivation 
and task engagement. System, 49, 120-132. doi:10.1016/j.system.2015.01.004

Mouratidis, A., Vansteenkiste, M., Michou, A., \& Lens, W. (2013). Perceived structure and achievement goals as predictors of students' self-regulated learning and affect and the mediating role of competence need satisfaction. Learning and Individual Differences, 23, 179-186. doi:10.1016/j.lindif.2012.09.001

Muthén, B. O., \& Muthén, \& B. O. (2017). Mplus user's guide (Version 8). Los Angeles, CA: Muthén \& Muthén.

Myers, S. A., Goodboy, A. K., \& Members of COMM 600. (2014). College student learning, motivation, and satisfaction as a function of effective instructor communication behaviors. Southern Communication Journal, 79, 14-26. doi:10.1080/1041794X.2013.815266

Neuendorf, K. A. (2002). The content analysis guidebook. Thousand Oaks, CA: Sage.

Paas, F. G. W. C. (1992). Training strategies for attaining transfer of problem-solving skill in statistics: A cognitive load approach. Journal of Educational Psychology, 84, 429-434. doi:10.1037/0022-0663.84.4.429

Patall, E. A. (2013). Constructing motivation through choice, interest, and interestingness. Journal of Educational Psychology, 105, 522-534. doi:10.1037/a0030307

Patall, E. A., Cooper, H., \& Robinson, J. C. (2008). The effects of choice on intrinsic motivation and related outcomes: A meta-analysis of research findings. Psychological Bulletin, 134, 270-300. doi:10.1037/0033-2909.134.2.270

Patall, E. A., Cooper, H., \& Wynn, S. R. (2010). The effectiveness and relative importance of choice in the classroom. Journal of Educational Psychology, 102, 
896-915. doi:10.1037/a0019545

Patall, E. A., Vasquez, A. C., Steingut, R. R., Trimble, S. S., \& Pituch, K. A. (2017). Supporting and thwarting autonomy in the high school science classroom. Cognition and Instruction, 35, 337-362. doi:10.1080/0737008.2017.1358722

Patrick, B. C., Hisley, J., \& Kempler, T. (2000). “What's everybody so excited about?”: The effects on teacher enthusiasm on student intrinsic motivation and vitality. The Journal of Experimental Education, 68, 10.1080/00220970009600093

Reber, R., Hetland, H., Chen, W., Norman, E., \& Kobbeltvedt, T. (2009). Effects of example choice on interest, control, and learning. The Journal of the Learning Sciences, 18, 509-548. doi:10.1080/10508400903191896

Reeve, J. (2002). Self-determination theory applied to educational settings. In E. L. Deci \& R. M. Ryan (Eds.), Handbook of self-determination research (pp. 183-204). Rochester, NY: University of Rochester Press.

Reeve, J. (2006). Teachers as facilitators: What autonomy-supportive teachers do and why their students benefit. The Elementary School Journal, 106, 225-236. doi: $10.1086 / 501484$

Reeve, J. (2009). Why teachers adopt a controlling motivating style toward students and how they can become more autonomy supportive. Educational Psychologist, 44, 159-175. doi:10.1080/00461520903028990

Reeve, J. (2016). Autonomy-supportive teaching: What is it, how to do it. In W. C. Liu, J. C. K., Wang, \& R. M. Ryan (Eds.), Building autonomous learners: Perspectives from research and practice using self-determination theory (pp. 129-152). New York, NY: Springer. 
Reeve, J., \& Jang, H. (2006). What teachers say and do to support students' autonomy during a learning activity. Journal of Educational Psychology, 98, 209-218. doi:10.1037/0022-0663.98.1.209

Reeve, J., Jang, H., Carrell, D., Jeon, S, \& Barch, J. (2004). Enhancing students' engagement by increasing teachers' autonomy support. Motivation and Emotion, 28, 147-169. doi:10.1023/b:moem.0000032312.95499.6f

Reeve, J., Nix, G., \& Hamm, D. (2003). Testing models of the experience of selfdetermination in intrinsic motivation and the conundrum of choice. Journal of Educational Psychology, 95, 375-392. doi:10.1037/0022-0663.95.2.375

Reis, H. T., Sheldon, K. M., Gable, S. L., Roscoe, J., \& Ryan, R. M. (2000). Daily wellbeing: The role of autonomy, competence, and relatedness. Personality and Social Psychology Bulletin, 26, 419-435. doi:10.1177/0146167200266002

Rocca, K. A. (2010). Student participation in the college classroom: An extended multidisciplinary literature review. Communication Education, 59, 185-213. doi:10.1080/03634520903505936

Ryan, R. M. (1982). Control and information in the intrapersonal sphere: An extension of cognitive evaluation theory. Journal of Personality and Social Psychology, 43, 450-461. doi: 10.1037/0022-3514.43.3.450

Ryan, R. M., \& Connell, J. P. (1989). Perceived locus of causality and internalization: Examining reasons for acting in two domains. Journal of Personality and Social Psychology, 57, 749-761. doi:10.1037/0022-3514.57.5.749

Ryan, R. M., \& Deci, E. L. (2000a). Self-determination theory and the facilitation of intrinsic motivation, social development, and well-being. American Psychologist, 
55, 68-78. doi:10.1037/0003-066X.55.1.68

Ryan, R. M., \& Deci, E. L. (2000b). The darker and brighter sides of human existence: Basic psychological needs as a unifying concept. Psychological Inquiry, 11, 319338. doi:10.1207/s15327965pli1104_03

Ryan, R. M., \& Deci, E. L. (2017). Self-determination theory: Basic psychological needs in motivation, development, and wellness. New York, NY: Guilford Press.

Ryan, R. M., Mims, V., \& Koestner, R. (1983). Relation of reward contingency and interpersonal context to intrinsic motivation: A review and test using cognitive evaluation theory. Journal of Personality and Social Psychology, 45, 736-750. doi:10.1037/0022-3514.45.4.736

Schneider, S., Nebel, S., Beege, M., \& Rey, G. D. (2018). The autonomy-enhancing effects of choice on cognitive load, motivation and learning with digital media. Learning and Instruction, 58, 161-172. doi:10.1016/j.learninstruc.2018.06.006

Schraw, G., Flowerday, T., \& Lehman, S. (2001). Increasing situational interest in the classroom. Educational Psychology Review, 13, 211-224. doi:10.2307/23363477

Schwartz, B. (2004). The paradox of choice: Why more is less. New York, NY: CCC, Harper Collins.

Sheldon, K. M., Elliot, A. J., Kim, Y., \& Kasser, T. (2001). What is satisfying about satisfying events? Testing 10 candidate psychological needs. Journal of Personality and Social Psychology, 80, 325-339. doi:10.1037/0022-3514.80.2.325

Sheldon, K. M., \& Krieger, L. S. (2007). Understanding the negative effects of legal education on law students: A longitudinal test of self-determination theory. Personality and Social Psychology Bulletin, 33, 883-897. 
doi:10.1177/0146167207301014

Sheldon, K. M., Ryan, R. M., \& Reis, H. T. (1996). What makes for a good day?: Competence and autonomy in the day and in the person. Personality and Social Psychology Bulletin, 22, 1270-1279. doi:10.1177/01461672962212007

Shiefele, U. (2009). Situational and individual interest. In K. R. Wentzel \& A. Wigfield (Eds.), Handbook of Motivation at School (pp. 197-222). New York, NY: Routledge.

Skinner, B. F. (1953). Science and human behavior. New York, NY: Macmillan.

Stefanou, C. R., Perencevich, K. C., DiCintio, M., Turner, J. C. (2004). Supporting autonomy in the classroom: Ways teachers encourage student decision making and ownership. Educational Psychologist, 39, 97-110. doi:10.1207/s15326985ep3902_2

Taylor, G., Jungert, T., Mageau, G. A., Schattke, K., Dedic, H., Rosenfield, S., \& Koestner, R. (2014). A self-determination theory approach to predicting school achievement over time: The unique role of intrinsic motivation. Contemporary Educational Psychology, 39, 342-358. doi:10.1016/j.cedpsych.2014.08.002

Thoemmes, F., MacKinnon, D. P., \& Reiser, M. R. (2010). Power analysis for complex mediational designs using monte carlo methods. Structural Equation Modeling, 17, 510-534. doi:10.1080/10705511.2010.489379

Titsworth, S., Mazer, J. P., Goodboy, A. K., Bolkan, S., \& Myers, S. A. (2015). Two meta-analyses exploring the relationship between teacher clarity and student learning. Communication Education, 64, 385-418. doi:10.1080/03634523.2015.1041998 
Vallerand, R. J., Frontier, M. S., \& Guay, F. (1997). Self-determination and persistence in a real life setting: Toward a motivational model of high school dropout. Journal of Personality and Social Psychology, 72, 1161-1176. doi:10.1037/0022-3514.72.5.1161

Vallerand, R. J., Pelletier, L. G., Blais, M. R., Briere, N. M., Senecal, C., \& Vallieres, E. F. (1992). The Academic Motivation Scale: A measure of intrinsic, extrinsic, and amotivation in education. Educational and Psychological Measurements, 52, 1003-1017. doi:10.1177/0013164492052004025

Vallerand, R. J., \& Ratelle, C. F. (2002). Intrinsic and extrinsic motivation: A hierarchical model. In E. L. Deci \& R. M. Ryan (Eds.), Handbook of selfdetermination research (pp. 37-63). Rochester, NY: University of Rochester Press.

Vansteenkiste, M., Aelterman, N., Muynck, G. D., Haerens, L., Patall, E., \& Reeve, J. (2018). Fostering personal meaning and self-relevance: A self-determination theory perspective on internalization. The Journal of Experimental Education, 86, 30-49. doi:10.1080/00220973.2017.1381067

Vansteenkiste, M., Sierens, E., Goossens, L., Soenens, B., Dochy, F., Mouratidis, A., ... Beyers, W. (2012). Identifying configurations of perceived teacher autonomy support and structure: Associations with self-regulated learning, motivation, and problem behavior. Learning and Instruction, 22, 431-439. doi:10.1016/j.learninstruc.2012.04.002

Vansteenkiste, M., Simons, J., Lens, W., Sheldon, K. M., \& Deci, E. L. (2004). Motivating learning, performance, and persistence: the synergistic role of intrinsic 
goals and autonomy support. Journal of Personality and Social Psychology, 87, 246-260. doi:10.1037/0022-3514.87.2.246

Vansteenkiste, M., Zhou, M., Lens, W., \& Sioenens, B. (2005). Experiences of autonomy and control among Chinese learners: Vitalizing or immobilizing. Journal of Educational Psychology, 97, 468-483. doi:10.1037/1122-0663.97.3.468

Wang, C. K., Ng, B. L. L., Liu, W. C., \& Ryan, R. M. (2016). Can being autonomysupportive in teaching improve students' self-regulation and performance?. In W.

C. Liu, J. C. K. Wang, \& R. M. Ryan (Eds.), Building autonomous learners: Perspectives from research and practice using self-determination theory (pp. 227243). New York, NY: Springer.

Wanzer, M. B., Frymier, A. B., \& Irwin, J. (2010). An explanation of the relationship between instructor humor and student learning: Instructional humor processing theory. Communication Education, 59, 1-18. doi:10.1080/03634520903367238

Weber, K., Corrigan, M., Fornash, B., \& Neupauer, N. C. (2003). The effect of interest on recall: An experiment. Communication Research Methods, 20, 116-123. doi:10.1080/08824090309388807

Wigfield, A., \& Eccles, J. S. (2000). Expectancy-value theory of achievement motivation. Contemporary Educational Psychology, 25, 68-81. doi:10.1006/ceps.1999.1015

Williams, S. (1998). An organizational model of choice: A theoretical analysis differentiating choice, personal control, and self-determination. Genetic, Social \& General Psychology Monographs, 124, 465-492.

Williams, J. D., Wallace, T. L., \& Sung, H. C. (2015). Providing choice in middle grade classrooms: An exploratory study of enactment variability and student reflection. 
Journal of Early Adolescence, 36, 527-550. doi:10.1177/0272431615570057

Wolf, E. J., Harrington, K. M., Clark, S. L., \& Miller, M. W. (2013). Sample size requirements for structural equation models: An evaluation of power, bias, and solution propriety. Educational and Psychological Measurement, 73, 913-934. doi:10.1177/0013164413495237

Zhang, Q. (2014). Assessing the effects of instructor enthusiasm on classroom engagement, learning goal orientation, and academic self-efficacy. Communication Teacher, 28, 44-56. doi:10.1080/17404622.2013.839047

Zuckerman, M., Porac, J., Lathin, D., Smith, R., \& Deci, E. L. (1978). On the importance of self- determination for intrinsically-motivated behavior. Personality and Social Psychology Bulletin, 4, 443-446. doi:10.1177/014616727800400317 


\section{APPENDICES}

\section{Appendix A}

\section{Study Advertisement/Cover Letter}

Hello WVU Students enrolled in a communication studies course,

My name is James Baker and I am a Ph.D. student in the Communication Studies Department here at West Virginia University. If you are a student at West Virginia University, are over the age of 18, and are currently enrolled in a Communication Studies course, you are eligible to participate in a WVU IRB-approved 2-PART research study that is part of my doctoral dissertation examining how students react to live lectures.

As a WVU student, you may earn extra credit for participation in this research study. To find out if you are eligible, please consult your course syllabus for your instructor's policy on extra credit. Please know that there are two parts to this research study that amount to a total of 1 hour of research extra credit (part $1=10$ minutes $\&$ part $2=50$ minutes).

\section{PART 1:}

The first part of this study will take approximately 10 minutes to complete an online survey. Once you complete this first survey at the link below, you will be provided with reminder information on the second part of this study that will take place one week later in the semester. If you wish to participate in this research study, you can follow the link below to complete the survey. If you do not complete the first part of this study, you will not be eligible to complete the second part of this study.

Link to (Part 1) survey:

\section{https://wvu.qualtrics.com/jfe/form/SV e5nmiVXx9RVU0It}

\section{PART 2:}

Also, to participate in this study you must have a smartphone and be able to attend part 2 of this study which is a live lecture scheduled in (INSERT LOCATION) on (INSERT DATE) and (INSERT DATE) from (INSERT TIME). To be a participant in part 2 of this study, you must be available to attend both days.

This study has been approved by West Virginia University's Institutional Review Board, and is on file as Protocol \#1812376106. This study is being conducted by James Baker and Dr. Alan K. Goodboy, if you would like more information about this research project, feel free to contact Co-investigator James Baker at jpb0020@mix.wvu.edu. Upon completing both parts of this study, your instructor will be emailed a confirmation of your participation in this 1 hour study.

Thank you very much for your interest in our study.

\author{
All the best, \\ Dr. Alan Goodboy \\ Professor \\ Principal Investigator \\ agoodboy@mail.wvu.edu
}

\author{
James Baker \\ Ph.D. Candidate \\ Co-investigator \\ Jpb0020@mix.wvu.edu
}


Appendix B

\section{Email Recruitment Script}

If you are a student at West Virginia University, are over the age of 18, and are currently enrolled in a Communication Studies course, you are eligible to participate in a WVU IRB-approved 2PART research study examining how students react to live lectures. This research is for a doctoral dissertation in the Department of Communication Studies here at WVU.

As a WVU student, you may earn extra credit for participation in this research study. To find out if you are eligible, please consult your course syllabus for your instructor's policy on extra credit. Please know that there are two parts to this research study that amount to a total of 1 hour of research extra credit (part $1=10$ minutes $\&$ part $2=50$ minutes).

\section{PART 1:}

The first part of this study will take approximately 10 minutes to complete an online survey. Once you complete this first survey at the link below, you will be provided with reminder information on the second part of this study that will take place one week later in the semester. If you wish to participate in this research study, you can follow the link below to complete the survey. If you do not complete the first part of this study, you will not be eligible to complete the second part of this study.

Link to (Part 1) survey:

https://wvu.qualtrics.com/jfe/form/SV_e5nmiVXx9RVU0It

\section{PART 2:}

Also, to participate in this study you must have a smartphone and be able to attend part 2 of this study which is a live lecture scheduled in (INSERT LOCATION) on (INSERT DATE) and (INSERT DATE) from (INSERT TIME). To be a participant in part 2 of this study, you must be available to attend both days.

This study has been approved by West Virginia University's Institutional Review Board, and is on file as Protocol \#1812376106. This study is being conducted by James Baker and Dr. Alan K. Goodboy, if you would like more information about this research project, feel free to contact Coinvestigator James Baker at jpb0020@ mix.wvu.edu. Upon completing both parts of this study, your instructor will be emailed a confirmation of your participation in this 1 hour study.

Thank you very much for your interest in our study.

All the best,

Dr. Alan Goodboy

Professor

Principal Investigator

agoodboy@mail.wvu.edu
James Baker

Ph.D. Candidate

Co-investigator

Jpb0020@mix.wvu.edu 


\author{
Appendix C \\ Reminder Email for Study
}

***Email that will be sent the day of live lecture experiment.***

Subject line of email: Reminder for TODAY'S study you signed up to receive extra credit in your Communication Studies course

Hello Participant!

Recently, you were invited and signed-up to participate in a WVU IRB-approved 2PART research study examining how students react to live lectures (IRB protocol \#1812376106).

Thank you for completing part one of this study, but the researchers wanted to send you a courtesy reminder that part 2 of this study will be taking place TODAY.

To participate in part 2 of this study you must: (a) attend the live lecture on (INSERT DESIGNATED DATE) in (INSERT LOCATION) from (INSERT TIME) and (b) bring your smartphone with you.

We ask that you show up at least 5 minutes before (INSERT START TIME) so we can start the lesson on time and send you on your way.

See you TODAY in (INSERT LOCATION) no later than (INSERT START TIME)!

All the best,

James Baker and Dr. Alan Goodboy

This study is being conducted by James Baker and Dr. Alan K. Goodboy, if you would like more information about this research project, feel free to contact Co-investigator James Bakerat.jpb0020@mix.wvu.edu 
Appendix D

Debrief Email

\section{Subject line of email: More information about the study you completed this evening!}

Good evening all!

The researcher (James Baker) wanted to take a moment to provide you with some important information regarding the lecture you attended this evening. As you already know, the lesson you attended was part of a research study conducted by James Baker who is a doctoral student and Dr. Alan Goodboy who is a Full Professor, both of who work in the department of Communication Studies here at West Virginia University. The purpose of this study was to examine if an instructor who gives choices during their instruction will impact students' motivation, learning, and communication.

The lecturer told you today that he was teaching you about environmental communication to receive feedback and suggestions on his teaching. However, James was really trained and either gave you choices or made sure you had no choices during instruction. Additionally, concluding the lecture you were given the opportunity to sign-up for the 5 options to learn more about environmental communication. Unfortunately, these were created by the researchers and will not be taking place this semester as stated during the lesson. This does constitute deception and the researchers wanted to make you aware of this.

That being said, please know that the packet of information you provided to the researchers will be kept confidential and will in no way affect your academic standing at the university.

The researchers welcome any questions that you may have and are happy to discuss the results of the study once the data analyses are completed in a few months. You are welcome to contact the principle investigator, Dr. Alan Goodboy, at agoodboy@mail.wvu.edu. Or the Co-investigator, James Baker, at jpb0020@mix.wvu.edu

Thank you again for your help on my dissertation. I greatly appreciate your participation.

All the best,

James Baker

$\mathrm{Ph} . \mathrm{D}$. Candidate

Co-investigator

Jpb0020@mix.wvu.edu
Dr. Alan Goodboy

Professor

Principal Investigator

agoodboy@mail.wvu.edu 
Appendix E

13-item Test

Instructions: You were introduced to new concepts related to environmental communication and climate change. Time to put your knowledge to the test. Circle the correct answer.

1) Climate change can best be described as?

a. The day-to-day changes in weather

b. The day-to-day changes in climate

c. How the atmosphere "behaves" over a relatively long period of time

d. The growing number and intensity of storms

On a scale ranging from $0 \%$ to $100 \%$, how confident are you that you provided the correct answer to question 1 ?

On a scale ranging from 0 to 100 , how difficult was question 1 ?

2) describes an upward trend in global temperatures, whereas describes a phenomenon responsible for sea level rises, variable changes in weather patterns, and shifts in growing seasons.

a. Climate change; Global Warming

b. Global warming; Climate change

c. The greenhouse effect; Global warming

d. Climate change; The greenhouse effect

On a scale ranging from $0 \%$ to $100 \%$, how confident are you that you provided the correct answer to question 2 ?

On a scale ranging from 0 to 100 , how difficult was question 2 ?

3) Based on what you learned about risk communication, which of the following objectives of the Environmental Protection Agency (EPA) is most directly involved in the communication of risk?

a. Identify, protect, and preserve endangered and threatened species.

b. Develop regulations and establish national standards for the enforcement of environmental legislation.

c. Share information with governmental organizations and businesses to improve risk understanding that help people act responsibly.

d. Identify and research known environmental problems in order to prescribe remedies and remediation measures, and proscribe activities that contribute to the problems.

On a scale ranging from $0 \%$ to $100 \%$, how confident are you that you provided the correct answer to question 3?

On a scale ranging from 0 to 100 , how difficult was question 3 ? 
4) Organizations such as the Environmental Protection Agency (EPA) assess risk from environmental stressors like ocean acidification and desertification. To these organizations, risk is a function of and
a. Severity; Likelihood
b. Impact; Outrage
c. Costs; Benefits
d. Exposure; Probability

On a scale ranging from $0 \%$ to $100 \%$, how confident are you that you provided the correct answer to question 4 ?

On a scale ranging from 0 to 100 , how difficult was question 4 ?

5) Organizations conduct risk assessments and typically follow a 4-step procedure. Based on what you learned today, which of the following was NOT mentioned as step in assessing risks:

a. Detecting the potential source of danger

b. Developing a plan to manage the danger

c. Calculating the potential impact of exposure

d. Assessing the total amount of acceptable risk

On a scale ranging from $0 \%$ to $100 \%$, how confident are you that you provided the correct answer to question 5 ?

On a scale ranging from 0 to 100 , how difficult was question 5 ?

6) refers to the process or method for bridging the gap between science and the public, so the public can more accurately weigh costs and benefits and make informed decisions regarding environmental issues.
a. Advocacy campaigning
b. Green persuasion
c. Risk communication
d. Communicating sustainability

On a scale ranging from $0 \%$ to $100 \%$, how confident are you that you provided the correct answer to question 6 ?

On a scale ranging from 0 to 100 , how difficult was question 6 ? 
7) The company Patagonia has successfully connected its products and services with environmentally-friendly initiatives and being "green" in the minds of consumers. Based on what you learned from the lesson today, Patagonia is engaging in which of the following methods?
a. Greenwashing
b. Green consumerism
c. Green persuasion
d. Green marketing

On a scale ranging from $0 \%$ to $100 \%$, how confident are you that you provided the correct answer to question 7 ?

\section{On a scale ranging from 0 to 100 , how difficult was question 7 ?}

8) Unfortunately, the clothing business you own has been accused of engaging in some less than eco-friendly behaviors. To distract the public's attention from these bad practices, you decide to rebrand your clothing with an advertising campaign that features people wearing your apparel in forests, kayaking, and cleaning up beaches, and incorporate a cute panda in the brand label. This business strategy is best described as an example of:
a. Greenwashing
b. Green consumerism
c. Green persuasion
d. Green marketing

On a scale ranging from $0 \%$ to $100 \%$, how confident are you that you provided the correct answer to question 8 ?

On a scale ranging from 0 to 100 , how difficult was question 8 ?

9) Today we talked about three different frames used in green marketing. Imagine that your clothing company has decided to come out with a new line of jeans that are made from recycled materials, which you make sure to advertise to all your customers. Based on what you learned today, which type of frame would this be?
a. Nature as backdrop
b. Nature as outcome
c. Nature as product
d. Nature as company

On a scale ranging from $0 \%$ to $100 \%$, how confident are you that you provided the correct answer to question 9?

On a scale ranging from 0 to 100 , how difficult was question 9? 
10) Now, imagine that your clothing company has decided to come out with a new line of winter jackets. To advertise these jackets, you use vivid images of people wearing your jackets hiking in forests, climbing massive mountains, and kayaking through beautiful artic ice caps. Which type of frame would this be?
a. Nature as backdrop
b. Nature as outcome
c. Nature as product
d. Nature as company

On a scale ranging from $0 \%$ to $100 \%$, how confident are you that you provided the correct answer to question 10 ?

On a scale ranging from 0 to 100 , how difficult was question 10 ?

11) An advocacy campaign can best be described as?

a. A strategic course of action to achieve a specific purpose.

b. Improving a brands image by promoting green initiatives.

c. A strategic method of persuasion to distract consumers from poor economic practices.

d. An objective and empirical way of criticizing an environmental policy.

On a scale ranging from $0 \%$ to $100 \%$, how confident are you that you provided the correct answer to question 11 ?

On a scale ranging from 0 to 100 , how difficult was question 11 ?

12) We talked about four essential features of an advocacy campaign. Based on that discussion, which of the following is NOT a feature of advocacy campaigns?

a. Campaigns target small numbers of influential people

b. Campaigns include several communication activities

c. Campaigns are purposeful

d. Campaigns have a time limit

On a scale ranging from $0 \%$ to $100 \%$, how confident are you that you provided the correct answer to question 12 ?

On a scale ranging from 0 to 100 , how difficult was question 12 ?

13) Imagine you are trying to develop a campaign to get policy makers to pass a very important water bill that will restrict major corporations from polluting water supplies. To create a successful campaign, you decide to target two major corporations and try to convince their investors to delay their future contributions to their business and politicians until the bill passes. This method reflects which feature of what we learned about successful advocacy campaigns?

a. Develop a clear and concrete objective

b. Use specific strategies to influence decision makers

c. Identify important decision makers

d. Influence the secondary audience to eventually persuade the primary audience

On a scale ranging from $0 \%$ to $100 \%$, how confident are you that you provided the correct answer to question 13 ?

On a scale ranging from 0 to 100 , how difficult was question 13 ? 
Appendix F

Pilot Study \# 1

\section{Coding Sheets}

Bloom Taxonomy

\begin{tabular}{|c|c|c|c|c|c|c|}
\hline & Remember & Understand & Apply & Analyze & Evaluate & Create \\
\hline & $\begin{array}{l}\text { Retrieve } \\
\text { relevant } \\
\text { knowledge } \\
\text { from long-term } \\
\text { memory }\end{array}$ & $\begin{array}{l}\text { Construct meaning from } \\
\text { instructional messages, } \\
\text { including oral, written, } \\
\text { and graphic } \\
\text { communication }\end{array}$ & $\begin{array}{l}\text { Carry out or } \\
\text { use a procedure } \\
\text { in a given } \\
\text { situation }\end{array}$ & $\begin{array}{l}\text { Break material into } \\
\text { constituent parts } \\
\text { and determine how } \\
\text { parts relate to one } \\
\text { another and to an } \\
\text { overall structure or } \\
\text { purpose }\end{array}$ & $\begin{array}{l}\text { Make } \\
\text { judgments } \\
\text { based on } \\
\text { criteria and } \\
\text { standards }\end{array}$ & $\begin{array}{l}\text { Put elements together } \\
\text { to form a coherent or } \\
\text { functional whole; } \\
\text { reorganize elements } \\
\text { into a new pattern or } \\
\text { structure }\end{array}$ \\
\hline & $\begin{array}{l}\text { Keywords: } \\
\text { Recognize \& } \\
\text { recall }\end{array}$ & $\begin{array}{l}\text { Keywords: Interpreting, } \\
\text { exemplifying, } \\
\text { classifying, } \\
\text { summarizing, inferring, } \\
\text { comparing, explaining }\end{array}$ & $\begin{array}{l}\text { Keywords: } \\
\text { Executing, } \\
\text { implementing }\end{array}$ & $\begin{array}{l}\text { Keywords: } \\
\text { Differentiating, } \\
\text { organizing, } \\
\text { attributing }\end{array}$ & $\begin{array}{l}\text { Keywords: } \\
\text { Checking, } \\
\text { critiquing }\end{array}$ & $\begin{array}{l}\text { Keywords: } \\
\text { Generating, planning, } \\
\text { producing }\end{array}$ \\
\hline Researcher & $\begin{array}{l}\text { Q1, Q2, Q3, } \\
\text { Q4, Q6, Q11 }\end{array}$ & Q5, Q7, Q12 & $\begin{array}{l}\text { Q8, Q9, Q10, } \\
\text { Q13 }\end{array}$ & & & \\
\hline Expert & $\begin{array}{l}\text { Q1, Q2, Q4, } \\
\text { Q5, Q6, Q11 }\end{array}$ & Q3, Q7, Q8, Q12 & Q9, Q10, Q13 & & & \\
\hline
\end{tabular}

Learning Objectives

\begin{tabular}{|c|c|c|c|c|c|c|}
\hline & $\begin{array}{l}\text { Recall the } \\
\text { difference } \\
\text { between } \\
\text { climate change } \\
\text { and global } \\
\text { warming. }\end{array}$ & $\begin{array}{l}\text { Remember the } \\
\text { definition and } \\
\text { goal of risk } \\
\text { communication. }\end{array}$ & $\begin{array}{l}\text { Understand the } \\
4 \text { steps of } \\
\text { conducting risk } \\
\text { assessment. }\end{array}$ & $\begin{array}{l}\text { Understand the } \\
\text { two methods of } \\
\text { communicating } \\
\text { sustainability } \\
\text { (green marking \& } \\
\text { green washing). }\end{array}$ & $\begin{array}{l}\text { Apply the two methods } \\
\text { of communicating } \\
\text { sustainability (green } \\
\text { marking \& green } \\
\text { washing) including the } \\
\text { three frames of green } \\
\text { marketing to your own } \\
\text { business practices. }\end{array}$ & $\begin{array}{l}\text { Understand } \\
\text { advocacy } \\
\text { campaigns and } \\
\text { the four features } \\
\text { necessary to } \\
\text { create a } \\
\text { successful } \\
\text { campaign. }\end{array}$ \\
\hline Researcher & $\mathrm{Q} 1, \mathrm{Q} 2$ & Q3, Q4, Q6 & Q5 & Q7 & Q8, Q9, Q10 & Q11, Q12, Q13 \\
\hline Expert & $\mathrm{Q} 1, \mathrm{Q} 2$ & Q3, Q4, Q6 & Q5 & Q7, Q8 & Q9, Q10 & Q11, Q12, Q13 \\
\hline
\end{tabular}


Pilot Study \# 2

Bloom Taxonomy

\begin{tabular}{|l|l|l|l|l|l|l|}
\hline & \multicolumn{1}{|c|}{ Remember } & \multicolumn{1}{|c|}{ Understand } & \multicolumn{1}{|c|}{ Apply } & \multicolumn{1}{c|}{ Analyze } & Evaluate & \multicolumn{1}{c|}{ Create } \\
\hline & $\begin{array}{l}\text { Retrieve relevant } \\
\text { knowledge from } \\
\text { long-term } \\
\text { memory }\end{array}$ & $\begin{array}{l}\text { Construct meaning from } \\
\text { instructional messages, } \\
\text { including oral, written, and } \\
\text { graphic communication }\end{array}$ & $\begin{array}{l}\text { Carry out or use } \\
\text { a procedure in a } \\
\text { given situation }\end{array}$ & $\begin{array}{l}\text { Break material } \\
\text { into constituent } \\
\text { parts and } \\
\text { determine how } \\
\text { parts relate to one } \\
\text { another and to an } \\
\text { overall structure } \\
\text { or purpose }\end{array}$ & $\begin{array}{l}\text { Make } \\
\text { judgments } \\
\text { based on } \\
\text { criteria and } \\
\text { standards }\end{array}$ & $\begin{array}{l}\text { Put elements } \\
\text { together to form a } \\
\text { coherent or } \\
\text { functional whole; } \\
\text { reorganize } \\
\text { elements into a } \\
\text { new pattern or } \\
\text { structure }\end{array}$ \\
\hline & $\begin{array}{l}\text { Keywords: } \\
\text { Recognize \& } \\
\text { recall }\end{array}$ & $\begin{array}{l}\text { Keywords: Interpreting, } \\
\text { exemplifying, classifying, } \\
\text { summarizing, inferring, } \\
\text { comparing, explaining }\end{array}$ & $\begin{array}{l}\text { Keywords: } \\
\text { Executing, } \\
\text { implementing }\end{array}$ & $\begin{array}{l}\text { Keywords: } \\
\text { Differentiating, } \\
\text { organizing, } \\
\text { attributing }\end{array}$ & $\begin{array}{l}\text { Keywords: } \\
\text { Checking, } \\
\text { critiquing }\end{array}$ & $\begin{array}{l}\text { Keywords: } \\
\text { Generating, } \\
\text { planning, } \\
\text { producing }\end{array}$ \\
\hline Researcher & $\begin{array}{l}\text { Q1, Q2, Q4, Q6, } \\
\text { Q11 }\end{array}$ & $\begin{array}{l}\text { Q3, Q5, Q7, Q8, Q9, Q10, } \\
\text { Q12, Q13, Q14, Q15 }\end{array}$ & & & & \\
\hline Expert & $\begin{array}{l}\text { Q1, Q2, Q3, Q4, } \\
\text { Q5, Q6, Q11 }\end{array}$ & $\begin{array}{l}\text { Q7, Q8, Q9, Q10, Q12, } \\
\text { Q13, Q14, Q15 }\end{array}$ & & & & \\
\hline
\end{tabular}

Learning Objectives

\begin{tabular}{|c|c|c|c|c|c|}
\hline & $\begin{array}{l}\text { Recall the } \\
\text { difference } \\
\text { between climate } \\
\text { change and } \\
\text { global warming. }\end{array}$ & $\begin{array}{l}\text { Remember the } \\
\text { definition and } \\
\text { goal of risk } \\
\text { communication. }\end{array}$ & $\begin{array}{l}\text { Understand the } 4 \\
\text { steps of conducting } \\
\text { risk assessment. }\end{array}$ & $\begin{array}{l}\text { Understand the two } \\
\text { methods of communicating } \\
\text { sustainability (green } \\
\text { marking \& green washing) } \\
\text { including the three frames } \\
\text { of green marketing. }\end{array}$ & $\begin{array}{l}\text { Understand advocacy } \\
\text { campaigns and the four } \\
\text { features necessary to create a } \\
\text { successful campaign. }\end{array}$ \\
\hline Researcher & Q1, Q2 & Q4, Q6 & Q3, Q5 & Q7, Q8, Q9, Q10 & Q11, Q12, Q13, Q14, Q15 \\
\hline Expert & $\mathrm{Q} 1, \mathrm{Q} 2$ & Q6 & Q3, Q4, Q5 & Q7, Q8, Q9, Q10 & Q11, Q12, Q13, Q14, Q15 \\
\hline
\end{tabular}


Main Study Coding rubric for Conceptual Learning Question

\section{Clear and concrete objective}

a. Advocacy campaigns hone in on a single very specific action, event, or decision to move campaign to its broader goal:

b. EX: stopping landfills across North Eastern Seaboard or in Midwest, stopping the sale of shark fins, improving watering methods for crops

\section{Determine important decision makers}

a. Determine the primary and secondary audience

b. Target the people that can make your desired change and the individuals that can urge them to act.

c. EX: convincing news outlet to urge policy makers, targeting law makers, targeting governmental agencies

3. Use specific strategies to influence decision makers

a. Have a critical source of influence or leverage that if implemented is able to persuade a primary decision maker

b. EX: boycott a company's product, have people divest their holdings, etc.

\begin{tabular}{|c|c|c|c|}
\hline $\mathbf{0}$ & 1 & 2 & 3 \\
\hline No conceptual learning & Low conceptual learning & Moderate conceptual learning & High conceptual learning \\
\hline $\begin{array}{l}\text { No answer was given; } \\
\text { The wrong answers were } \\
\text { given to all three parts }\end{array}$ & $\begin{array}{l}\text { Only one of the three parts } \\
\text { were answered correctly } \\
2 \text { or } 3 \text { parts were answered } \\
\text { correctly, but examples were } \\
\text { incorrect or missing } \\
\text { Introduced the terms, but did } \\
\text { not define }\end{array}$ & $\begin{array}{l}\text { Two of the three parts were } \\
\text { answered correctly including } \\
\text { definitions. } \\
\text { All three parts were answered } \\
\text { correctly and fully, but missing } 1 \text { or } \\
2 \text { examples }\end{array}$ & $\begin{array}{l}\text { All three parts were answered } \\
\text { correctly and fully } \\
\text { All three parts include correct } \\
\text { examples }\end{array}$ \\
\hline
\end{tabular}


Appendix G

Pilot Study \# 1 Survey

\section{1) Sex (Circle One):}

Male

Female

Nonbinary

Female to Male Transgender

Male to Female Transgender

Other

Prefer not to answer

2) Age:

\section{INSERT (CONTROL/TREATMENT) LECTURE SCRIPT HERE}

Below is a list of common instructor behaviors. Please indicate the degree to which you agree James (lecturer) engaged in each of the following behaviors. Write your answer in the space provided. There is neither a right nor wrong answer.

\begin{tabular}{|ccccc|}
\hline $\begin{array}{c}\text { Strongly } \\
\text { Disagree }\end{array}$ & Disagree & Neutral & Agree & Strongly \\
1 & 2 & 3 & 4 & Agree \\
\hline
\end{tabular}

1. The teacher gave students a lot of choices during the lesson.

2. The teacher did not give students much choice over the information discussed during the lesson.

3. When it comes to the lesson, the teacher gave students all kinds of things to choose from.

4. The teacher did not give students a chance to choose anything about the lesson.

5. The teacher did not give students many choices when it comes to the information presented during the lesson. 
List (no need to explain) the three most important theoretical concepts you recall learning from the lesson you just read. In other words, focus on general (theoretical or conceptual) principles about communication rather than specific do's and don'ts. Do this from memory. Please do not review the lecture scripts.

1.

2.

3.

Please indicate (circle) on the scale below how confident you feel that the three principles that you listed are, in fact, the three most important principles from the lesson.

\begin{tabular}{|l|l|l|l|l|l|l|l|l|l|l|l|}
\hline Not confident & 1 & 2 & 3 & 4 & 5 & 6 & 7 & 8 & 9 & 10 & Highly confident \\
\hline Certain & 1 & 2 & 3 & 4 & 5 & 6 & 7 & 8 & 9 & 10 & Not at all certain \\
\hline Not at all sure & 1 & 2 & 3 & 4 & 5 & 6 & 7 & 8 & 9 & 10 & Highly assured \\
\hline
\end{tabular}

INSERT 13-ITEM TEST HERE 
Appendix $\mathrm{H}$

Pilot Study \# 2 Survey

PLAY (CONTROL/TREATMENT) LECTURE AUDIO FILE

\section{1) Sex (Circle One):}

Male

Female to Male Transgender

Prefer not to answer
Female

Male to Female Transgender
Nonbinary

Other

2) Age:

Below is a list of common instructor behaviors. Please indicate the degree to which you agree James (lecturer) engaged in each of the following behaviors. Write your answer in the space provided. There is neither a right nor wrong answer.

\begin{tabular}{|c|cccc|}
\hline $\begin{array}{c}\text { Strongly } \\
\text { Disagree }\end{array}$ & Disagree & Neutral & Agree & $\begin{array}{c}\text { Strongly } \\
\text { Agree }\end{array}$ \\
$\mathbf{1}$ & $\mathbf{2}$ & $\mathbf{3}$ & $\mathbf{4}$ & $\mathbf{5}$ \\
\hline
\end{tabular}

1. The teacher gave students a lot of choices during the lesson.

2. The teacher did not give students much choice over the information discussed during the lesson.

3. When it comes to the lesson, the teacher gave students all kinds of things to choose from.

4. The teacher did not give students a chance to choose anything about the lesson.

5. The teacher did not give students many choices when it comes to the information presented during the lesson. 
Please indicate the degree to which you agree with the following statements. Write your answer in the space provided. There is neither a right nor wrong answer.

\begin{tabular}{|ccccc|}
\hline $\begin{array}{c}\text { Strongly } \\
\text { Disagree }\end{array}$ & Disagree & Neutral & Agree & $\begin{array}{c}\text { Strongly } \\
\text { Agree }\end{array}$ \\
1 & 2 & 3 & 4 & 5 \\
\hline
\end{tabular}

1. I have learned a great deal from this lesson.

2. I have learned more in other lessons than in this lesson.

3. My knowledge on this topic has increased since the beginning of the lesson.

4. I have learned nothing from this lesson.

5. I can see clear changes in my understanding of this topic.

6. I did not understand what I learned from this lesson.

7. I can clearly recall what I have learned from this lesson.

8. I am unable to recall what I have learned from this lesson.

9. I would be unable to use this information from this lesson.

10. I have learned information that I can apply.

\section{I am interested in this lesson because...}

1.... I can remember the lesson material.

2. ... I feel like I am learning topics covered in the lesson.

3. ... I can understand the flow of ideas.

4. ... I understand the lesson material.

5....The information covered in the lesson is making me more knowledgeable.

6. ...The information in the lesson is useful.

7. ... I realize what is expected of me. 
Appendix I

Pilot Study \# 3 Survey

\section{1) Sex (Circle One):}

Male

Female

Nonbinary

Female to Male Transgender

Male to Female Transgender

Other

Prefer not to answer

2) Age:

INSERT REVISED 15-ITEM TEST HERE 


\section{Appendix $\mathbf{J}$}

\section{Revised 15-item Test}

\section{Test}

Instructions: You were introduced to new concepts related to environmental communication and climate change. Time to put your knowledge to the test. Circle the correct answer.

1) describes long term changes in weather patterns and how the atmosphere "behaves" over a relatively long period of time.
a. The greenhouse effect
b. Global warming
c. The atmospheric warming effect
d. Climate change

2) describes an upward temperature trend across the entire Earth.
a. The greenhouse effect
b. Global warming
c. The atmospheric warming effect
d. Climate change

3) describes the third step of risk assessment focused on calculating the potential impact of an environmental issue.
a. Exposure assessment
b. Risk characterization
c. Dose-response assessment
d. Hazard identification

4) To organizations like the Environmental Protection Agency (EPA) risk is a function of and
a. Severity; Likelihood
b. Impact; Panic
c. Costs; Rewards
d. Contact; Mortality

5) describes the first step of risk assessment focused on identifying the source of danger of some environmental issue.
a. Exposure assessment
b. Risk characterization
c. Dose-response assessment
d. Hazard identification 
6) is when organizations show people the problems of an environmental issue so people can make an informed decision about that issue.
a. Green Marketing
b. Green persuasion
c. Communicating sustainability
d. Risk communication

7) Companies like Patagonia connect their clothing, products, and mission statement with outdoorsy images and being environmentally friendly. Patagonia is engaging in which of the following methods?
a. Greenwashing
b. Risk assessment
c. Product placement
d. Green marketing

8) If corporations, for example BP, cause massive oil spills and want to repair their company's image or identity, they rely on which of the following methods?
a. Greenwashing
b. Risk assessment
c. Product placement
d. Green marketing

9) Companies often advertise their products as organic, all natural, or made from recycled materials, which describes the frame of green marketing.
a. Nature as backdrop
b. Nature as outcome
c. Nature as product
d. Nature as company

10) Commercials for SUVs often show their vehicles crossing all sorts of terrain and driving through beautiful forests, which describes the frame of green marketing.
a. Nature as backdrop
b. Nature as outcome
c. Nature as product
d. Nature as company 
11) describes situations in which organizations or a groups of people come together to make a specific environmental change that must be achieved by some deadline.

a. Communicating sustainability

b. Advocacy campaigning

c. Green persuasion

d. Risk communication

12) The third feature of a successful advocacy campaign focuses on persuading policy members (primary audience) to make a desired change is known as

a. developing clear and concrete objectives

b. identifying important decision makers

c. implementing specific sources of leverage to persuade decision makers

d. deciding on a plan of action to reach the masses

13) The second feature of a successful advocacy campaign focuses on researching and isolating the specific policy makers who have the authority to make a change is known as

a. developing clear and concrete objectives

b. identifying important decision makers

c. implementing specific sources of leverage to persuade decision makers

d. deciding on a plan of action to reach the masses

14) Advocacy campaigns focus on very specific outcomes that are intended to result from the efforts of the campaign. This describes which of the following features of advocacy campaigns?

a. Campaigns target a large audience

b. Campaigns include several communication activities

c. Campaigns are purposeful

d. Campaigns have a time limit

15) An advocacy campaign's message must be clear and consistent in all events or activities associated with the campaign. This describes which of the following features of advocacy campaigns?

a. Campaigns target a large audience

b. Campaigns include several communication activities

c. Campaigns are purposeful

d. Campaigns have a time limit 


\section{Appendix K}

\section{Lecture Scripts}

\section{Learning Outcomes}

\section{$\underline{\text { Environmental Communication }}$}

Recall the difference between climate change and global warming.

Remember the definition and goal of risk communication.

Understand the 4 steps of conducting risk assessment.

Understand the two methods of communicating sustainability (green marking \& green washing) including the three frames used in green marketing.

Understand advocacy campaigns and the four features necessary to create a successful campaign.

\section{OPENNING MESSAGE TO LECTURE}

Instructor: Good evening, thank you all for coming to this live lecture on environmental communication. My name is James Baker and I am $3^{\text {rd }}$ year doctoral student finishing up my degree here at WVU. I plan on pursuing a career in teaching and my advisor suggested that I practice teaching several different topics and get feedback from students. I appreciate you all being here to help me with my teaching and my research.

Before we begin the lesson, I would like to take care of some housekeeping details and reduce some of your uncertainty for coming here. Yes, the lesson today is the second part of a research study and when you leave today you will have completed this study. As soon as you turn in your feedback survey and leave today, your Communication Studies instructor will get notified of your participation.

That said, today's lesson is mainly designed for you to give me feedback on my teaching.

You all have been given a packet. The first page simply introduces me and lets you know that you being here will in no way affect your university standing. The second page is blank and can be used for taking notes if you would like. The rest of the packet has questions regarding my teaching, and I ask that you hold off on that until I make an announcement at the end of the lesson.

Before we move on are there any questions for me? 
Alright, the game plan for today is to introduce environmental communication and pay close attention to climate change.

[CHOICE Manipulation] = throughout the lesson today I want to give you all choices over the information that we cover and allow you to dictate how the lecture will unfold. This is sort of a choose your own adventure lecture, meaning you all will decide on the direction of this lesson.

[NO CHOICE Manipulation] = We have a bit of information to cover today, therefore we do not have much time to waste. You may see several topics in the lesson, but I plan to cover them in a certain order.

Let's get started.

\section{Zoom in on Environmental Communication Definition}

\section{ENVIRONMENTAL COMMUNICATION}

We need to start with understanding what environmental communication is.

Environmental communication can be defined as the pragmatic and constitutive modes of expression of our ecological relationships in the world, including those with nonhuman systems, elements, and species. In simpler terms it is communication about environmental affairs. This includes diverse forms of communication like interpersonal, organizational, and mediated communication about environmental issues or problems. One popular area within environmental communication is climate change. Therefore we are going to spend the majority of our time together tackling this topic.

\section{Zoom out of Environmental Communication Definition}

Zoom in on Climate Change

\section{CLIMATE CHANGE}

Broadly stated, climate change is any change in global or regional climate patterns. Essentially, climate change is how the atmosphere "behaves" over relatively long periods of time. Instead of the day-to-day weather, climate change is looking at averages and the patterns of weather over many, many, many years. In the last 650,000 years, the Earth has seen seven cycles of climate change between glacial periods of cooling and glacial periods or warming. It is important to note that climate change is a naturally occurring phenomena of our planet.

However, according to many scientists, we are currently going through a warming period, which is attributed mainly to the over production of carbon dioxide and methane gas in our atmosphere. Take a look at the recent information from NASA (POINT TO IMAGE). We have been above the typical amount of $\mathrm{CO} 2$ (and rising) since the 50s. This is mainly because of overproduction of greenhouse gases and fluctuations in the greenhouse effect. 
At this point I would like to point out a key distinction between climate change and what is commonly referred to as global warming. Climate change is a scientific phenomenon that describes how the atmosphere "behaves" over relatively long periods of time. However, global warming describes the upward temperature trend across the entire Earth. Climate change includes the increased temperature trends described by global warming, but also encompasses changes such as sea level rise; the ice mass loss in Greenland and Antarctica; shifts in growing seasons; and extreme weather events.

\section{Zoom out of Climate Change}

[CHOICE Manipulation] = as mentioned, I want you all to choose where we take this lesson next. We can either talk about climate change and environmental communication in the context of the ocean or terrestrial ecosystems (like land and plants).

To make sure I hear from everyone we are going to be using an online voting system on our smartphones. Please take out your smartphone and if you forgot yours see if your neighbor will allow you to use their phone when they are finished.

\section{Zoom in on Voting Link}

Please go to the following link. It may ask you to create a username for your response, but you are able to skip this.

You will see the following question: "What topic of climate change would you like to talk about?" Please select the answer where you want our lecture to go next. I will give you all some time to vote for your choice.

Alright, may I have everyone's attention. Let's bring our attention to the front.

Select the appropriate topic based on the votes

[NO CHOICE Manipulation] = as mentioned, there are several topics to discuss under the umbrella of climate change and environmental communication. We will be talking about (INSERT TOPIC FROM CHOICE CONDITION) today.

\section{Zoom in on Oceans}

\section{OCEANS}

Okay, so... let's turn our attention to the oceans. Scientists have demonstrated that global climate change has resulted in many different observable effects on the environment, one of which is our oceans. It no surprise that as the Earth's climate increases so does ocean temperatures. 


\section{Carbon-based Consequences}

Nearly, a third of the carbon dioxide released by human sources have dissolved into the ocean, which increases the acidity of the water. Luckily, almost all ecosystems rely on a photosynthetic organisms to transform this $\mathrm{CO} 2$ into food and oxygen. Unfortunately, acidification of the oceans because of this excess $\mathrm{CO} 2$ stunts the growth of major species that our economy relies on such as: corals, mollusks, oysters, clams, and other crustaceans. In other words, acidification of our oceans decreases the photosynthesis process, which has major chain reaction effects.

Take a look at the image here (POINT TO IMAGE). Predators rely on smaller species that are suffering as a result of acidification. It's just a chain reaction of larger predators (like us) suffering from ocean acidification.

Let's watch this brief video that explains in more detail how the oceans are absorbing $\mathrm{CO} 2$ at a rapid rate and transforming these ecosystems.

Zoom in on video and play acidifying waters corrode northwest shellfish

\section{Zoom out of video}

Now that we understand acidification of oceans, let's take a look at what this means for environmental communication.

[CHOICE Manipulation] = Here is another place where you all can choose where we go next. We can either talk about risk communication, communicating sustainability, or advocacy campaigns.

Alright, take out your smartphones again. Time to vote. Where are we going next?

\section{Zoom in on Voting Link}

Please go to the following link. You will see the following question: "What do you want to talk about next?" Please select the answer where you want our lecture to go. I will give you all some time to vote for your choice.

Alright, may I have everyone's attention. Let's bring our attention to the front.

Select the appropriate topic based on the votes

[NO CHOICE Manipulation] $=$ We have three different areas of information to discuss within climate change and ocean effects. We will talk about (INSERT $1^{\text {st }}$ TOPIC FROM CHOICE CONDITION) first, then (INSERT $2^{\text {nd }}$ TOPIC FROM CHOICE 
CONDITION), and finally (INSERT $3^{\text {rd }}$ TOPIC FROM CHOICE CONDITION).

\section{OCEANS- RISK COMMUNICATION}

\section{Zoom in on Risk Communication}

Alright... Let's talk about what risk communication is and the steps of risk assessment.

First, risk communication can be defined as the exchange of information with the goal of improving risk understanding, affecting risk perception, and/or equipping people to act appropriately in response to an identified risk. A simpler way of putting this is that risk communication is all about bridging the gap between the science behind risk assessments and the public, so the public can way the costs and benefits and make an informed decision. Essentially, risk communication focuses on showing people the potential risks attributed to some environmental issue, so people can decide on what to do about the issue.

For example, in the U.S. the Environmental Protection Agency (EPA) is responsible for evaluating public health and ecological risk. Organizations like this one calculate the likelihood that a certain number of people or an ecological system (like our oceans) will suffer some harm over time from exposure to a hazard or environmental stressor, such as acidification. Again, risk is a function of severity and likelihood (of harm).

Essentially, to these organizations risk is a function of the severity of ocean acidification and the likelihood of harm caused by acidification over time.

Second, let's talk about risk assessment. Risk assessment is simply the evaluation of the degree of harm or danger from some condition. For example, take a look at the image on the right (POINT TO IMAGE). Risk assessment is about evaluating the harm associated with burning fossil fuels and adding excess $\mathrm{CO} 2$ and other greenhouse gases to our oceans, which causes more acidification and other dangerous outcomes. There are four clear steps to risk assessment, so let's apply this to ocean acidification.

First. Hazard Identification. We need to identify or detect the potential or actual source of danger. For example, what sort of greenhouse gases are causing ocean acidification?

Second. Exposure Assessment. We need to assess the pathways of exposure and determine important details, such as the amount of exposure, length of exposure, and how frequent exposure must be in order for $\mathrm{CO} 2$ and other greenhouse gases to disrupt the oceanic ecosystem.

Third. Dose-Response Assessment. We need to calculate and estimate the potential outcomes of the hazard. For example, determine the effects of ocean acidification on 
shellfish, our economy, the ocean chemistry, etc.

Fourth. Risk Characterization. We need to assess how much risk is acceptable and how much risk is too much. Basically, how much $\mathrm{CO} 2$ can be added to our oceans without causing too much harm.

Once again, these four steps to risk assessment include: identify the potential or actual source of danger, assess the pathways of exposure and determine important details, calculate and estimate the potential outcomes of the hazard, and assess how much risk is acceptable and how much risk is too much.

\section{Summary}

The key takeaway from this section of information is that major organizations like the EPA take important steps to assess risk and attempt to communicate those risks to the public, so the public can weigh the costs and benefits and make an informed decision regarding a particular issue (like ocean acidification).

\section{Zoom out of risk communication}

[CHOICE Manipulation] = Alright... where should we go next? We can either talk about communicating sustainability or advocacy campaigns.

Time to take out your smartphones again. It's time to vote. What's the next topic we want to cover?

\section{Zoom in on Voting Link}

Please go to the following link. You will see the following question: "What do you want to talk about next?" Please select the answer where you want our lecture to go. Of course we have already talked about risk communication, so please pick from the remaining two topics. I will give you all some time to vote for your choice.

Alright, may I have everyone's attention. Let's bring our attention to the front.

Select the appropriate topic based on the votes

[NO CHOICE Manipulation] $=$ That wraps up our conversation on the risk communication, next we will talk about (INSERT $2^{\text {nd }}$ TOPIC FROM CHOICE CONDITION).

\section{OCEAN EFFECTS - COMMUNICATING SUTAINABILITY}

\section{Zoom in on Communicating Sustainability}


Alright... let's chat about communicating sustainability and the ideas of green marketing and greenwashing.

First of all, a lot companies try to create an eco-friendly identity and communicate sustainability by connecting their products, goods, services, or brands with "green" (ecofriendly) initiatives. Most people don't want to harm the Earth and companies try to tap into this and sell you on the idea that purchasing their goods or supporting their brand is a way of being "green" or environmentally friendly.

The company Patagonia is a great example of this. Their mission statement highlights this environmental sustainability. Patagonia's mission is to "Build the best product, cause no unnecessary harm, use business to inspire and implement solutions to the environmental crisis" (like climate change, ice caps melting, ocean acidification, etc.). In order to accomplish this mission Patagonia tracks the carbon footprint of its products, uses recyclable materials, promotes the sale of secondhand products, encourages civic engagement, donates to environmental grants, and advocates for more sustainable policies. Again, the goal is to communicate sustainability and connect their products to being environmentally good.

Clearly, Patagonia is devoted to being green and sustaining our environment, which is a great example of green marketing.

\section{Change Slide}

Green marketing is all about associating the company's products, services, or identity with environmental values and images. The most popular form of green marketing is associating a company's products with popular images and slogans that suggest a concern for the environment (like images of mountains, clear lakes, rushing water, forests, basically anything outdoorsy). This is also typically done by using environmentally friendly labels, such as organic, non-toxic, GMO-free, biodegradable, all-natural, free range, fair-trade, recycled, ozone-friendly, and many more.

There are three frames that are important for green marketing. These include nature as backdrop, nature as product, and nature as outcome.

First. Using nature as the backdrop you are placing your product or company in nature trying to connect the two. For example, think of an SUV commercial that shows the vehicle crossing all types of terrain and having a beautiful forest backdrop.

Second. Green marketing can be framed in the products themselves, such as marketing something as being all natural or organic. 
Third. Green marketing also tries to frame products as not being a harm to the environment or may even be beneficial for the environment. A great example of this is all the products we have all seen that have been marketed as biodegradable or good for the environment. Another great example is the Prius, because it is always marketed as good for the environment. Therefore, by purchasing the company's product you are helping the environment.

Some companies are devoted to being green (like Patagonia). But... what happens when some companies are not as devoted to this or are the cause of some environmental issues. Well... they rely on greenwashing.

\section{Change Slide}

Greenwashing is when corporations have made major environmental mistakes and attempt to repair their identity and image. Greenwashing focuses on the corporation's efforts to divert people's attention from their poor environmental behavior or products to their green initiatives or green image.

For example, let's say reports have come out that my company BP, which does a lot of offshore oil drilling, has contributed significantly to ocean acidification. Well, I need to enhance the image of my company and associate my company with environmental images, practices, or products. Therefore, I may release a video to divert the public's attention away from my corporation's poor behaviors to our good behaviors. For example, I may release this video:

\section{Zoom in on video}

The sole goal of that video is to greenwash my company and get people to focus on how green and environmentally friendly BP is. The hope is that people won't focus on how my corporation contributes to climate change or ocean acidification. Rather, people will focus on all the cool environmentally friendly things my company is doing.

\section{Summary}

The key takeaway from this section is that a lot companies tap into people's needs to preserve our planet by communicating sustainability. Right, so companies can simply associate their products with eco-friendly images (green marketing) or divert the public's attention from the bad to cool eco-friendly initiative (green washing). The goal is to convince the public that the company's products, vision, and brands are eco-friendly. That purchasing these things is a great way for people to do their part for the environment.

\section{Zoom out of Communicating Sustainability}


[CHOICE Manipulation] = Alright... where should we go next? We can either talk about risk communication or advocacy campaigns.

Time to take out your smartphones again. It's time to vote. What's the next topic we want to cover?

\section{Zoom in on Voting Link}

Please go to the following link. You will see the following question: "What do you want to talk about next?" Please select the answer where you want our lecture to go. Of course we have already talked about communicating sustainability, so please pick from the remaining two topics. I will give you all some time to vote for your choice.

Alright, may I have everyone's attention. Let's bring our attention to the front.

Select the appropriate topic based on the votes

[NO CHOICE Manipulation] $=$ That wraps up our conversation on communicating sustainability, next we will talk about (INSERT $2^{\text {nd }}$ TOPIC FROM CHOICE CONDITION).

\section{OCEAN - ADVOCACY CAMPAIGNS}

Zoom in on Advocacy Campaigns

Alright... Let's take a look at what advocacy campaigns are and what makes them successful.

An advocacy campaign is a strategic course of action, involving communication, which is undertaken for a specific purpose. Essentially, advocacy campaigns are concerted efforts by people or organizations to secure a specific outcome in a certain timeframe for a specified audience. Another simpler way of thinking about advocacy campaigns is thinking of a group of people coming together to make a very specific change in a certain amount of time.

What I want to highlight here is that advocacy campaigns go beyond just questioning or criticizing a policy or societal issue. Meaning, advocacy campaigns are more than people in Boston just voicing their criticism of how terrible ocean acidification is for shellfish. Advocacy campaigns go further and might try to block a permit for construction of a nearby landfill or plant by organizing local residents, businesses, and churches to lobby city council members who have the power to decide against the permit.

Advocacy campaigns draw on several modes or ways of getting the public involved in an issue, such as community organizing, lobbying campaigns, boycotts, media events, green 
consumerism, etc.

\section{Change Slide}

There are four features to advocacy campaigns. Let's take a look at these advocacy campaigns sponsored by the International Atomic Energy Agency (IAEA) and walk through these features:

First. Campaigns are purposeful, meaning they have specific outcomes that are intended to result from the communication efforts of the campaign. For example, if we look at these IAEA campaigns, they each have a very specific purpose, like stopping the sale of shark fins or protecting deep-sea corals.

Second. Campaigns are aimed at a large audience. They do not focus their attention on just a few people, rather they focus on trying to use organized efforts to communicate with the masses to get a large body of people involved in their purpose.

Third. Campaigns have a time limit and timeline. This means that most campaigns have a desired outcome, like a vote on a bill or a passage of a law that must be achieved by some deadline. If not achieved then then the advocacy campaign may not be able to take any further action, because it may be too late.

Finally. Campaigns involve an organized set of communication activities. This means any sort of activity or event associated with the campaign has a clear and consistent message to educate or mobilize others.

Once again, the four features of an advocacy campaign include: purposeful, aimed at a large audience, have a time limit and timeline, and involve an organized set of communication activities.

\section{Change Slide}

Alright... let's wrap-up this section with three key features that make an advocacy campaign successful.

First and probably unsurprising, to be successful advocacy campaigns must have a clear and concrete objective. Basically really good campaigns hone in on a very a specific action, event, or decision that moves the campaign closer to its broader goal. For example, a specific action the IAEA may take is stopping the development of landfills across the Northern U.S. coastlines. Campaigns really struggle when their message is inconsistent or hard to follow.

Second. Successful campaigns identify important decision makers, like their primary and 
secondary audience. The primary audience includes the decision makers who have the authority to act on or implement the objectives of the campaign, such as governmental agencies, corporations, and policy makers. The secondary audience is a segment of the public who may have some sort of power to influence the primary audience, like the news media or opinion leaders. Therefore, for campaigns to be successful you have to target the people that can make your desired change and the individuals that can urge them to act.

Finally. Successful campaigns have specific strategies to influence decision makers. This means successful campaigns have a critical source of influence or leverage that if implemented is able to persuade a primary decision maker to act on the campaigns objective. For example, an advocacy campaign may attempt to have people boycott a company's products and target investors to divest their holdings in the company to weaken the company's financial strength and political power.

I would like to close this section with a great example of an advocacy campaign. The intergovernmental panel on climate change (known as the IPCC) likes to release videos, like the one I am about to show you, that arguably are meant to educate and send a clear message regarding climate change. They are urging policy makers and governmental officials to head the recommendations of scientists.

Let's take a look

\section{Zoom in on video}

That is just a great example of a campaign designed to get people (secondary audience) involved in urging the government and policy makers (primary audience) to act now.

\section{Zoom out of video}

[CHOICE Manipulation] = Alright $\ldots$ where should we go next? We can either talk about risk communication or communicating sustainability.

Time to take out your smartphones again. It's time to vote. What's the next topic we want to cover?

\section{Zoom in on Voting Link}

Please go to the following link. You will see the following question: "What do you want to talk about next?" Please select the answer where you want our lecture to go. Of course we have already talked about advocacy campaigns, so please pick from the remaining two topics. I will give you all some time to vote for your choice. 
Alright, may I have everyone's attention. Let's bring our attention to the front.

Select the appropriate topic based on the votes

[NO CHOICE Manipulation] = That wraps up our conversation on advocacy campaigns, next we will discuss (INSERT $2^{\text {nd }}$ TOPIC FROM CHOICE CONDITION). 


\section{TERRESTRIAL ECOSYSTEMS}

\section{Zoom in on Terrestrial Ecosystems}

Okay, so... let's turn our attention to terrestrial ecosystems. Scientists have demonstrated that global climate change has resulted in many different observable effects on the environment, one of which is our lands. It no surprise that as the Earth's climate increases our terrestrial environment will also change.

\section{Carbon-based Consequences}

One major change that has occurred is desertification. Desertification is the land degradation in dry-land ecosystems resulting from climate variations and human activities. Desertification does not refer to the expansion of existing deserts. It occurs because dry-land ecosystems, which cover over one third of the world's land area, are extremely vulnerable to overexploitation and inappropriate land use. Poverty, political instability, deforestation, overgrazing and bad irrigation practices can all undermine the productivity of the land. Essentially, desertification reduces the biological and economic productivity of dry-land ecosystems.

Let's watch this brief video that explains in more detail what desertification is and its implications for transforming these ecosystems.

Zoom in on video and play acidifying waters corrode northwest shellfish

\section{Zoom out of video}

Now that we understand desertification, let's take a look at what this means for environmental communication.

[CHOICE Manipulation] = Here is another place where you all can choose where we go next. We can either talk about risk communication, communicating sustainability, or advocacy campaigns.

Alright, take out your smartphones again. Time to vote. Where are we going next?

\section{Zoom in on Voting Link}

Please go to the following link. You will see the following question: "What do you want to talk about next?" Please select the answer where you want our lecture to go. I will give you all some time to vote for your choice.

Alright, may I have everyone's attention. Let's bring our attention to the front. 
[NO CHOICE Manipulation] = We have three different areas of information to discuss within climate change and ocean effects. I feel like talking about (INSERT $1^{\text {st }}$ TOPIC FROM CHOICE CONDITION) first, then (INSERT $2^{\text {nd }}$ TOPIC FROM CHOICE CONDITION), and finally (INSERT $3^{\text {rd }}$ TOPIC FROM CHOICE CONDITION). We are going to do what I feel like.

\section{TERRESTRIAL ECOSYSTEMS- RISK COMMUNICATION}

\section{Zoom in on Risk Communication}

Alright... Let's talk about what risk communication is and the steps of risk assessment.

First, risk communication can be defined as the exchange of information with the goal of improving risk understanding, affecting risk perception, and/or equipping people to act appropriately in response to an identified risk. A simpler way of putting this is that risk communication is all about bridging the gap between the science behind risk assessments and the public, so the public can weigh the costs and benefits and make an informed decision. Essentially, risk communication focuses on showing people the potential risks attributed to some environmental issue, so people can decide on what to do about the issue.

For example, in the U.S. the Environmental Protection Agency (EPA) is responsible for evaluating public health and ecological risk. Organizations like this one calculate the likelihood that a certain number of people or an ecological system (like our oceans) will suffer some harm over time from exposure to a hazard or environmental stressor, such as acidification. Again, risk is a function of severity and likelihood (of harm).

Essentially, to these organizations risk is a function of the severity of desertification and the likelihood of harm caused by desertification over time.

\section{Change slide}

Second, let's talk about risk assessment. Risk assessment is simply the evaluation of the degree of harm or danger from some condition. For example, take a look at the image on the right (POINT TO IMAGE). Risk assessment is about evaluating the harm associated with droughts, flooding, deforestation, or overgrazing that have potentially dangerous outcomes. There are four clear steps to risk assessment, so let's apply this to desertification.

First. Hazard Identification. We need to identify or detect the potential or actual source of danger. For example, what sort of factors are causing desertification?

Second. Exposure Assessment. We need to assess the pathways of exposure and 
determine important details, such as the amount of exposure, length of exposure, and how frequent exposure must be for desertification to disrupt the terrestrial ecosystem.

Third. Dose-Response Assessment. We need to calculate and estimate the potential outcomes of the hazard. For example, determine the effects of desertification on crop yields, economic sustainability, the soil chemistry, etc.

Fourth. Risk Characterization. We need to assess how much risk is acceptable and how much risk is too much. Basically, how much desertification can be acceptable without causing too much harm.

\section{Summary}

The key takeaway from this section of information is that major organizations like the EPA take important steps to assess risk and attempt to communicate those risks to the public, so the public can way the costs and benefits and make an informed decision regarding a particular issue (like desertification).

\section{Zoom out of risk communication}

[CHOICE Manipulation] = Alright...where should we go next? We can either talk about communicating sustainability or advocacy campaigns.

Time to take out your smartphones again. It's time to vote. What's the next topic we want to cover?

\section{Zoom in on Voting Link}

Please go to the following link. You will see the following question: "What do you want to talk about next?" Please select the answer where you want our lecture to go. Of course we have already talked about risk communication, so please pick from the remaining two topics. I will give you all some time to vote for your choice.

Alright, may I have everyone's attention. Let's bring our attention to the front.

Select the appropriate topic based on the votes

[NO CHOICE Manipulation] = That wraps up our conversation on the risk communication, next we will talk about (INSERT $2^{\text {nd }}$ TOPIC FROM CHOICE CONDITION).

\section{TERRESTRIAL ECOSYSTEMS - COMMUNICATING SUTAINABILITY}

\section{Zoom in on Communicating Sustainability}


Alright... let's chat about communicating sustainability and the ideas of green marketing and greenwashing.

First of all, a lot companies try to create an eco-friendly identity and communicate sustainability by connecting their products, goods, services, or brands with "green" (ecofriendly) initiatives. Most people don't want to harm the Earth and companies try to tap into this and sell you on the idea that purchasing their goods or supporting their brand is a way of being "green" or environmentally friendly.

The company Patagonia is a great example of this. Their mission statement highlights this environmental sustainability. Patagonia's mission is to "Build the best product, cause no unnecessary harm, use business to inspire and implement solutions to the environmental crisis" (like climate change, ice caps melting, ocean acidification, etc.). In order to accomplish this mission Patagonia tracks the carbon footprint of its products, uses recyclable materials, promotes the sale of secondhand products, encourages civic engagement, donates to environmental grants, and advocates for more sustainable policies. Again, the goal is to communicate sustainability and connect their products to being environmentally good.

Clearly, Patagonia is devoted to being green and sustaining our environment, which is a great example of green marketing.

\section{Change Slide}

Green marketing is all about associating the company's products, services, or identity with environmental values and images. The most popular form of green marketing is associating a company's products with popular images and slogans that suggest a concern for the environment (like images of mountains, clear lakes, rushing water, forests, basically anything outdoorsy). This is also typically done by using environmentally friendly labels, such as organic, non-toxic, GMO-free, biodegradable, all-natural, free range, fair-trade, recycled, ozone-friendly, and many more.

There are three frames that are important for green marketing. These include nature as backdrop, nature as product, and nature as outcome.

First. Using nature as the backdrop you are placing your product or company in nature trying to connect the two. For example, think of an SUV commercial that shows the vehicle crossing all types of terrain and having a beautiful forest backdrop.

Second. Green marketing can be framed in the products themselves, such as marketing something as being all natural or organic. 
Third. Green marketing also tries to frame products as not being a harm to the environment or may even be beneficial for the environment. A great example of this is all the products we have all seen that have been marketed as biodegradable or good for the environment. Another great example is the Prius, because it is always marketed as good for the environment. Therefore, by purchasing the company's product you are helping the environment.

Some companies are devoted to being green (like Patagonia). But... what happens when some companies are not as devoted to this or are the cause of some environmental issues. Well... they rely on greenwashing.

\section{Change Slide}

Greenwashing is when corporations have made major environmental mistakes and attempt to repair their identity and image. Greenwashing focuses on the corporation's efforts to divert people's attention from their poor environmental behavior or products to their green initiatives or green image.

For example, let's say reports have come out that my company BP, which does a lot of land oil drilling in dry-lands, has contributed significantly to desertification. Well, I need to enhance the image of my company and associate my company with environmental images, practices, or products. Therefore, I may release a video to divert the public's attention away from my corporation's poor behaviors to our good behaviors. For example, I may release this video:

\section{Zoom in on video}

The sole goal of that video is to greenwash my company and get people to focus on how green and environmentally friendly BP is. The hope is that people won't focus on how my corporation contributes to climate change or desertification. Rather, people will focus on all the cool environmentally friendly things my company is doing.

\section{Summary}

The key takeaway from this section is that a lot companies tap into people's needs to preserve our planet by communicating sustainability. Right, so companies can simply associate their products with eco-friendly images (green marketing) or divert the public's attention from the bad to cool eco-friendly initiative (green washing). The goal is to convince the public that the company's products, vision, and brands are eco-friendly. That purchasing these things is a great way for people to do their part for the environment.

\section{Zoom out of Communicating Sustainability}


[CHOICE Manipulation] = Alright... where should we go next? We can either talk about risk communication or advocacy campaigns.

Time to take out your smartphones again. It's time to vote. What's the next topic we want to cover?

\section{Zoom in on Voting Link}

Please go to the following link. You will see the following question: "What do you want to talk about next?" Please select the answer where you want our lecture to go. Of course we have already talked about communicating sustainability, so please pick from the remaining two topics. I will give you all some time to vote for your choice.

Alright, may I have everyone's attention. Let's bring our attention to the front.

Select the appropriate topic based on the votes

[NO CHOICE Manipulation] $=$ That wraps up our conversation on communicating sustainability, next we will talk about (INSERT $2^{\text {nd }}$ TOPIC FROM CHOICE CONDITION).

\section{TERRESTRIAL ECOSYSTEM - ADVOCACY CAMPAIGNS}

\section{Zoom in on Advocacy Campaigns}

Alright... Let's take a look at what advocacy campaigns are and what makes them successful.

An advocacy campaign is a strategic course of action, involving communication, which is undertaken for a specific purpose. Essentially, advocacy campaigns are concerted efforts by people or organizations to secure a specific outcome in a certain timeframe for a specified audience. Another way of thinking about advocacy campaigns is thinking of a group of people coming together to make a very specific change in a certain amount of time.

What I want to highlight here is that advocacy campaigns go beyond just questioning or criticizing a policy or societal issue. Meaning, advocacy campaigns are more than people in the Midwest just voicing their criticism of how terrible desertification is for their crops. Advocacy campaigns go further and might try to block a permit for construction of a nearby landfill or plant by organizing local residents, businesses, and churches to lobby city council members who have the power to decide against the permit.

Advocacy campaigns draw on several modes or ways of getting the public involved in an issue, such as community organizing, lobbying campaigns, boycotts, media events, green 
consumerism, etc.

\section{Change Slide}

There are four features to advocacy campaigns. Let's take a look at this advocacy campaign sponsored by the United Nations Convention to Combat Desertification and walk through these features:

First. Campaigns are purposeful, meaning they have specific outcomes that are intended to result from the communication efforts of the campaign. For example, if we look at these UNCCD's campaign on world day to combat desertification, they have a very specific purpose focused on sustainable land management.

Second. Campaigns are aimed at a large audience. They do not focus their attention on just a few people, rather they focus on trying to use organized efforts to communicate with the masses to get a large body of people involved in their purpose.

Third. Campaigns have a time limit and timeline. This means that most campaigns have a desired outcome, like a vote on a bill or a passage of a law that must be achieved by some deadline. If not achieved then then the advocacy campaign may not be able to take any further action, because it may be too late.

Finally. Campaigns involve an organized set of communication activities. This means any sort of activity or event associated with the campaign has a clear and consistent message to educate or mobilize others.

Once again, the four features of an advocacy campaign include: purposeful, aimed at a large audience, have a time limit and timeline, and involve an organized set of communication activities.

\section{Change Slide}

Alright... let's wrap-up this section with three key features that make an advocacy campaign successful.

First and probably unsurprising, to be successful advocacy campaigns must have a clear and concrete objective. Basically really good campaigns hone in on a very a specific action, event, or decision that moves the campaign closer to its broader goal. For example, a specific action the UNCCD may take is stopping the development of landfills across the U.S. Midwest or improving methods of watering soils. Campaigns really struggle when their message is inconsistent or hard to follow.

Second. Successful campaigns identify important decision makers, like their primary and 
secondary audience. The primary audience includes the decision makers who have the authority to act on or implement the objectives of the campaign, such as governmental agencies, corporations, and policy makers. The secondary audience is a segment of the public who may have some sort of power to influence the primary audience, like the news media or opinion leaders. Therefore, for campaigns to be successful you have to target the people that can make your desired change and the individuals that can urge them to act.

Finally. Successful campaigns have specific strategies to influence decision makers. This means successful campaigns have a critical source of influence or leverage that if implemented is able to persuade a primary decision maker to act on the campaigns objective. For example, an advocacy campaign may attempt to have people boycott a company's products and target investors to divest their holdings in the company to weaken the company's financial strength and political power.

I would like to close this section with a great example of an advocacy campaign. The intergovernmental panel on climate change (known as the IPCC) likes to release videos, like the one I am about to show you, that arguably are meant to educate and send a clear message regarding climate change. They are urging policy makers and governmental officials to head the recommendations of scientists.

Let's take a look

\section{Zoom in on video}

That is just a great example of a campaign designed to get people (secondary audience) involved in urging the government and policy makers (primary audience) to act now.

\section{Zoom out of video}

[CHOICE Manipulation] = Alright...where should we go next? We can either talk about risk communication or communicating sustainability.

Time to take out your smartphones again. It's time to vote. What's the next topic we want to cover?

\section{Zoom in on Voting Link}

Please go to the following link. You will see the following question: "What do you want to talk about next?" Please select the answer where you want our lecture to go. Of course we have already talked about advocacy campaigns, so please pick from the remaining two topics. I will give you all some time to vote for your choice. 
Alright, may I have everyone's attention. Let's bring our attention to the front.

Select the appropriate topic based on the votes

[NO CHOICE Manipulation] $=$ That wraps up our conversation on advocacy campaigns, next we will discuss (INSERT $2^{\text {nd }}$ TOPIC FROM CHOICE CONDITION).

\author{
***END OF LECTURE MESSAGE*** \\ (after discussing three topics of EITHER oceans or terrestrial)
}

Wow...we have tackled quite a bit of information on environmental communication and climate change this evening. Now as you heard at the beginning of the lecture, I am looking for some feedback on my teaching. If you turn to page (INSERT PAGE \#) of the packet given to you at the beginning, you will see some questions for you to fill out about my teaching and the lesson today.

Before you begin, I want to bring your attention to the final page of the packet. You will see 5 brief descriptions of free opportunities to learn more about climate change and environmental communication. You will see a line below each option. To sign-up all you have to do is put your unique identifier code you created for this study on as many lines as you would like. Once you are done with signing up, please rip that last page off of the survey and I will give you an envelope to put it in on your way out.

From the bottom of my heart I truly appreciate you all taking the time the time to be here this evening and I look forward to your feedback. Once you are finished with the packet you can turn it into the either box at the front of the room.

Thank you again and I hope you have a good rest of your evening. 
Appendix L

Pre-Survey

INSERT STUDY ADVERTISEMENT HERE

\section{1) Sex (Circle One):}

Male

Female

Nonbinary

Female to Male Transgender

Male to Female Transgender

Other

Prefer not to answer

2) Age:

3) Class Rank (circle one): $\quad$ First-year Sophomore Junior Senior

Other (specify):

4) The ethnicity with which you most closely identify (circle one):

Asian/Asian American Black/African-American Hispanic

Native American White/Caucasian $\quad$ Middle Eastern

Other (specify):

You will be attending a lecture on environmental communication and climate change.

Below is a list of common perceptions students have regarding this topic of

information. For each of the following statements, please indicate how true it is for you, using the following scale:

\begin{tabular}{|c|c|c|c|c|c|c|}
\hline $\begin{array}{c}\text { Not at all } \\
\text { true of me } \\
1\end{array}$ & 2 & 3 & $\begin{array}{c}\text { Somewhat } \\
\text { true of me } \\
4\end{array}$ & 5 & 6 & $\begin{array}{c}\text { Very true } \\
\text { of me } \\
7\end{array}$ \\
\hline
\end{tabular}

5. The topic of climate change is quite enjoyable.

6. I think the topic of climate change is boring.

7. I would describe the topic of climate change as very interesting.

8. I enjoy the topic of climate change very much.

9. While learning about climate change, I will think about how much I enjoy this topic.

10. Climate change is fun to learn about.

11. This topic will not hold my attention at all. 
As you were informed, this study has two parts:

(1) complete pre-survey and get assigned a day and time to attend a lecture

(2) attend assigned day and time for the lecture.

In order to keep the information you provide for both parts together, we need you to create a unique identifier code. We would like to ensure you that this identifier code will only be used to pair the information of both parts of the study and will be removed before data analysis. Also, please remember your actual performance in this study and your refusal to participate or withdrawal from this study will no way affect your class standing, grades, job status, or status in any athletic or other activity associated with West Virginia University.

We ask that your unique code be your initials followed by your birth date.

For example, say your name is John Smith and you were born January 14, 1994, your unique code would be: JS1141994.

My unique identifier code is:

$$
\text { ***Sign-Up Survey*** }
$$

***Participants will randomly receive one of the following end of survey messages***

Treatment:

1) You have been assigned to attend the live lecture on environmental communication in (INSERT LOCATION) on (INSERT DATE) from (TIME).

In order to complete part 2 of this study, you must arrive at this classroom at least 5 minutes before 5:00 pm on (INSERT DATE).

Two separate dates were set for this study, but due to the limits on classroom capacity, we need you to come to this designated day and time. If you attempt to come to the other lecture date that you were not assigned we will not be able to let you in the classroom and you will not be able to participate in part 2 of this study.

Please click the following link to sign up:

https://wvu.qualtrics.com/jfe/form/SV_eIDpjx1jqeuGfrv

OR

Control:

2) You have been assigned to attend the live lecture on environmental communication in (INSERT LOCATION) on (INSERT DATE) from (TIME). 
In order to complete part 2 of this study, you must arrive at this classroom at least 5 minutes before 5:00 pm on (INSERT DATE).

Two separate dates were set for this study, but due to the limits on classroom capacity, we need you to come to this designated day and time. If you attempt to come to the other lecture date that you were not assigned we will not be able to let you in the classroom and you will not be able to participate in part 2 of this study.

Please click the following link to sign up:

https://wvu.qualtrics.com/jfe/form/SV_2ru09qeg2TnHJhH

***Participants will be guided to either the treatment or control sign-up surveys, but will answer the following questions in both.***

\section{To sign-up for PART 2 of this study, please answer the following questions:}

You just created a unique identifier code for the previous survey. In the space provided below, please provide this unique code.

Recall, this code is your initials followed by your birth date (e.g., JS1141994).

My unique identifier code is:

1) What is your WVU Mix email?

2) What is the title of the ONE Communication Studies course that you are trying to receive extra credit?

(EX: COMM 104, COMM 105, or COMM 306, etc.)

3) What is the COMM instructor's name (for the same course you listed above) that you are trying to receive extra credit?

(EX: Watts, Pitts, Kromka, Knoster, West, Howard, Jackson, etc.)

Thank you for signing up and we will see you in a week on your assigned date. 


\section{Appendix M}

Feedback Survey

\section{Hello All!}

First and foremost, thank you for taking the time to be here this evening to attend this live lecture on environmental communication. The researchers ask that you pay close attention to the lesson and have provided you with a blank piece of paper on the following page in case you would like to take some notes.

As you were informed at the beginning of today, James is interested in pursuing a career in teaching. He would like your feedback regarding his teaching today. Please wait until the lesson is complete and James makes an announcement to start the feedback survey. When completing the survey please answer each question in regard to James and his teaching today.

There are no right or wrong answers and completing this survey is voluntary. You may skip certain questions if you want and you may stop completing the questions at any time. Although, we are asking you to provide your unique identifier code, this code will be removed before we analyze the information. Your completion of this feedback will in no way affect your university standing.

Thank you all for your help today and your feedback.

All the best,

James Baker 
Before answering this feedback survey you were required to complete a pre-survey and create a unique identifier code. In the space provided below, please provide this unique code. Recall, this code is your initials followed by your birth date (e.g., JS1141994).

My unique identifier code is:

$* * * * * * * * * * * * * * * * * * * * * * * * * * * * * * * * * * * * * * * * * * * * * * * * * * * * * * * * * * * * * * * * * * * * * * * * * * * * *$

Below is a list of common behaviors that instructors have been observed doing in class. Use the scale below to indicate the extent to which you agree with each statement. Write your answer in the space provided. There is neither a right nor wrong answer.

\begin{tabular}{|cccccccc|}
\hline $\begin{array}{c}\text { Strongly } \\
\text { disagree }\end{array}$ & Disagree & $\begin{array}{c}\text { Somewhat } \\
\text { Disagree }\end{array}$ & $\begin{array}{c}\text { Neither } \\
\text { agree nor } \\
\text { disagree }\end{array}$ & $\begin{array}{c}\text { Somewhat } \\
\text { agree }\end{array}$ & Agree & $\begin{array}{c}\text { Strongly } \\
\text { agree }\end{array}$ \\
1 & 2 & 3 & 4 & 5 & 6 & 7 \\
\hline
\end{tabular}

1. The instructor is one of the funniest instructors I know.

2. The instructor is not a funny instructor.

3. The instructor is humorous

4. The lesson today was easy to understand.

5. The lesson today made sense.

6. The lesson today was straightforward.

7. The lesson today was clear.

8. The lesson today was easy to follow.

9. The instructor gestured while talking to the class.

10. The instructor used a monotone/dull voice when talking to the class.

11. The instructor looked at the class while talking.

12. The instructor smiled at the class while talking.

13. The instructor had a tense body position while talking to the class.

14. The instructor moved around the classroom while teaching.

15. The instructor looked at the board or notes while talking to the class.

16. The instructor had a relaxed body position while talking to the class.

17. The instructor frowned at the class while talking.

18. The instructor used a variety of vocal expressions when talking to the class.

19. The instructor has a contagious energy about him.

20. The instructor is full of dynamic energy when he teaches.

21. The instructor just lights up the room when he teaches.

22. The instructor is a bit dull. 
Below are a series of statements that describe the classroom environment. In regard to the lesson today, please indicate the degree to which you agree with the following statements.

\begin{tabular}{|ccccccc|}
\hline $\begin{array}{c}\text { Strongly } \\
\text { disagree }\end{array}$ & Disagree & $\begin{array}{c}\text { Somewhat } \\
\text { Disagree }\end{array}$ & $\begin{array}{c}\text { Neither } \\
\text { agree nor } \\
\text { disagree }\end{array}$ & $\begin{array}{c}\text { Somewhat } \\
\text { agree }\end{array}$ & Agree & $\begin{array}{c}\text { Strongly } \\
\text { agree }\end{array}$ \\
$\mathbf{1}$ & $\mathbf{2}$ & $\mathbf{3}$ & $\mathbf{4}$ & $\mathbf{5}$ & $\mathbf{6}$ & $\mathbf{7}$ \\
\hline
\end{tabular}

23. Learning new concepts during this lesson was fulfilling to me.

24. Developing my understanding of the content was rewarding to me.

25. Learning new things from this lesson makes me feel better about myself.

26. Understanding new concepts from this lesson was enjoyable to me.

27. I find learning new things from this lesson to be unfulfilling.

28. It was personally satisfying for me to learn new concepts from this lesson.

29. I get a sense of fulfillment when I learn new thing from lessons like the one today.

30. I did not enjoy trying to comprehend new ideas from this lesson.

31. Learning new things from this lesson makes me feel like I am growing as a person.

32. I desire to learn new things from lessons like the one today because it gives me a sense of fulfillment.

Below is a list of common perceptions students have regarding information they learn. For each of the following statements, please indicate how true it is for you, using the following scale:

\begin{tabular}{|c|c|c|c|c|c|c|}
\hline $\begin{array}{c}\text { Not at all } \\
\text { true of me } \\
1\end{array}$ & 2 & 3 & $\begin{array}{c}\text { Somewhat } \\
\text { true of me } \\
4\end{array}$ & 5 & 6 & $\begin{array}{c}\text { Very true } \\
\text { of me } \\
7\end{array}$ \\
\hline
\end{tabular}

33. The topic of climate change was quite enjoyable.

34. I thought the topic of climate change was boring.

35 . I would describe the topic of climate change as very interesting.

36. I enjoyed the topic of climate change very much.

37. While I was learning about climate change, I was thinking about how much I enjoyed this topic.

38. Climate change is fun to learn about.

39. This topic did not hold my attention at all. 
Below is a list of common responses students have to an instructor. Circle the number that best represents your response.

Your likelihood of actually enrolling in another course with this instructor if your schedule would permit would be:

\begin{tabular}{|l|l|l|l|l|l|l|l|l|}
\hline 40. Unlikely & 1 & 2 & 3 & 4 & 5 & 6 & 7 & Likely \\
\hline 41. Impossible & 1 & 2 & 3 & 4 & 5 & 6 & 7 & Possible \\
\hline 42. Improbable & 1 & 2 & 3 & 4 & 5 & 6 & 7 & Probable \\
\hline 43. Would not & 1 & 2 & 3 & 4 & 5 & 6 & 7 & Would \\
\hline
\end{tabular}

Below is a list of common behaviors that students tend to enact in and outside of the classroom. Please indicate how often you would engage in the following behaviors if James was your regular instructor. Write your answer in the space provided. There is neither a right nor wrong answer.

\begin{tabular}{|ccccc|}
\hline $\begin{array}{c}\text { Strongly } \\
\text { Disagree }\end{array}$ & Disagree & Neutral & Agree & $\begin{array}{c}\text { Strongly } \\
\text { Agree }\end{array}$ \\
$\mathbf{1}$ & $\mathbf{2}$ & $\mathbf{3}$ & $\mathbf{4}$ & $\mathbf{5}$ \\
\hline
\end{tabular}

If James were my regular instructor I would... 44. complain to others to express my frustrations with this course. 45. express my disappointment about this course to other people because it helps me feel better. 46. talk to other students to see if they also have complaints about this teacher. 47. complain about my teacher and course because it makes me feel better. 48. attempt to feel better about my frustrations in this class by communicating with other people.

49. talk to other students when I am annoyed with my teacher in hopes that I am not the only one.

50. try to feel better about this course by explaining my aggravations to others. 51. complain about my teacher to get my frustrations off of my chest. 52. criticize my teacher's practices to other students because I hope they share my criticism.

53. talk to other students so we can discuss the problems we have in class. 
The following questions are focused on your perceptions of the overall lecture today. Please circle the appropriate number that indicates your perception of the information from today's lecture.

54. How familiar were you with this topic before today?

(Circle the appropriate number)

\begin{tabular}{|c|c|c|c|c|}
\hline Not at all & & & & Very much \\
\hline 1 & 2 & 3 & 4 & 5 \\
\hline
\end{tabular}

55. How much did you already know about the subject being discussed?

(Circle the appropriate number)

\begin{tabular}{|c|c|c|c|c|}
\hline Not at all & & & & Very much \\
\hline 1 & 2 & 3 & 4 & 5 \\
\hline
\end{tabular}

56. To what extent had you been exposed to the material in this lesson in the past? (Circle the appropriate number)

\begin{tabular}{|c|c|c|c|c|}
\hline Not at all & & & & Very much \\
\hline 1 & 2 & 3 & 4 & 5 \\
\hline
\end{tabular}

57. How difficult would the material have been to understand if it was taught in an ideal manner (e.g., by an ideal teacher, in a way that was simple to comprehend, etc.)?

(Circle the appropriate number)

\begin{tabular}{|c|c|c|c|c|c|c|c|c|}
\hline $\begin{array}{c}\text { Very, } \\
\text { very low }\end{array}$ & & & & & & & & $\begin{array}{c}\text { Very, very } \\
\text { much }\end{array}$ \\
\hline 1 & 2 & 3 & 4 & 5 & 6 & 7 & 8 & 9 \\
\hline
\end{tabular}

Below is a list of additional common instructor behaviors. Please indicate the degree to which you agree James engaged in each of the following behaviors. Write your answer in the space provided. There is neither a right nor wrong answer.

\begin{tabular}{|ccccc|}
\hline $\begin{array}{c}\text { Strongly } \\
\text { Disagree }\end{array}$ & Disagree & Neutral & Agree & $\begin{array}{c}\text { Strongly } \\
\text { Agree }\end{array}$ \\
$\mathbf{1}$ & $\mathbf{2}$ & $\mathbf{3}$ & $\mathbf{4}$ & $\mathbf{5}$ \\
\hline
\end{tabular}

58. The teacher gave me a lot of choices during the lesson.

59. The teacher did not give me much choice over the information discussed during the lesson.

60. When it comes to the lesson, the teacher gave me all kinds of things to choose from.

61. The teacher did not give me a chance to choose anything about the lesson.

62. The teacher did not give me many choices when it comes to the information presented during the lesson. 
The next statements tap into your experiences during the lesson. Please indicate for each of the statements to what extent they are true for you.

\begin{tabular}{|ccccc|}
\hline Not at all true & $\begin{array}{c}\text { Rather not } \\
\text { true }\end{array}$ & $\begin{array}{c}\text { Sometimes true/ } \\
\text { sometimes not } \\
\text { true }\end{array}$ & Rather true & Totally true \\
1 & 2 & 3 & 4 & 5 \\
\hline
\end{tabular}

During this lesson:

63. I felt a sense of choice and freedom in the things I thought and did.

64. I felt forced to do things I would not choose to do.

65. I felt like the suggestions given reflected what I want myself.

66. I felt obligated to think and act in a certain way.

67. I felt like the way the information was delivered reflected how I wanted it myself.

68. I felt pressured to think and act in a certain way.

69. Most of the information I learned felt like 'I had to'.

70. I felt like what was told really interested me.

71. Have you ever had James Baker as an instructor? (Circle one)

Yes or No

72. During the lesson today, you were given 3 opportunities to choose how the lecture would unfold. Of these three opportunities, how many times did the lecturer follow your choice? (Circle one)
a. 0
b. 1
c. 2
d. 3

73. Do you believe climate change is a real scientific phenomenon? (Circle one)

Yes or No 
Here is one short answer question

Please read the question carefully and use the space below to respond.

1. In the space provided below, please walk me through the three features necessary to make an advocacy campaign successful AND make sure to provide an example of each feature.

1.

2.

3.

This is the end of the survey, but on the following page are several ways to get more information on environmental communication.

Take a look!

As mentioned at the end of the lecture, below is a brief description of $\mathbf{5}$ opportunities to learn more about environmental communication and climate change. These are 5 
free WVU sponsored events that are taking place this semester. Please read the brief descriptions and feel free to sign-up for as many opportunities as you would like. When you are done, please remove this page from the survey and place it in the designated box in the front of the room.

1) Training session at the West Virginia State Geographic Information Systems (GIS) Center located in Brooks Hall. This training will give you a hands-on experience with analyzing geographical areas in West Virginia to understand climate shifts throughout the state.

My unique identifier code is:

2) The Renewable Materials and Bioenergy Research Center will be screening a film on ways to improve the efficiency of creating renewable energy and its impact on climate change.

My unique identifier code is:

3) The WVU Evansdale Greenhouse is offering guided-tours to explore how different climates can be manipulated to stunt or promote plant growth.

My unique identifier code is:

4) The Institute of Water, Security, and Science here at WVU has been conducting research on Morgantown's water consumption and ecological contaminants for the past 10 years. They will be having a hands-on demonstration of their findings at their facilities located in the Agricultural Sciences Building.

My unique identifier code is:

5) The College of Engineering and Mineral Resources is hosting a debate in the Mountainlair on the projected consequences and potential benefits of climate change. This promises to be a heated debate between expert researchers here at WVU.

My unique identifier code is:

Thank you for your help! 
Appendix N

Prezi Presentation of Lecture Material

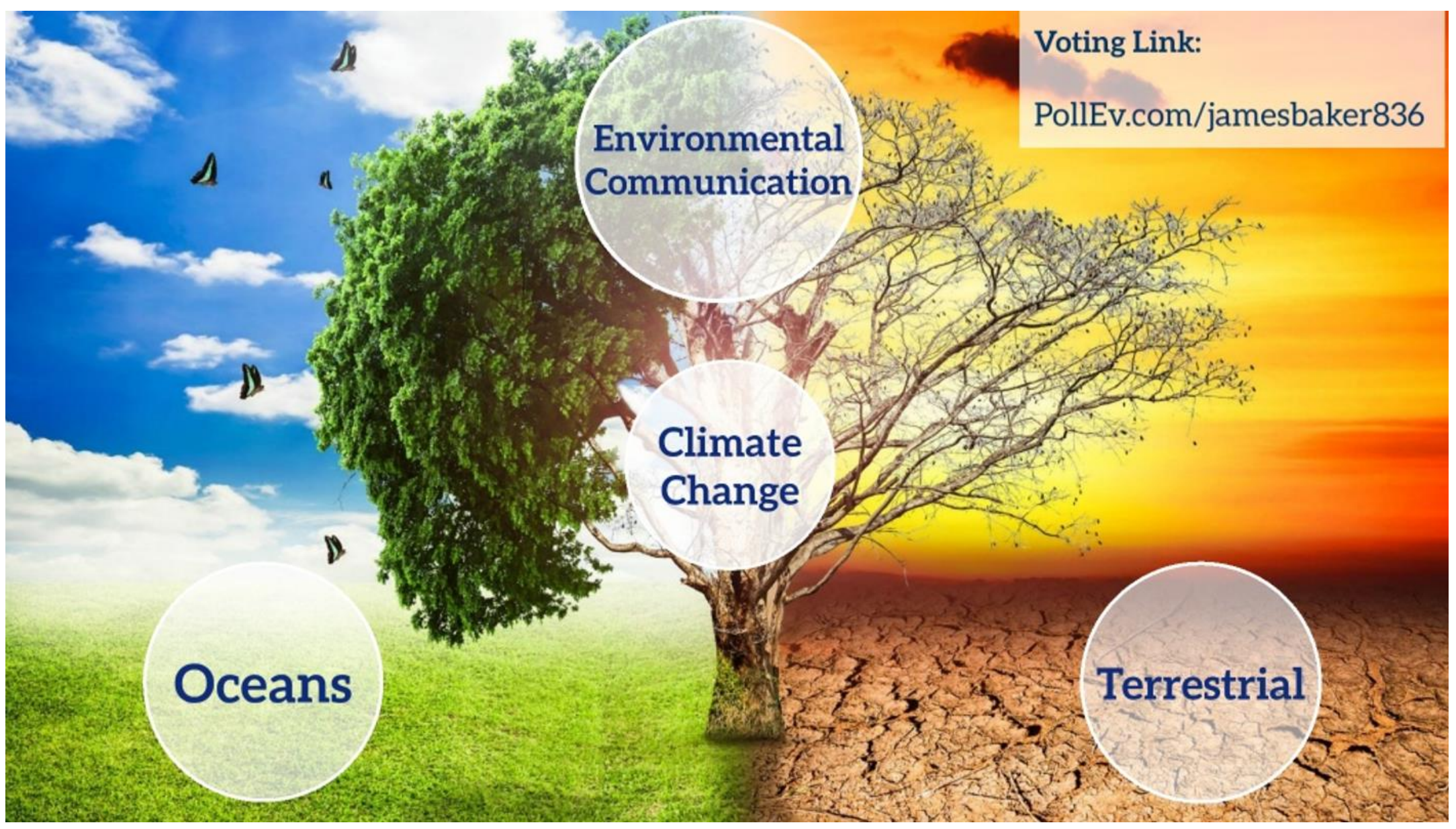

Link to Prezi: https://prezi.com/p/omgavuytto71/ 
***Environmental Communication Lesson Slide-By-Slide Layout***

Slide $=$ Environmental Communication

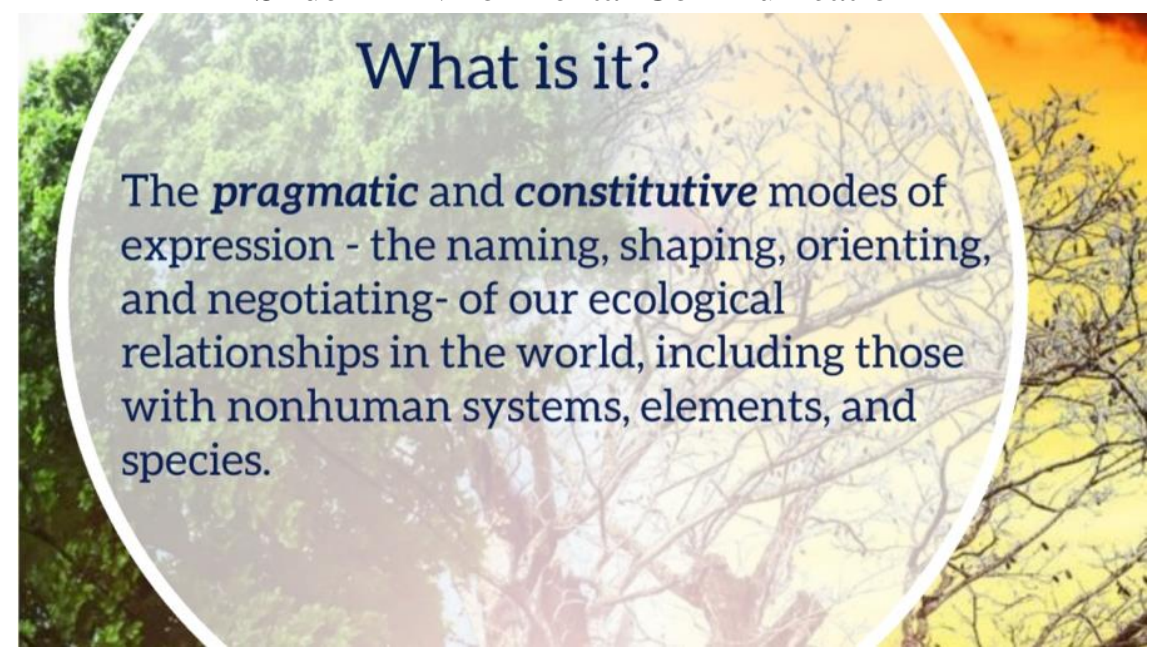

Slide $=$ Climate Change

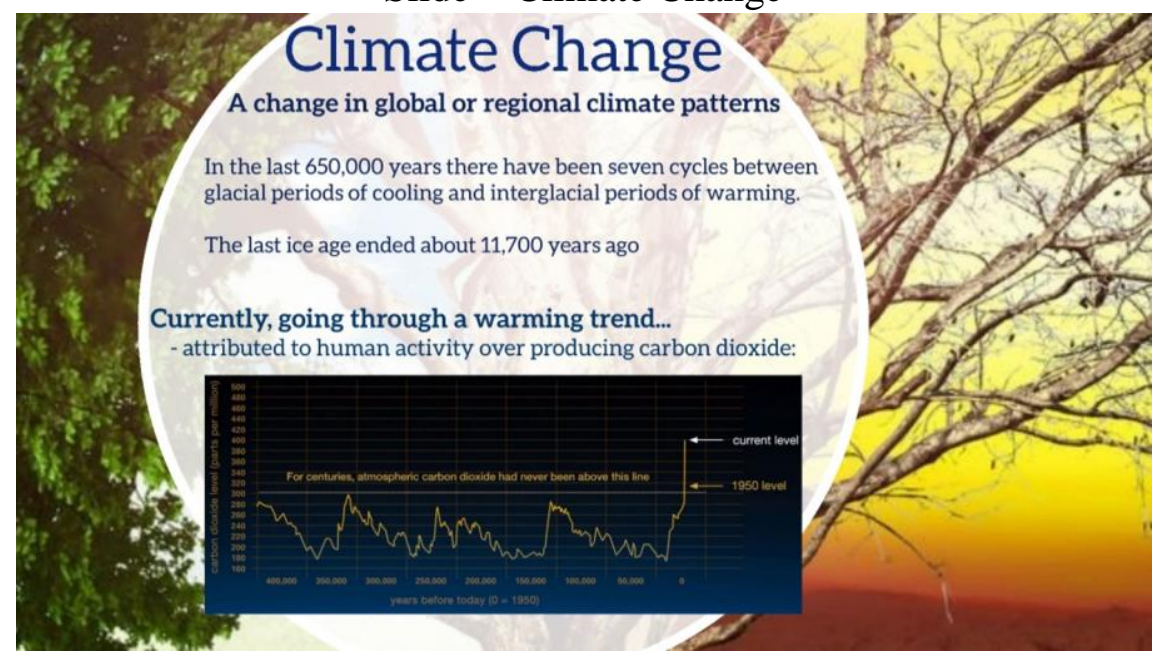




\section{Ocean Effects Path}

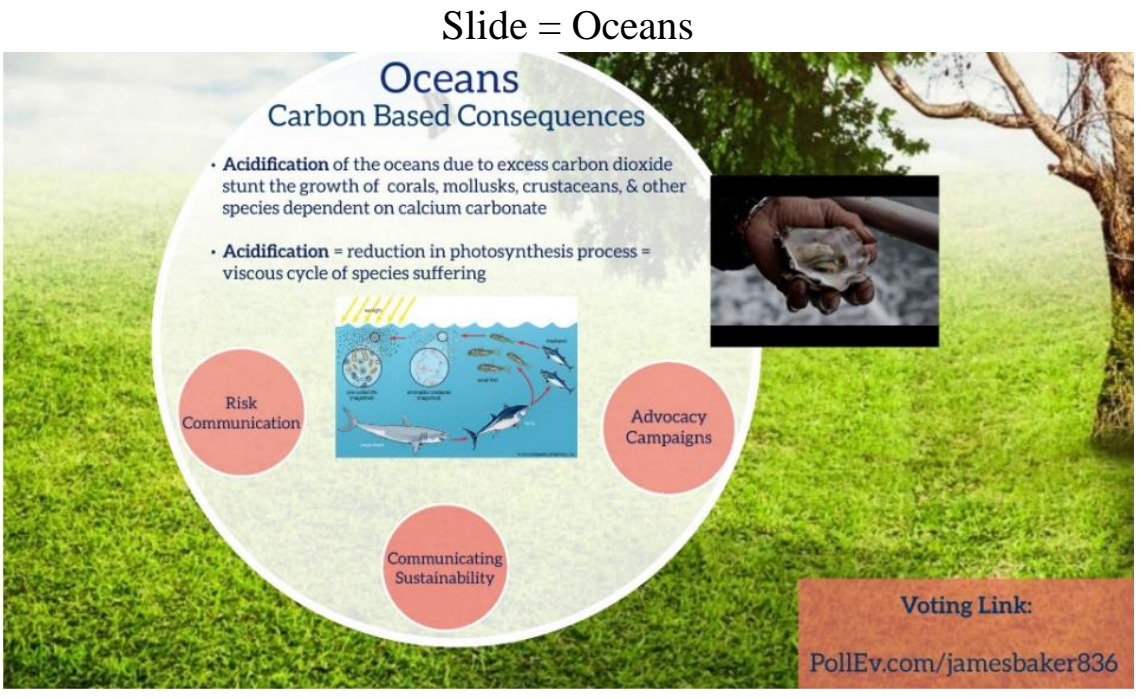

\section{Risk Communication}

\section{Slide $=$ Risk Communication}

\section{Risk Communication}

- The exchange of information with the goal of improving risk understanding, affecting risk perception, and/or equipping people to act appropriately in response to an identified risk
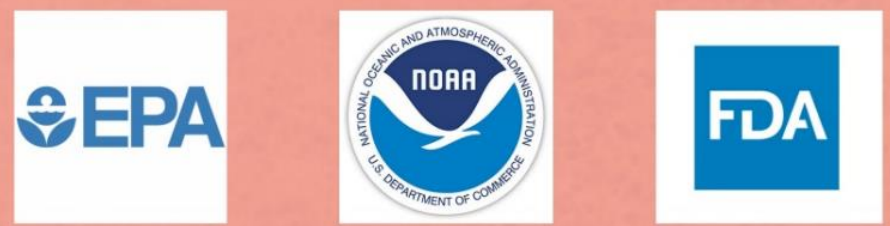

- Calculation of the likelihood that a certain number of people or an ecological system will suffer some harm over time from exposure to a hazard or environmental stressor (e.g., acidification)

- Risk = Severity X Likelihood

\section{Slide $=$ Risk Assessment}

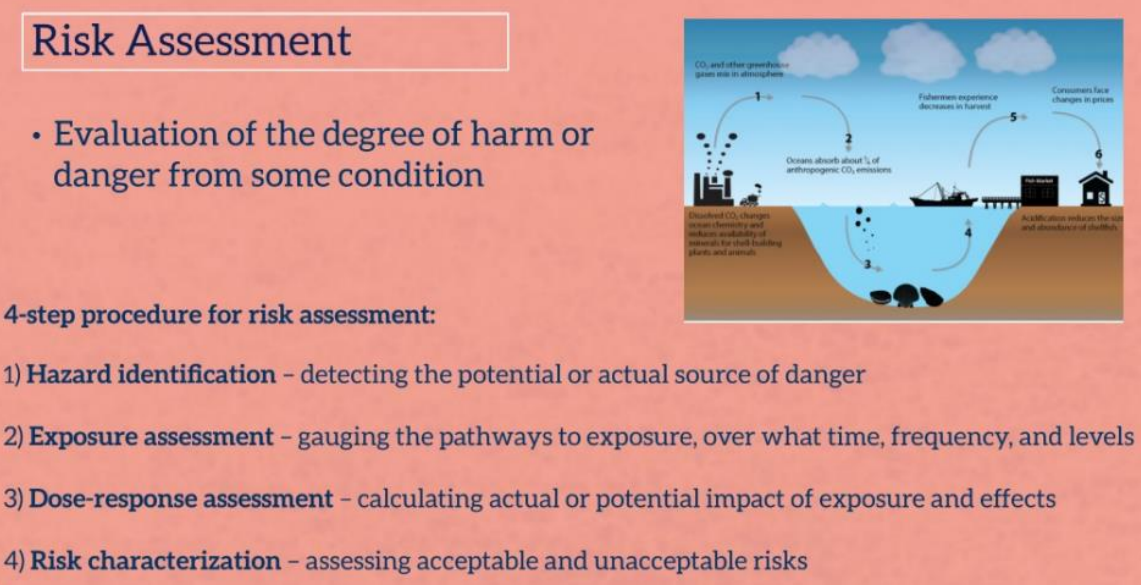




\section{Communicating Sustainability}

Slide $=$ Communicating Sustainability

\section{Communicating Sustainability \\ - Industries try to improve their environmental performance and link their goods, services, or brands with "green" initiatives}

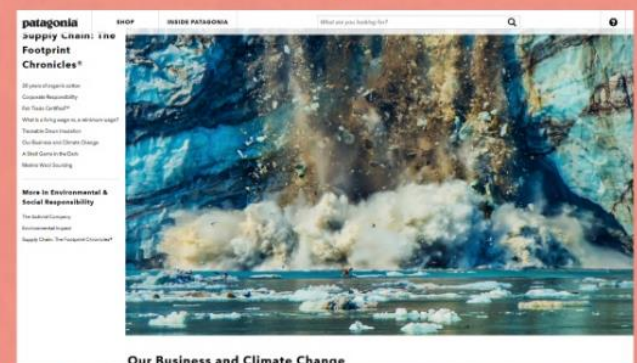

"Build the best product, cause no unnecessary harm, use business to inspire and implement solutions to the environmental crisis."

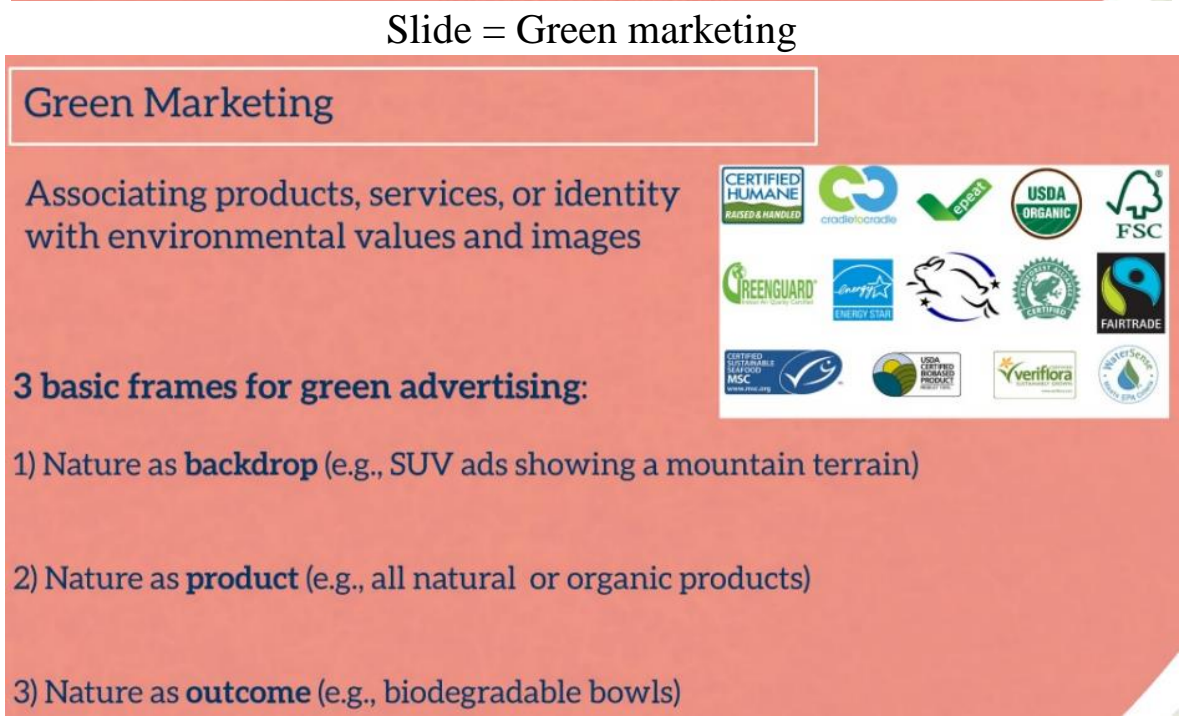

Slide $=$ Greenwashing

\section{Greenwashing}

Efforts by corporations to mislead or divert attention from corporation's poor environmental behavior or products

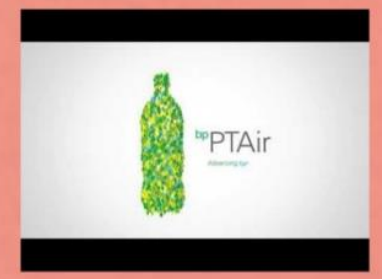

Image Enhancement - improving the brands image or credibility by associating with a positive environmental image, practices, or products 


\section{Advocacy Campaigns}

Slide $=$ Advocacy Campaigns

\section{Advocacy Campaigns}

A strategic course of action, involving communication, which is undertaken for a specific purpose

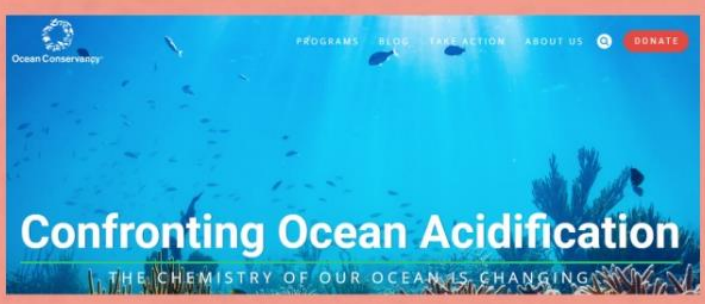

Goes beyond strictly criticizing policy or societal values

\section{Slide $=$ Features of Campaigns}

\section{4 features of campaigns:}

1) Purposeful - specific outcomes result from the communication efforts

2) Aimed at a large audience - going beyond communication with just one or a few people

3) Defined time limit - desired outcome must be achieved by some deadline

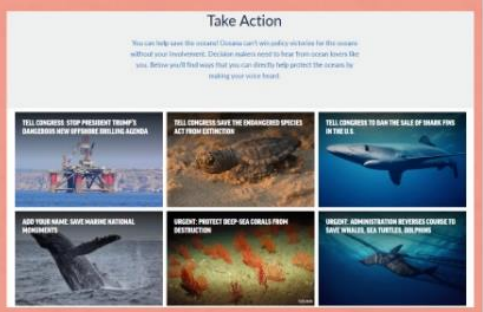

4) Organized set of communication activities the campaign's message is present in all efforts to educate and/or mobilize others

\section{Slide $=$ Features of Campaigns}
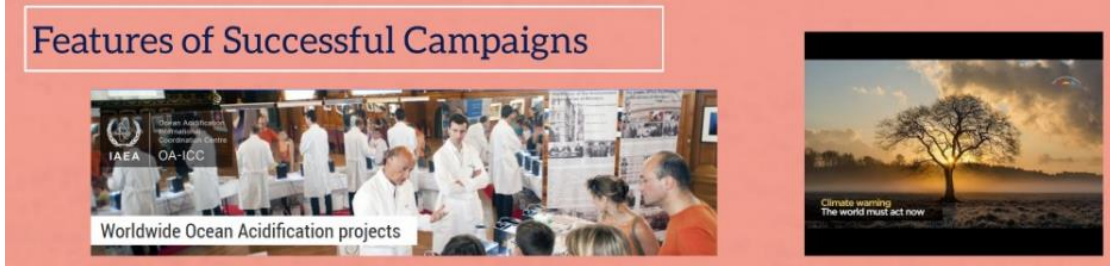

1) Clear objectives - a specific action, event, or decision that achieves campaigns broader goal

2) Determine important decision makers - primary and secondary audience

3) Develop strategies to influence decision makers - source of influence that will persuade a primary decision maker to act on the campaigns objective 
Terrestrial Ecosystem Path

Slide $=$ Terrestrial Ecosystems

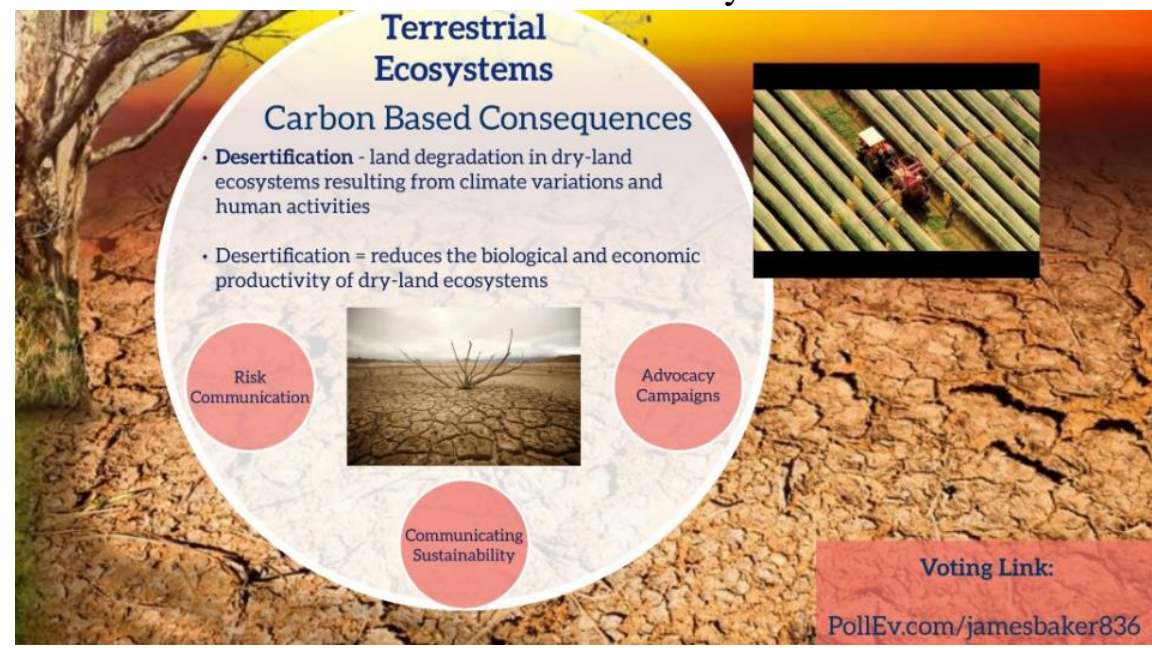

Risk Communication

Slide $=$ Risk Communication

\section{Risk Communication}

- The exchange of information with the goal of improving risk understanding, affecting risk perception, and/or equipping people or groups to act appropriately in response to an identified risk
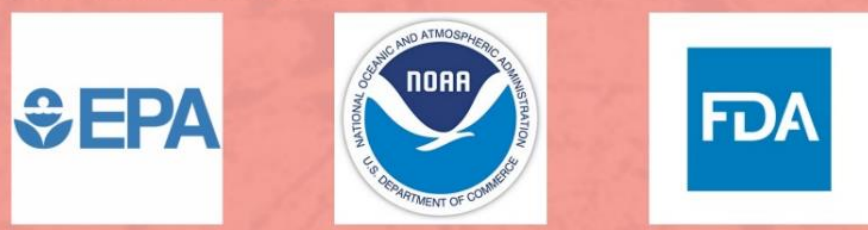

- Calculation of the likelihood that certain number of people or an ecological system will suffer some harm over time from exposure to a hazard or environmental stressor (e.g., desertification)

- Risk = Severity X Likelihood

Slide $=$ Risk Assessment

Risk Assessment
- Evaluation of the degree of harm or
danger from some condition
4-step procedure for risk assessment:
1) Hazard identification - detecting the potential or actual source of danger
3) Exposure assessment - gauging the pathways to exposure, over what time, frequency, and levels
4) Risk characterization - assessing acceptable and unacceptable risks




\section{Communicating Sustainability}

Slide $=$ Communicating Sustainability

\section{Communicating Sustainability \\ - Industries try to improve their environmental performance and link their goods, services, or brands with "green" initiatives}

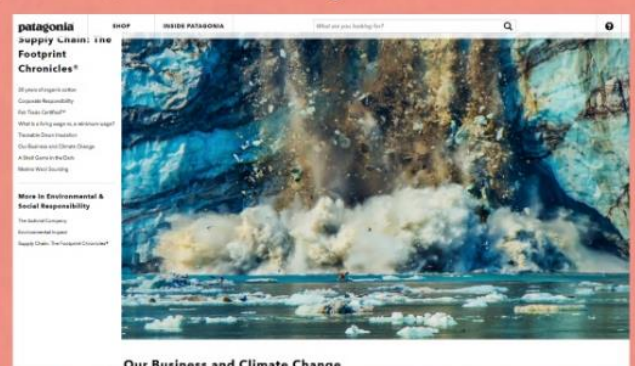

"Build the best product, cause no unnecessary harm, use business to inspire and implement solutions to the environmental crisis."

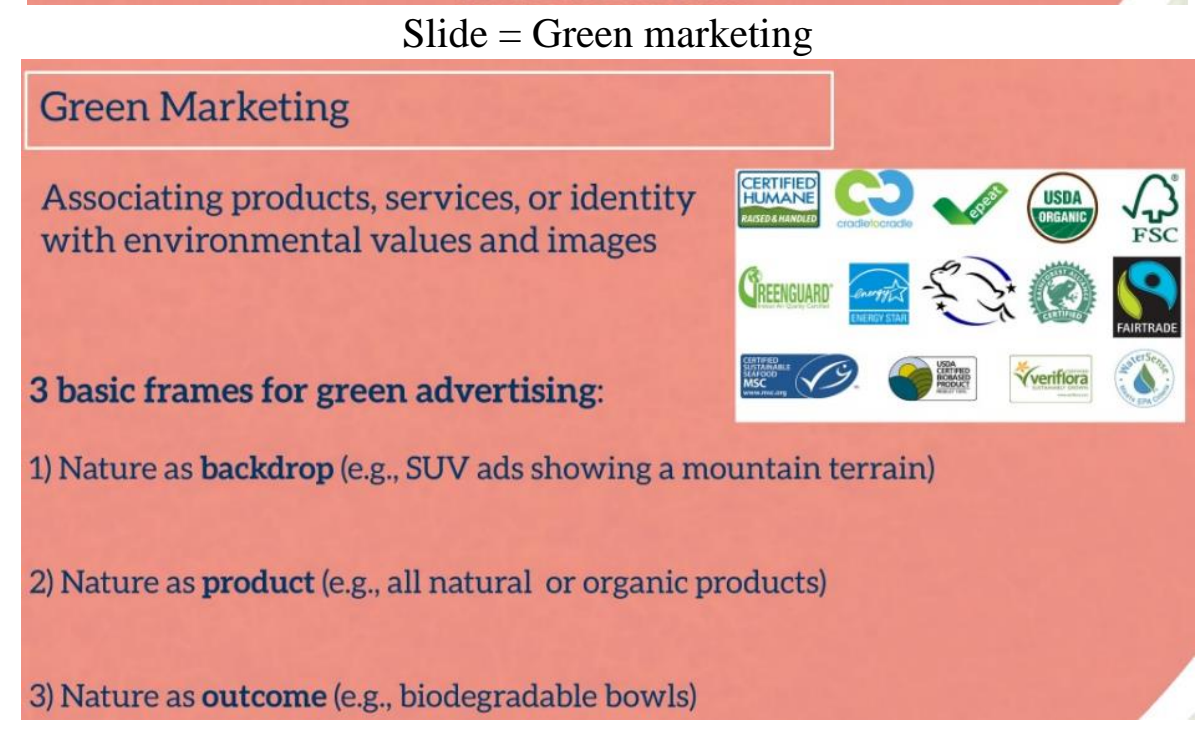

Slide $=$ Greenwashing

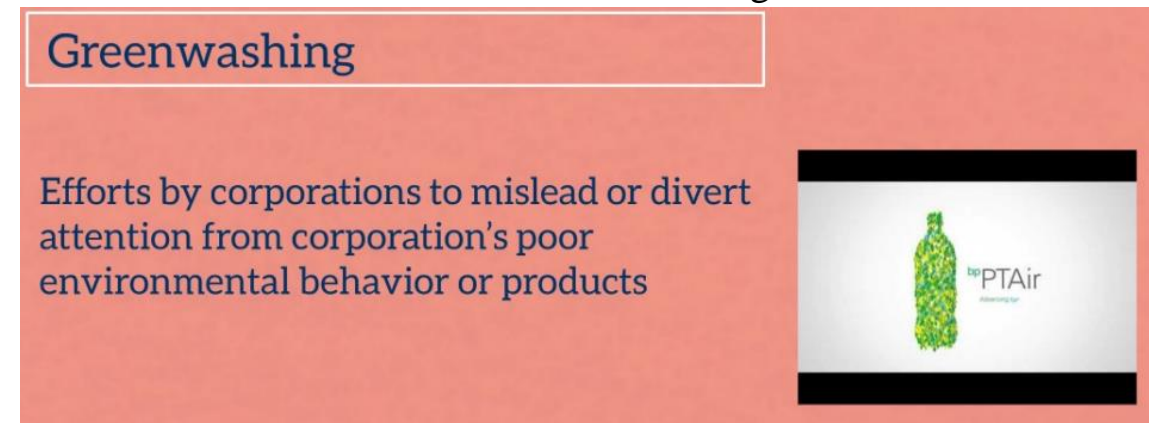

Image Enhancement - improving the brands image or credibility by associating with a positive environmental image, practices, or products 


\section{Advocacy Campaigns}

Slide $=$ Advocacy Campaigns

\section{Advocacy Campaigns}

A strategic course of action, involving communication, which is undertaken for a specific purpose

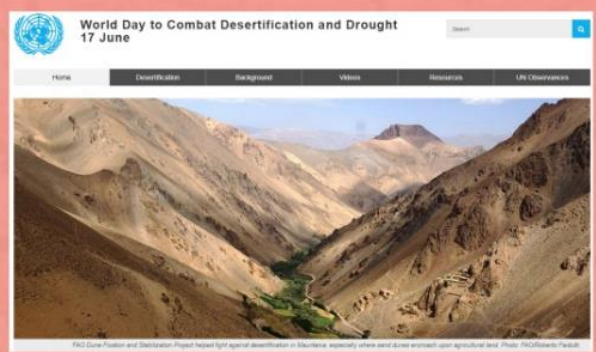

Goes beyond strictly criticizing policy or societal values

Slide $=$ Features of Campaigns

\section{4 features of campaigns:}

1) Purposeful - specific outcomes result from the communication efforts

2) Aimed at a large audience - going beyond communication with just one or a few people

3) Defined time limit - desired outcome must be achieved by some deadline

4) Organized set of communication activities -

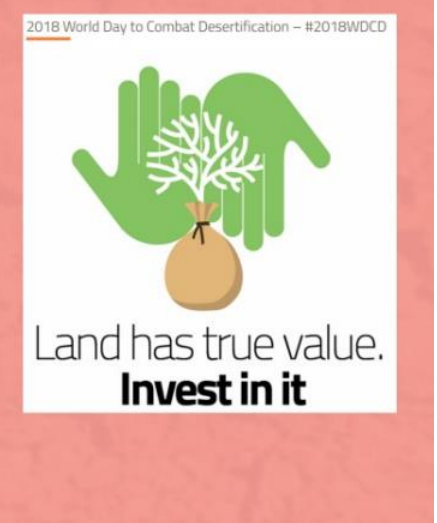

the campaign's message is present in all efforts to educate and/or mobilize others

\section{Slide $=$ Features of Campaigns}

\section{Features of Successful Campaigns}
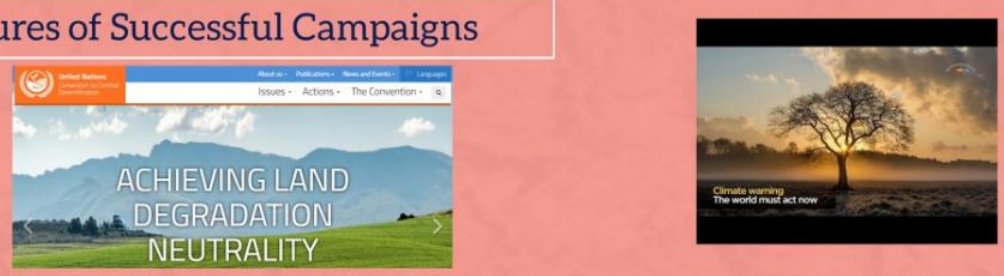

1) Clear objectives - an objective is a specific action, event, or decision that achieves campaigns broader goal

2) Determine important decision makers - primary and secondary audience

3) Develop strategies to influence decision makers - source of influence that will persuade a primary decision maker to act on the campaigns objective 